\title{
Warming does not delay the start of autumnal leaf coloration but slows its progress rate
}

Nan Jiang

https://orcid.org/0000-0001-5151-5715

Miaogen Shen ( $\nabla$ shen.miaogen@gmail.com )

Philippe Ciais

Matteo Campioli

Josep Peñuelas

Christian Körner

Ruyin Cao

Shilong Piao

Licong Liu

Shiping Wang

Eryuan Liang

Nicolas Delpierre

Kamel Soudani

Yuhan Rao

Leonardo Montagnani

Lukas Hörtnagl

Eugénie Paul-Limoges

Ranga Myneni

Georg Wohlfahrt

Yongshuo Fu

Ladislav Šigut

Andrej Varlagin

Jin Chen

Yanhong Tang

Wenwu Zhao

\section{Research Article}

Keywords: autumnal leaf senescence, global warming, leaf coloration onset, Northern Hemisphere, photoperiod

Posted Date: February 15th, 2022

DOI: https://doi.org/10.21203/rs.3.rs-1352963/v1 
License: (c) (i) This work is licensed under a Creative Commons Attribution 4.0 International License. Read Full License

Version of Record: A version of this preprint was published at Global Ecology and Biogeography on August 14th, 2022. See the published version at https://doi.org/10.1111/geb.13581. 


\section{ABSTRACT}

Aim: Initiation of autumnal leaf senescence is critical for plant overwintering and ecosystem dynamics. Previous studies focused solely on the advanced stages of autumnal leaf senescence and claimed that climatic warming delays senescence, despite the fundamental differences among the stages of senescence. However, the timing of onset of leaf coloration $\left(D_{\mathrm{LCO}}\right)$, the earliest visual sign of senescence, has been rarely studied. Our aim is to assess the response of $D_{\text {LCO }}$ to temperature across the Northern Hemisphere.

Location: $30-75^{\circ} \mathrm{N}$ in the Northern Hemisphere.

Time period: $2000-2018$.

Major taxa studied: Deciduous vegetation.

Methods: We retrieved $D_{\text {LCO }}$ from high temporal-resolution satellite data, which was then validated by PhenoCam observations. We then investigated the temporal changes in $D_{\text {LCO }}$ and the relationship between $D_{\text {LCO }}$ and temperature by using $D_{\text {LCO }}$ from satellite data and ground phenological observations. We further estimated the timing of onset of autumnal decline in maximum canopy photosynthetic capacity, an indicator of leaf senescence earlier than $D_{\mathrm{Lco}}$, from FLUXNET $\mathrm{CO}_{2}$ fluxes data, and assessed its response to temperature.

Results: $D_{\text {LCO }}$ was not significantly $(P<0.05)$ delayed between 2000 and 2018 in $94 \%$ of the area. $D_{\text {LCO }}$ was positively correlated with pre- $D_{\text {LCO }}$ mean daily minimum temperature $\left(T_{\min }\right)$ in only $9 \%$ of the area, likely because of the overriding photoperiodic control, particularly for woody vegetation, whereas the end of leaf coloration $\left(D_{\mathrm{LCE}}\right)$ was positively correlated with pre- $D_{\mathrm{LCE}}$ mean $T_{\min }$ over a larger area $(34 \%)$.

Main conclusions: The coloration progress rate is more sensitive than its start date to temperature, indicating an extension of the duration of leaf senescence under warming. This study indicates that the leaf coloration onset was not responsive to climate warming and provides observational evidence of photoperiod control of autumnal leaf senescence at biome and continental scales. 
Keywords: autumnal leaf senescence, global warming, leaf coloration onset, Northern Hemisphere, photoperiod

\section{1 | INTRODUCTION}

In contrast to the leaves of evergreen conifers, those of northern deciduous plants are not sufficiently tolerant of freezing to survive cold periods and, therefore, are shed before the onset of winter. This autumnal senescence process is controlled by changes in gene expression and metabolic adjustments that include the degradation of macromolecules (e.g., chlorophyll), a decrease in photosynthesis, and, importantly, the recycling and reallocation of nutrients (Thomas \& Stoddart, 1980; Gan \& Amasino, 1997). Without timely leaf senescence and abscission, early frost would lead to a loss of leaf resources. In parallel to leaf senescence, carbon sink activity ceases progressively, and plants switch to nutrient recovery and resorption processes (Keskitalo et al., 2005; Estiarte \& Peñuelas, 2015). Changes in the timing of key steps of leaf senescence extensively influence ecosystem structure and functions, and this could further affect the climate system (Peñuelas et al., 2009; Richardson et al., 2013). Senescence starts as a cryptic phenological process before any visible symptoms become apparent (Körner \& Basler, 2010). The timing of the start of the leaf coloration following senescence varies, depending on the rate of the senescence process, which is related to environmental conditions (e.g., temperature) (Fracheboud et al., 2009). Hence, the process of autumnal leaf senescence has two phases (Fig. 1a): (1) a visually indistinguishable ontogenetic stage that precedes (2) a visible change in leaf color (Tang et al., 2016). The timing of leaf coloration is the focus of in situ phenological observations and has been the main concern of most autumnal phenological studies to date. 

$D_{\text {PDO }}$ $D_{\text {LCO }}$ $D_{\text {LCE }}$

Chlorophyll degradation Carotenoid degradation Anthocyanin accumulation

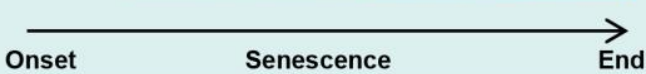

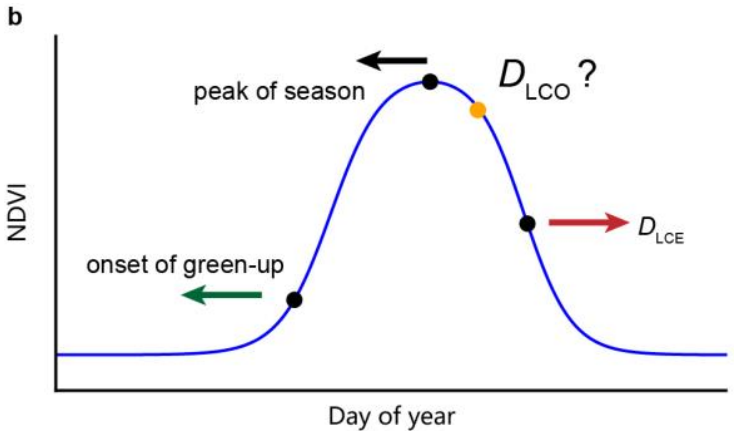

54 Fig. 1 Conceptual graphs illustrating (a) the developmental processes in pigments during leaf senescence that are related to photosynthetic capacity and leaf color; and (b) phenological changes retrieved from normalized difference vegetation index (NDVI) data in the last few decades. In (a), $D_{\text {PDO }}$ and $D_{\text {LCO }}$ are the timings of the onsets of the decrease in maximum canopy photosynthetic capacity and leaf coloration in autumn, respectively; $D_{\text {LCE }}$ is the timing of the end of leaf coloration. In (b) the onset of green-up corresponds to a $20 \%$ increase in NDVI, the peak of the season corresponds to the maximum NDVI, and $D_{\text {LCO }}$ and $D_{\text {LCE }}$ correspond to $10 \%$ and 50\% decreases, respectively, in NDVI. The leftward and rightward arrows indicate advance of onset of green-up and peak of season and delay of $D_{\mathrm{LCE}}$ over the past few decades. The question mark indicates a research gap regarding temporal changes in $D_{\text {LCO }}$ and their drivers.

Satellite and ground-based observations indicate that climate warming in the last several decades has substantially advanced the onset of spring green-up and the peak of the growing season, and it has slightly delayed the timing of the end of leaf coloration $\left(D_{\mathrm{LCE}}\right.$, the time when the normalized difference vegetation index [NDVI] decreases by $50 \%$ of its annual amplitude in the second half of a year in satellite-based studies (White et al., 1997; Ganguly et al., 2010; Nagai et al., 2010; Yu et al., 2010; Melaas et al., 2013; Lukasová et al., 2019)) in the Northern Hemisphere (Fig. 1b) (Jeganathan et al., 2014; Fu et al., 2015; Gill et al., 2015; Xu et al., 2016; Piao et al., 2019; Menzel et al., 2020). In addition to temperature, an increase in precipitation also delays $D_{\mathrm{LCE}}$ in temperate dry grasslands in the northern middle latitudes (Liu et al., 2016). Besides these abiotic factors, temporal changes in $D_{\mathrm{LCE}}$ are also associated with the onset of green-up in some temperate tree species (Keenan \& Richardson, 2015) and in boreal ecosystems 
(Liu et al., 2016). In contrast to $D_{\mathrm{LCE}}$, the timing of onset of leaf coloration $\left(D_{\mathrm{LCO}}\right)$ has been inadequately studied (Fig. 1b). In particular, it is not known whether $D_{\text {LCO }}$ is sensitive to climate and whether it has been responsive to recent climate change. $D_{\text {LCO }}$ is of key importance because it indicates when leaf senescence becomes apparent and its progress accelerates (Fig. 1b). As shown by experiments on young trees, some temperate and boreal woody species use the shortening of the photoperiod as a signal for the onset of leaf senescence (Table S1), but many in situ and satellite observations indicate that increased temperature induces delays in the advanced stages of senescence such as $D_{\text {LCE }}$ (Estrella \& Menzel, 2006; Delpierre et al., 2009; Jeong et al., 2011; Ge et al., 2015; Gill et al., 2015; Liu et al., 2016).

The dominant photoperiodic control of early senescence implies that $D_{\text {LCO }}$ should not be delayed, even if the temperature increases, because its timing is controlled only by daylength (Hypothesis 1). On the other hand, without photoperiodic control, shifts in $D_{\text {LCO }}$ are expected in the case of climatic warming (Hypothesis 2). Alternatively, if $D_{\text {LCO }}$ is influenced by both photoperiod and temperature, the relationships between $D_{\mathrm{LCO}}$ and temperature should vary among different areas because the strength of the photoperiod signal varies (Hypothesis 3 ). We tested these hypotheses by investigating temporal changes in $D_{\text {LCO }}$ and the interannual relationships between $D_{\mathrm{LCO}}$ and pre- $D_{\mathrm{LCO}} T_{\min }$ (the mean of monthly average daily minimum temperature for an optimized period preceding $\left.D_{\mathrm{LCO}}\right)$ for northern vegetation $\left(30^{\circ} \mathrm{N}-75^{\circ} \mathrm{N}\right.$, cropland pixels excluded) during the period 2000-2018. Since only a few in situ observational programs or networks have monitored $D_{\mathrm{LCO}}$, we determined $D_{\mathrm{LCO}}$ from a 5-day composite time series of the NDVI derived from daily surface spectral reflectance (MOD09CMG) at a spatial resolution of $0.05^{\circ}$, provided by the spaceborne Moderate Resolution Imaging Spectroradiometer (MODIS) (Vermote, 2015). We defined $D_{\text {LCO }}$ as the first date when daily NDVI, fitted from 5-day NDVI, decreased by $10 \%$ of its annual amplitude during the descending period of each year (Fig. 1b). To complement the NDVI data, we also used 332 time series of $D_{\text {LCO }}$ observed by professional observers according to standard observation guidelines (China Meteorological Administration, 1993) in the field in China (Fig. S1a; Table S2) and the timing of onset of autumnal decline in maximum canopy photosynthetic capacity $\left(D_{\text {PDO }}\right)$ derived from eddy covariance $\mathrm{CO}_{2}$ flux observations ( $\mathrm{Gu}$ et al., 2009; Shen et al., 2014) at 36 sites from 
106

107

108

109

110

111

112

113

114

115

116

117

118

119

120

121

122

123

124

125

\section{2 | MATERIALS AND METHODS}

\section{1 $\mid D_{\text {LCo }}$ estimated from satellite observations of NDVI time series}

The NDVI is a proxy for vegetation greenness and has been widely used for phenological studies at large spatial scales (Myneni et al., 1997). NDVI has also been proved capable of detecting the onset of leaf coloration (Soudani et al., 2012; Yang et al., 2014; Mariën et al., 2019;

Soudani et al., 2020; Zhao et al., 2020). Previous studies have usually used half-month/16-day composite NDVI time series to retrieve phenological metrics. However, because the color of leaves often changes abruptly (Wang \& Zhu, 2019), NDVI time-series data with higher temporal resolution are required. We estimated phenological metrics (i.e., the timing of the onset and the advanced stages of leaf coloration and the onset of green-up) for 2000-2018 from a 5-day composite NDVI time series produced from the MODIS reflectance product (MOD09CMG Collection 6, available at https://ladsweb.modaps.eosdis.nasa.gov, accessed on 29 January 2019) (Vermote, 2015). MOD09CMG provides an estimate of daily surface spectral reflectance at a spatial resolution of $0.05^{\circ}$. The quality of the daily surface reflectance data from MOD09CMG is unsatisfactory owing to cloud and snow contamination (Vermote, 2015), so we used the 5-day maximum value composite approach (Zhang, 2015), combined with a Savitzky-Golay filter (Cao et al., 2018), to produce a high-quality NDVI time series before determining $D_{\text {LCo. First, }}$ NDVI values that were lower than the uncontaminated winter (December-February) mean NDVI were replaced by the latter (Beck et al., 2006; Zhang et al., 2007). After that, cloud-contaminated and irregularly high and low NDVI values were identified and reconstructed by using a Savitzky-Golay filter (Cao et al., 2018). Details for preparing the high-quality NDVI time series are given in Section 1 of the Supplementary Methods.

We focused on natural vegetation by excluding pixels dominated by cropland, artificial surfaces, permanent snow or ice, and water bodies on the basis of the MODIS land-cover map for the middle year of the time series (2009) (MCD12C1 Version 6) (Friedl \& Sulla-Menashe, 2015) https://ladsweb.modaps.eosdis.nasa.gov, accessed on 20 August 2018). Some pixels were also excluded from analysis because of sparse vegetation coverage, weak seasonality, or NDVI 
peaking in October-April. We adopted three criteria for pixel exclusion: mean annual NDVI must be $>0.10$, NDVI should peak between May and September in the multiyear mean NDVI time series, and a pixel should be discarded if the mean NDVI for July and August is $<1.15$ times the mean NDVI for December or for January-February in any year.

Two types of method can generally be used to estimate the parameters of vegetation

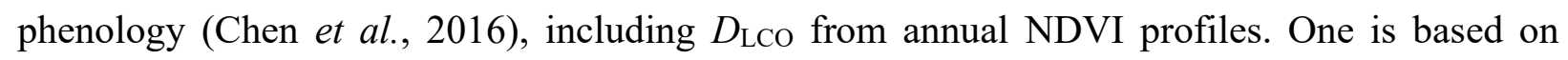
thresholds (White et al., 1997), whereas the other is based on inflection points (Zhang et al., 2003). We applied the threshold-based method by first using a generalized sigmoid function to fit the NDVI annual profile [Equation (7) in Klosterman et al. (2014)] and then determined D LCO as the first date when NDVI decreased by $10 \%$ of its annual amplitude in the descending period (Leblans et al., 2017; Richardson et al., 2018). Though a smaller decrease in NDVI corresponds to an earlier stage of leaf coloration, consideration of it would introduce more uncertainty. The advanced stages of leaf coloration were determined as the dates when NDVI decreases by $20 \%$, $30 \%, 40 \%$, and $50 \%$ (corresponding to the timing of the end of leaf coloration, $D_{\mathrm{LCE}}$ ), respectively. We defined the timing of the onset of green-up as the date when NDVI increased by $20 \%$ (Yu et al., 2010). We also determined $D_{\text {LCO }}$ by using the algorithm based on inflection points owing to the slight difference between the methods for detecting phenological parameters. We defined $D_{\text {LCO }}$ as the date when the rate of change of the curvature of a double logistic function (Beck et al., 2006; Elmore et al., 2012) fitted to the NDVI time series reached its first local minimum in the descending period (Zhang et al., 2003).

It is unreasonable to validate the satellite derived $D_{\text {LCO }}$ by comparing it with $D_{\text {LCO }}$ of a few plant individuals from ground observation because of mismatch in spatial coverage, different definitions of phenological metrics, and the spatial heterogeneity in phenological phases among individuals for a pixel. Fortunately, pairs of field observations of NDVI and leaf coloration showed well consistency between the start of NDVI decrease and leaf coloration onset (Soudani et al., 2012; Soudani et al., 2020). Moreover, the comparison between start of autumn from satellite observed NDVI and field observations of leaf coloration onset for the entire area covered by the pixel also showed little difference between them (Zhao et al., 2020). Those 
studies suggest that NDVI is capable to detect the onset of leaf coloration if the observed leaves or individuals are identical between ground and satellite observations. However, there are very limited pairs of compatible observations of NDVI and leaf coloration that can be used for the validation. Considering the high capability of PhenoCam in capturing the variations in leaf coloration onset (Klosterman et al., 2014; Wingate et al., 2015; Klosterman \& Richardson, 2017; Nezval et al., 2020), we used the PhenoCam Dataset V2.0 (Richardson et al., 2018; Seyednasrollah et al., 2019a; Seyednasrollah et al., 2019b) to assess the relationships between satellite $D_{\mathrm{LCO}}$ and the $D_{\mathrm{LCO}}$ derived from GCC (green chromatic coordinate) and VCI (vegetation contrast index) observed by PhenoCam (Section 2 of the Supplementary Methods).

\section{2 | DLCo from in situ phenological observations}

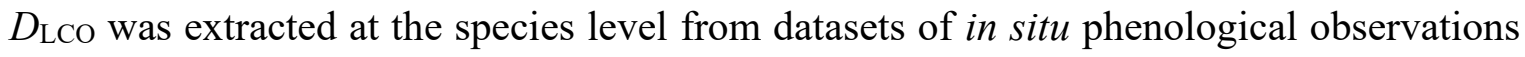
in China provided by the Chinese Academy of Sciences (CAS). The CAS dataset uses the date of first leaf coloring as $D_{\text {LCO. }}$ For a given species at a given site, the date of first leaf coloring was identified as the day when the first batch (about 5\%) of leaves on more than half of three to five marked individuals started to change color (China Meteorological Administration, 1993). The in situ phenological observations were performed according to standard observation guidelines (China Meteorological Administration, 1993) every other day by professional observers trained well by CAS. The CAS dataset is available from National Earth System Science Data Sharing Infrastructure, National Science and Technology Infrastructure of China (http://www.geodata.cn, accessed on 25 July 2018).

\section{3 | DPDO estimated from maximum canopy photosynthetic capacity}

The timing of the onset of the decrease in maximum canopy photosynthetic capacity in autumn (in day of year, $D_{\mathrm{PDO}}$ ) is defined as the date when the capacity decreases by $10 \%$ of its annual amplitude after the data have been fitted to a generalized sigmoid function [Equation (7) in Klosterman et al.(2014)]. The capacity was calculated from half-hourly or hourly gross primary productivity (GPP_NT_CUT_MEAN) based on eddy covariance measurements in the FLUXNET2015 dataset (http://fluxnet.fluxdata.org/data/fluxnet2015-dataset/, accessed on 10 March 2018) (Pastorello et al., 2017). We followed the procedure of Shen et al.(2014) to 
estimate daily canopy photosynthetic capacity, except that the parameters in the rectangular hyperbolic function were estimated by using half-hourly/hourly GPP and incident shortwave radiation calculated by using 15-day moving windows throughout a year. We used data from the sites in non-Mediterranean (Köppen-Geiger climate classification) and non-cultivated (International Geosphere-Biosphere Programme classification) regions at middle and high northern latitudes $\left(30^{\circ} \mathrm{N}-75^{\circ} \mathrm{N}\right)$. In a similar way to the pixel exclusion process that was applied to the satellite retrievals, we discarded sites where weak seasonality (i.e., the mean maximum canopy photosynthesis for June-August was $<1.15$ times that for December or for January and February) was detected in any year and sites where capacity did not peak in May-September.

\section{4 | Cold events before $D_{\text {LCO }}$ (or DPDO)}

A sudden drop of nighttime temperature to the freezing point can induce leaf coloration in a few days (Körner, 2007), and this could have interfered with our partial correlation analysis between $D_{\mathrm{LCO}}$ (or $D_{\mathrm{PDO}}$ ) and temperature. In our study, such sudden drops in temperature before $D_{\text {LCO }}\left(\right.$ or $D_{\text {PDO }}$ ) that induce rapid leaf senescence, named cold events, were determined from daily minimum air temperature $\left(T_{\min }\right)$. First, we determined the $T_{\min }$ threshold below which there could potentially be a cold event for each pixel; this was the lowest $T_{\min }$ during the 6 to 35 days before $D_{\mathrm{LCO}}$ for all years. If the lowest $T_{\min }$ was higher than $0{ }^{\circ} \mathrm{C}$, the $T_{\min }$ threshold was set to $0{ }^{\circ} \mathrm{C}$. Second, for a given pixel, a year was determined as a candidate cold event year if the lowest $T_{\min }$ in the period 1 to 5 days before $D_{\text {LCO }}$ was lower than the above-mentioned $T_{\min }$ threshold. Then, from the years that were not candidate cold event years, we determined the latest $D_{\text {LCO }}$ that was not caused by a cold event for that pixel. Finally, a $D_{\text {LCO }}$ was recognized as caused by a cold event if it was both in the candidate cold event years and earlier than the latest

$211 D_{\text {LCO }}$ that was not caused by a cold event. This empirical approach may have overestimated the 212 number of years with cold events before $D_{\mathrm{LCO}}$, but our objective was to exclude as many cold 213 events as possible. On clear nights, the temperature of the canopy surface could be lower than 214 the air temperature, so we also evaluated the first step by using $2{ }^{\circ} \mathrm{C}$ as the $T_{\min }$ threshold. The 215 cold events for in situ $D_{\mathrm{LCO}}$ and $D_{\mathrm{PDO}}$ were determined similarly. The cold event years accounted for a very small fraction of years with phenological data (Table S4). 
Here, the daily minimum temperature used to determine cold events for satellite-derived

$218 D_{\text {LCO }}$ was extracted from the CRU-NCEP dataset (Version 7.2, https://vesg.ipsl.upmc.fr, assessed on 10 January 2019), which provides 6-hourly data at a spatial resolution of $0.5^{\circ} \times 0.5^{\circ}$ through 2016 (Viovy, 2018). The CRU-NCEP 7.2 is a combination of two datasets: the CRU

221

222

223

224

225

226

227

228

229

230

231

232

233

234

235

236

237

238

239

240

241

242

243 TS3.2 $0.5^{\circ} \times 0.5^{\circ}$ monthly data covering the period 1901 to 2002 and the NCEP reanalysis $2.5^{\circ}$ $\times 2.5^{\circ}$ 6-hourly data covering the period 1948 to 2016 . We determined daily $T_{\min }$ as the minimum value of the four 6-hourly minimum temperature values for each day. The CRU-NCEP data were resampled at $0.05^{\circ} \times 0.05^{\circ}$ by replication to match the $D_{\text {LCO data. Daily }}$ $T_{\min }$ for in situ observations in China was extracted from the "Daily Surface Climate Variables of China" catalog (a dataset named SURF_CLI_CHN_MUL_DAY_V3.0), which includes daily climate data for 2474 sites in China from January 1951 to July 2014, provided by the Chinese Meteorological Administration via an offline request on 18 January 2015. The distance between phenological and meteorological stations was less than $25 \mathrm{~km}$. Daily $T_{\min }$ for $D_{\text {PDO }}$ was calculated from the half-hourly temperature dataset provided by FLUXNET2015.

\section{5 | Analyses}

Temporal trends in $D_{\text {LCO }}$ were quantified as the slopes of linear regressions between a variable and year by using OLSR. To complement the temporal changes assessed by using OLSR, a non-parametric approach (the Theil-Sen estimator (Sen, 1968; Theil, 1992)) was also

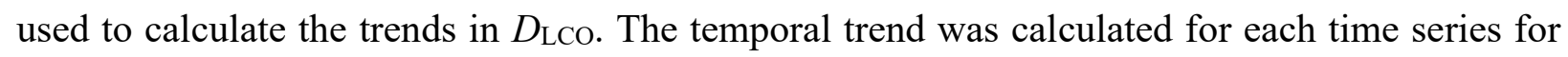
the ground-based observations and for each pixel for the satellite observations. We focused only on the temporal trends for the pixels and time series of in situ phenological observations with a multiyear mean of $D_{\mathrm{LCO}}$ occurring after the summer solstice. Phenological records were not available for some of the years of the time series for calculating more trends or correlations, because the time series may have had missing values owing to a lack of observation. However, the time series used for the regressions contained at least 10 years of observational records and at least one record for any 3 consecutive years. If two or more parts of the time series met these criteria, the most recent part was used.

$T_{\min }$ has long been recognized as the indicator of the thermal condition that induces autumnal leaf coloration (Tang et al., 2016). We investigated the impacts of temperature and precipitation, respectively, on the satellite-derived $D_{\text {LCO }}$ by calculating the $R_{\mathrm{TN}}$ values between 
$D_{\mathrm{LCO}}$ and the mean of monthly average daily minimum temperature $\left(T_{\min }\right)$ for the pre- $D_{\mathrm{LCO}}$ period, with concurrent total precipitation as the control variable, and between $D_{\text {LCO }}$ and pre- $D_{\text {LCO }}$ total precipitation $\left(R_{\mathrm{PRE}}\right)$, with concurrent $T_{\min }$ as the control variable for $2000-2018$. The pre- $D_{\text {LCO }}$ period for $T_{\min }$ (Fig. S2) was defined as the period preceding the multiyear mean $D_{\mathrm{LCO}}$ for which $T_{\min }$ had the strongest interannual partial correlation with $D_{\mathrm{LCO}}$, with concurrent total precipitation as a control variable. The candidate period had the earliest start in June and a fixed end at the multiyear mean $D_{\text {LCO }}$, at steps of 1 month. If the multiyear mean $D_{\text {LCO }}$ was in the first half of a month, then the pre- $D_{\text {LCO }}$ period ended at the month preceding the multiyear mean $D_{\text {LCO. }}$ Otherwise, the pre- $D_{\text {LCO }}$ period ended at the month of the multiyear mean $D_{\text {LCO. }}$ The pre- $D_{\text {LCO }}$ period for precipitation was defined similarly. The impacts of climatic factors on the advanced stages of leaf coloration were investigated similarly. The data for $T_{\min }$ and precipitation were extracted from the Climatic Research Unit (CRU) Time-Series (TS) 4.03 dataset (http://data.ceda.ac.uk, accessed on 11 June 2019), which provided monthly data at a spatial resolution of $0.5^{\circ} \times 0.5^{\circ}$ until 2018 . It should be noted that $T_{\min }$ in the dataset is an approximation of the mean of daily minimum temperature for a calendar month, which is arithmetically calculated from gridded monthly mean temperature and the diurnal temperature range (Harris et al., 2014) and does not exactly reflect the interannual variations in the absolute minimum temperature (Körner \& Hiltbrunner, 2018) experienced by plants before $D_{\text {LCO. The }}$ CRU data were resampled at $0.05^{\circ} \times 0.05^{\circ}$ by replication to match the $D_{\text {LCO }}$ data. We also investigated the impact of $T_{\min }$ and precipitation on $D_{\mathrm{LCO}}$ from ground-based observations in China and on $D_{\mathrm{PDO}}$ from eddy-covariance sites as complementary to satellite-derived of $D_{\mathrm{LCO}}$. Climatic data from the nearest meteorological station $(<25 \mathrm{~km})$, provided by the Chinese Meteorological Administration, were used for in situ D $\mathrm{LCO}$ in China.

\section{3 | RESULTS}

\subsection{Comparison of satellite $D_{\text {LCo }}$ with PhenoCam $D_{\text {LCo }}$}

The satellite $D_{\text {LCO }}$ explained about $80 \%$ of the variations in PhenoCam derived $D_{\text {LCO }}(\mathrm{N}=$ 378 and 377 for GCC and VCI) (Fig. 2). The difference between the satellite $D_{\text {LCO }}$ and the 274 PhenoCam $D_{\text {LCO }}$ are caused by the mismatch between the annual NDVI and GCC (or VCI) trajectories due to difference in spatial coverage between the PhenoCam and satellite pixel in the 

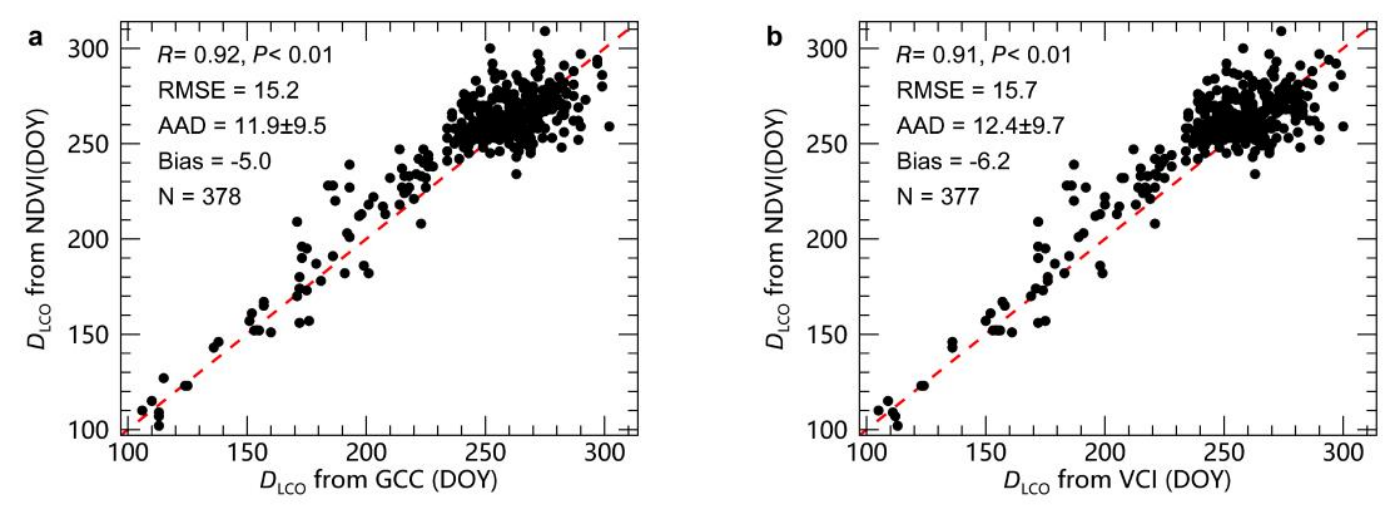

278 Fig. 2 Comparison between satellite $D_{\text {LCO }}$ and PhenoCam $D_{\text {LCO }}$. The PhenoCam $D_{\text {LCO }}$ was determined from GCC (a) and VCI (b), respectively. $R$ : Pearson's correlation coefficient; RMSE: root mean square error; AAD: average absolute difference; bias is defined as the difference between the mean of satellite $D_{\text {LCO }}$ and the mean of PhenoCam $D_{\text {LCO }}$, and negative bias means the PhenoCam $D_{\text {LCO }}$ is earlier than satellite $D_{\text {LCO. }}$

\subsection{Temporal trends in $D_{\text {LCO }}$}

$D_{\text {LCO }}$ was not significantly delayed in $94 \%$ of the area during the study period, as assessed by ordinary least squares regression (OLSR) between satellite-derived $D_{\text {LCO }}$ and respective years. The few pixels with a significant delay trend $(6 \% ; P<0.05, t$-test $)$ were scattered across the Northern Hemisphere (Fig. 3a). Leaf color often changes rapidly owing to cold events in autumn; these rapid changes introduced noise to the $D_{\mathrm{LCO}}$ time series and trends. Excluding years with cold events before $D_{\text {LCO }}$ produced similar results (Fig. S3 and Table S5). Because the sample size (i.e., the number of years in the $D_{\text {LCO }}$ time series) for calculating the trend was small, we also used the Theil-Sen estimator to determine temporal $D_{\text {LCO }}$ trends. This method generated results supporting the lack of changes in $D_{\mathrm{LCO}}$ (no significant delay in $96 \%$ of the area; $P<0.05$, Mann-Kendall test; Fig. S4a and Table S6). When we redefined $D_{\text {LCO }}$ as the date when the rate of change of curvature of a double logistic curve (Beck et al., 2006) fitted to the NDVI series reached its first local minimum in the descending period (Zhang et al., 2003), we obtained similar results (Fig. S4b and c). Complementary to satellite-derived $D_{\mathrm{LCO}}$, we also examined the temporal changes of $D_{\mathrm{LCO}}$ by using ground-based leaf coloration data from China. $D_{\mathrm{LCO}}$ was not 
significantly delayed for $90 \%$ and $94 \%$ of the 332 time series as shown by OLSR (Fig. 3b) and the Theil-Sen method (Table S6), respectively. As with the remotely sensed data, excluding cold events from the ground-based data revealed only a few significant delays of $D_{\text {LCO }}$ (Table S5).
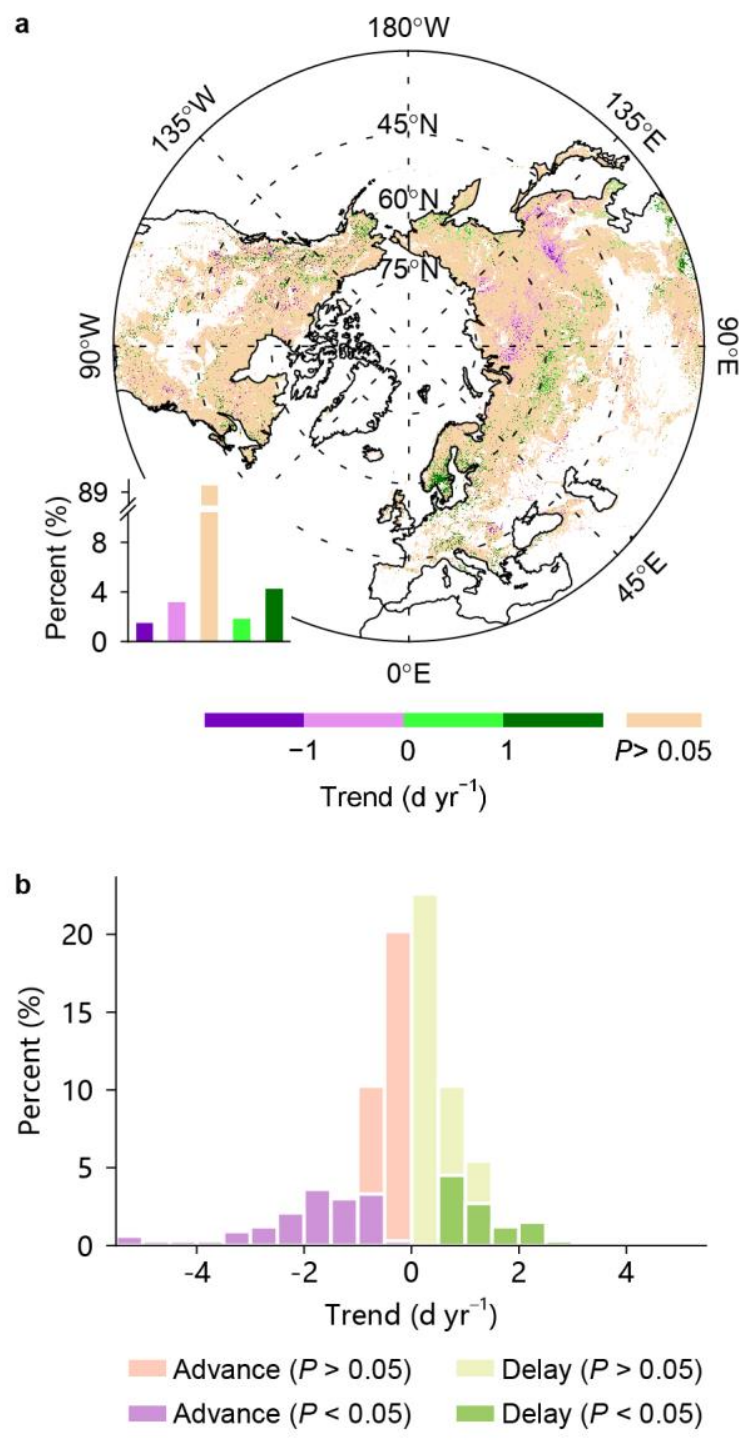

304 Fig. 3 Temporal trends in the timing of the onset of leaf coloration $\left(D_{\mathrm{LCO}}\right)$, as retrieved from satellite and in situ observations. a, Satellite-derived $D_{\text {LCO }}$ trends over 2000-2018. The bar chart in the bottom-left corner shows the percentage of area within each interval of the significant temporal trends and the percentage of area with nonsignificant trends, indicated by the color scale at the bottom. Positive and negative trend values refer to significantly delayed and advanced $D_{\mathrm{LCO}}$, respectively. $D_{\mathrm{LCO}}$ is defined as the date when NDVI decreases by $10 \%$ of its 
annual amplitude in autumn, based on a generalized sigmoid function fitted from the annual NDVI profile. Pixels dominated by croplands or with low vegetation coverage, weak seasonality, or peak NDVI in October-April were discarded. b, Ground-observed $D_{\text {LCo }}$ trends derived over 1971-1997 from in situ leaf coloration observations in China. Significant temporal trends were determined by using $t$-tests at $P<0.05$ and OLSR between $D_{\mathrm{LCO}}$ and respective years.

\subsection{Correlation between $D_{\mathrm{LCO}}$ and temperature}

With the same data that were used for $D_{\mathrm{LCO}}$ assessment, we verified that a delay in $D_{\mathrm{LCE}}$ was correlated with an increase in temperature for the period preceding $D_{\text {LCE }}$ (Estrella \& Menzel, 2006; Delpierre et al., 2009; Gill et al., 2015; Liu et al., 2016; Fu et al., 2018) (Fig. 4a and c). In addition, since in a few studies(Ren et al., 2017; Berman et al., 2020), end of leaf coloration was defined as the dates when NDVI drops by $60 \%$ or $90 \%$ of its annual amplitude, we also calculated the partial correlations between each of those dates and the temperature, respectively, and the correlations were similar to the that between $D_{\mathrm{LCE}}$ and the pre- $D_{\mathrm{LCE}}$ temperature (Fig. S5). $D_{\mathrm{LCO}}$, however, was not correlated with pre- $D_{\mathrm{LCO}} T_{\min }$, with only $9 \%$ of the area in scattered pixels showing a significant positive correlation and 5\% showing a significant negative correlation (Fig. $4 \mathrm{~b}$ ). $D_{\text {LCO }}$ was positively partially correlated with pre- $D_{\text {LCO }}$ total precipitation in $13 \%$ of the area, mainly in the temperate grassland of Northern America and in the middle latitudes of Eurasia, sub-arctic grassland, and alpine steppe of the Tibetan Plateau (Fig. S6). Therefore, neither pre- $D_{\mathrm{LCO}} T_{\min }$ nor precipitation was a useful predictor of $D_{\mathrm{LCO}}$ in most areas. We obtained similar results when using a pre- $D_{\text {LCO }}$ period with a fixed length $(1$ month preceding $D_{\mathrm{LCO}}$ ) to calculate pre- $D_{\mathrm{LCO}} T_{\min }$ (Fig. S7). Moreover, a shorter pre- $D_{\mathrm{LCO}}$ period (15 days preceding $D_{\mathrm{LCO}}$ ) showed similar results, with only $5 \%$ of the area showing a significant positive correlation between $D_{\mathrm{LCO}}$ and pre- $D_{\mathrm{LCO}} T_{\min }$ (Fig. S8). We also investigated the relationship between $D_{\mathrm{LCO}}$ and the lowest daily minimum temperature during the 15 days before the multiyear mean $D_{\text {LCO. }}$. We found that only $3 \%$ of the area showed a significant positive correlation (Fig. S9). A few studies have suggested that the date of onset of green-up may affect leaf coloration through legacy effects (Fu et al., 2014; Keenan \& Richardson, 2015; Liu et al., 2016), but including this date as an extra control variable in the partial correlation analyses did 
339 not affect the results (Fig. S10). The in situ phenological records in China indicated that 340 ground-observed $D_{\text {LCO }}$ was positively partially correlated with pre- $D_{\text {LCO }} T_{\min }$ for $13 \%$ of the time 341 series and was not correlated with pre- $D_{\mathrm{LCO}} T_{\min }$ for $82 \%$ of the time series (Table 1 ). Excluding $342 D_{\text {LCO }}$ caused by cold events produced similar results (Fig. S11 and Table S7). Overall, these 343 results suggest that an increase in pre- $D_{\mathrm{LCO}} T_{\min }$ is not likely to delay $D_{\mathrm{LCO}}$ in most areas in the 344 middle and high northern latitudes. 

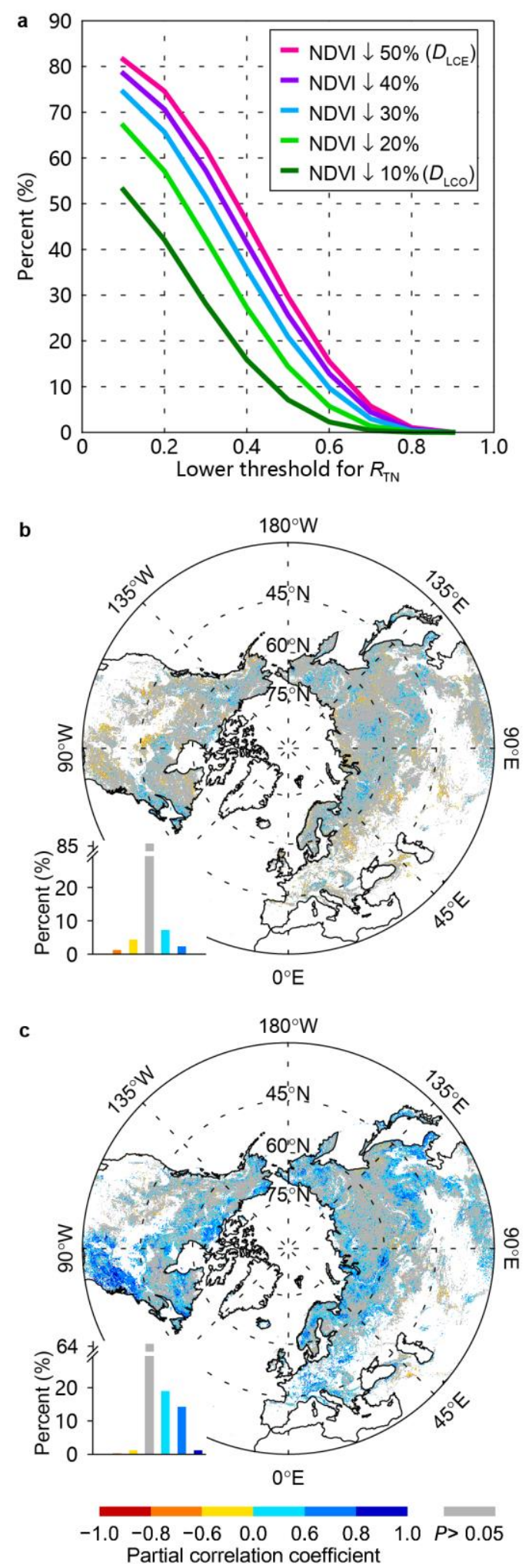

346 Fig. 4 Relationships between the timing of different stages of leaf coloration (retrieved from 347 satellite images) and the mean daily minimum temperature $\left(T_{\min }\right)$ for an optimized period 348 preceding the respective stage over the period 2000-2018. a, Percentage of area for which the 349 partial correlation coefficient $\left(R_{\mathrm{TN}}\right)$ between the timing of a given stage of leaf coloration 
(defined by NDVI decrease) and $T_{\min }$ for an optimized period preceding the stage is higher than a given threshold indicated by the horizontal axis. For example, $R_{\mathrm{TN}}$ for the onset of leaf coloration ( $D_{\mathrm{LCO}}, 10 \%$ decrease in NDVI) is higher than 0.2 in about $40 \%$ of the area. $\mathrm{b}$, Spatial pattern of the partial correlation coefficient between $D_{\mathrm{LCO}}$ and pre- $D_{\mathrm{LCO}} T_{\min }$. c, Spatial pattern of the partial correlation coefficient between timing of the end of leaf coloration $\left(D_{\mathrm{LCE}}, 50 \%\right.$ decrease in NDVI) and pre- $D_{\mathrm{LCE}} T_{\min }$. The bar charts in (b) and (c) show the percentage of area for each interval of the partial correlation coefficient $(P<0.05)$, with the coefficient indicated by the color scale at the bottom. Non-significant correlations $(P>0.05)$ are in gray. Pixels dominated by croplands or with low vegetation coverage, weak seasonality, or peak NDVI in October-April were discarded.

Table 1. Percentage of correlations between $D_{\mathrm{LCO}}$ or $D_{\mathrm{PDO}}$ and each climate factor for each interval of the partial correlation coefficient.

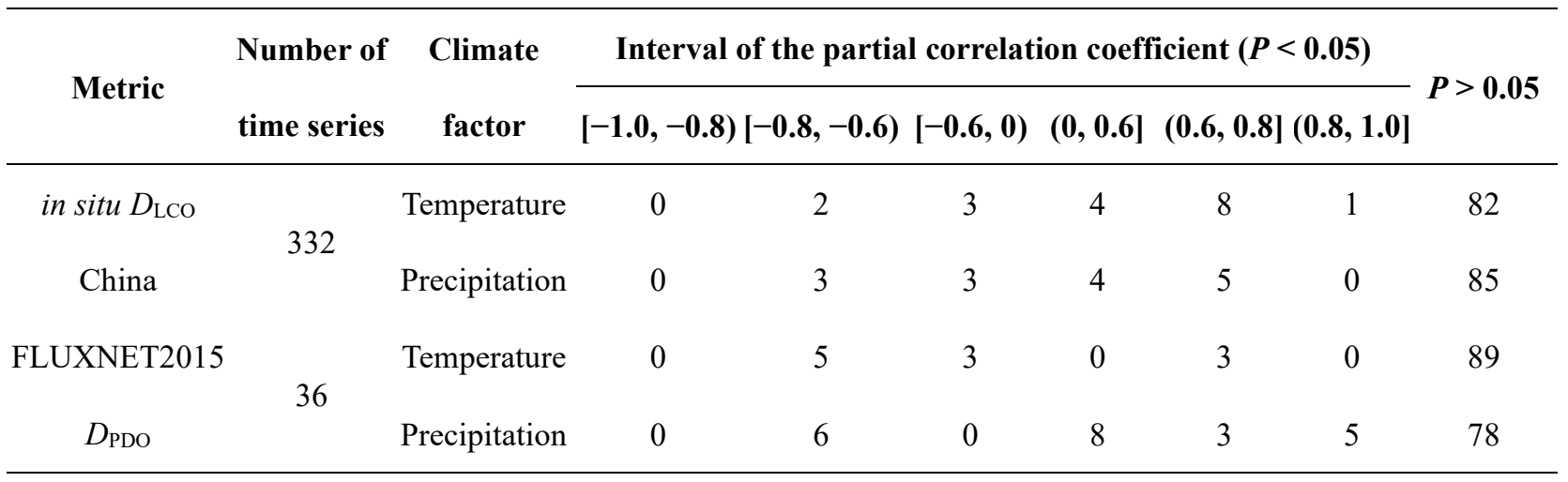

$D_{\text {PDO }}$, timing of the onset of the decrease in maximum canopy photosynthetic capacity in autumn; $D_{\text {LCO }}$, timing of the onset of leaf coloration in autumn. The relationships between $D_{\mathrm{LCO}}\left(\right.$ or $D_{\mathrm{PDO}}$ ) and temperature were determined by using a partial correlation analysis between $D_{\mathrm{LCO}}$ (or $D_{\mathrm{PDO}}$ ) and pre- $D_{\mathrm{LCO}}$ (or pre- $D_{\mathrm{PDO}}$ ) mean daily minimum temperature, with concurrent total precipitation as the control variable. The relationships between $D_{\text {LCO }}$ (or $D_{\text {PDo }}$ ) and pre- $D_{\mathrm{LCO}}$ (or pre- $D_{\mathrm{PDO}}$ ) precipitation were determined similarly. The data in the farthest right column indicate the percentages of area or time series with non-significant correlations.

In previous analyses of in situ and satellite observations (Garonna et al., 2014; Gill et al., 2015; Liu et al., 2016), the advanced stage of autumnal leaf senescence, indicated by $D_{\mathrm{LCE}}$, was significantly delayed in a larger proportion of areas, or time series, than was $D_{\mathrm{LCO}}$ in our study. 
373 In the current study, $D_{\text {LCE }}$ was also significantly delayed in more areas than $D_{\text {LCO }}$ (Fig. S12), 374 probably because the timings of the earlier stages of leaf coloration determined from satellite 375 data were less affected by $T_{\min }$ than the later stages (Fig. 4a and Fig. S13). Evidence for photoperiodic control of the start of leaf senescence (Keskitalo et al., 2005; Fracheboud et al., 2009) suggests that the early phases of leaf senescence are insensitive to warming, in contrast to the later phases. Since the degradation of chlorophyll starts earlier than leaf coloration (Lim et al., 2007; Tang et al., 2016), the timing of autumnal phenological metrics that closely follow chlorophyll degradation before $D_{\text {LCO }}$ should be less delayed by temperature increase than $D_{\text {LCO }}$ if chlorophyll degradation is triggered by the photoperiod. To test this deduction, we analyzed the relationship between $D_{\mathrm{PDO}}$ in autumn and pre- $D_{\mathrm{PDO}} T_{\min }$ (determined in a similar way to pre- $\left.D_{\mathrm{LCO}} T_{\mathrm{min}}\right)$, since $D_{\mathrm{PDO}}$ is notably strongly controlled by chlorophyll concentration. Indeed, $D_{\text {PDO }}$ was positively correlated with pre- $D_{\text {PDO }} T_{\min }$ in $3 \%$ of the 36 eddy-covariance towers and was not correlated with pre- $D_{\mathrm{PDO}} T_{\min }$ in $89 \%$ of the eddy-covariance records (Table 1).

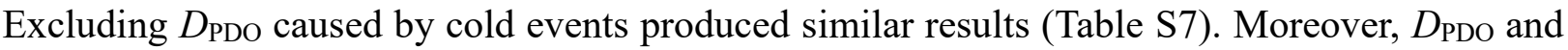
pre- $D_{\mathrm{PDO}} T_{\min }$ were less positively correlated than were NDVI-derived $D_{\mathrm{LCO}}$ and pre- $D_{\mathrm{LCO}} T_{\min }$ at the same sites during the same periods $\left(3 \%\right.$ and $6 \%$ of the sites for $D_{\text {PDO }}$ and $D_{\mathrm{LCO}}$, respectively, Table S8), probably because the start of autumnal chlorophyll degradation was controlled by photoperiod and was not delayed by higher temperature (Keskitalo et al., 2005; Fracheboud et al., 2009; Bauerle et al., 2012).

\section{4 | DISCUSSION}

\subsection{Whether summer NDVI decline contributed to the absence of $D_{\text {LCo delay and }}$}

\section{DLCo-temperature relationship}

Our findings are mainly based on $D_{\text {LCO }}$ determined on the annual trajectory of NDVI. In some deciduous forest, NDVI may decline in early summer (i.e., late May-July) before leaf coloration, and this may potentially interfere with the determination of $D_{\text {LCO }}$ to some extent (Elmore et al., 2012). To test whether early summer NDVI decline would affect the results in our study, for the pixels classified as deciduous broadleaf forest in the MODIS land-cover product in 2009, we redefined independently $D_{\text {LCO }}$ in three different ways: (1) We used a modified double logistic model that considers early summer NDVI decline (Elmore et al., 2012) 
to fit the NDVI time series instead of the original double logistic function for the pixels classified as deciduous broadleaf forest. $D_{\text {LCO }}$ was then determined as the date when the rate of change of the curvature of a double logistic function fitted to the NDVI time series reached its first local minimum in the descending period; (2) $D_{\text {LCO }}$ was defined as the date when NDVI decreased by $10 \%$ of its annual amplitude from 1 August. The maximum value used to determine the annual amplitude was the mean value of the upper quartile of the fitted NDVI values in August; and (3) DLCO was defined as the date when NDVI decreased by $10 \%$ of its annual amplitude from 16 August. The maximum value used to determine the annual amplitude was the mean value of the upper quartile of the fitted NDVI values in the second half of August. The results with deciduous broadleaf forest pixels redefined in these three ways (Figs. S14-S22) were similar to those calculated without considering the effect of early summer NDVI decline (Figs. 3-6; Fig. S4).

\subsection{Dependence of leaf senescence on daylength}

Overall, these results suggest that temperature does not initiate senescence in autumn in most areas; rather, it influences the speed of senescence after it starts (Fracheboud et al., 2009). The lack of a positive correlation between $D_{\mathrm{LCO}}$ (or $D_{\mathrm{PDO}}$ ) and pre- $D_{\mathrm{LCO}}$ (or pre- $D_{\mathrm{PDO}}$ ) temperature suggests an overriding photoperiodic control that makes the timing of the onset of leaf senescence stable. In the areas with longer daylengths (calculated for each pixel/location at multiyear mean $D_{\text {LCO }}$ over 2000-2018), there were proportionally fewer significant $D_{\text {LCO delays }}$ during 2000-2018 (Fig. 5a and Fig. S23a), and the positive relationship between $D_{\text {LCO }}$ and pre- $D_{\text {LCO }} T_{\min }$ was slightly weaker, as indicated by the smaller partial correlation coefficient between them (Fig. 5d). Such patterns were more prominent for woody vegetation than for herbaceous vegetation (Fig. 5b, c, e and f; Fig. S23b and c), in agreement with experimental findings suggesting that the initiation of leaf senescence in woody plants is likely controlled by photoperiod (Keskitalo et al., 2005; Fracheboud et al., 2009). These findings indicate stronger photoperiodic control in areas where daylength at $D_{\text {LCO }}$ is longer (i.e., shorter nights), possibly because plants respond to the length of uninterrupted darkness rather than daylength (Hamner, 1940; Borthwick \& Hendricks, 1960; Paus et al., 1986; Howe et al., 1995). Interestingly, for 
431 with pre- $D_{\mathrm{LCO}} T_{\min }$ in colder areas at a given daylength (Fig. $5 \mathrm{~d}-\mathrm{f}$ ), indicating a stronger effect 432 of temperature in areas with harsh temperature conditions, consistent with experimental studies 433 (Zohner et al., 2016; Ford et al., 2017). Therefore, although for these types of vegetation the 434 correlation between $D_{\mathrm{LCO}}$ and temperature is weak, probably because of stronger photoperiodic 435 control, there is still a signal of temperature influence on $D_{\mathrm{LCO}}$, reflecting a stronger selection 436 pressure in harsher temperature environments. The correlation between $D_{\mathrm{LCO}}$ and pre- $D_{\mathrm{LCO}}$ total 437 precipitation was independent of photoperiod and was slightly stronger for the areas with a 438 higher daily minimum temperature before $D_{\text {LCO }}$, mostly because of the stronger effect of 439 precipitation in delaying $D_{\mathrm{LCO}}$ in herbaceous vegetation (Figs. S5 and S24). The dependences of $440 D_{\mathrm{LCO}}$ trends on photoperiod and of the correlation between $D_{\mathrm{LCO}}$ and pre- $D_{\mathrm{LCO}} T_{\min }$ on 441 photoperiod were also found when years with cold events before $D_{\text {LCO }}$ were excluded (Fig. 442 S25).
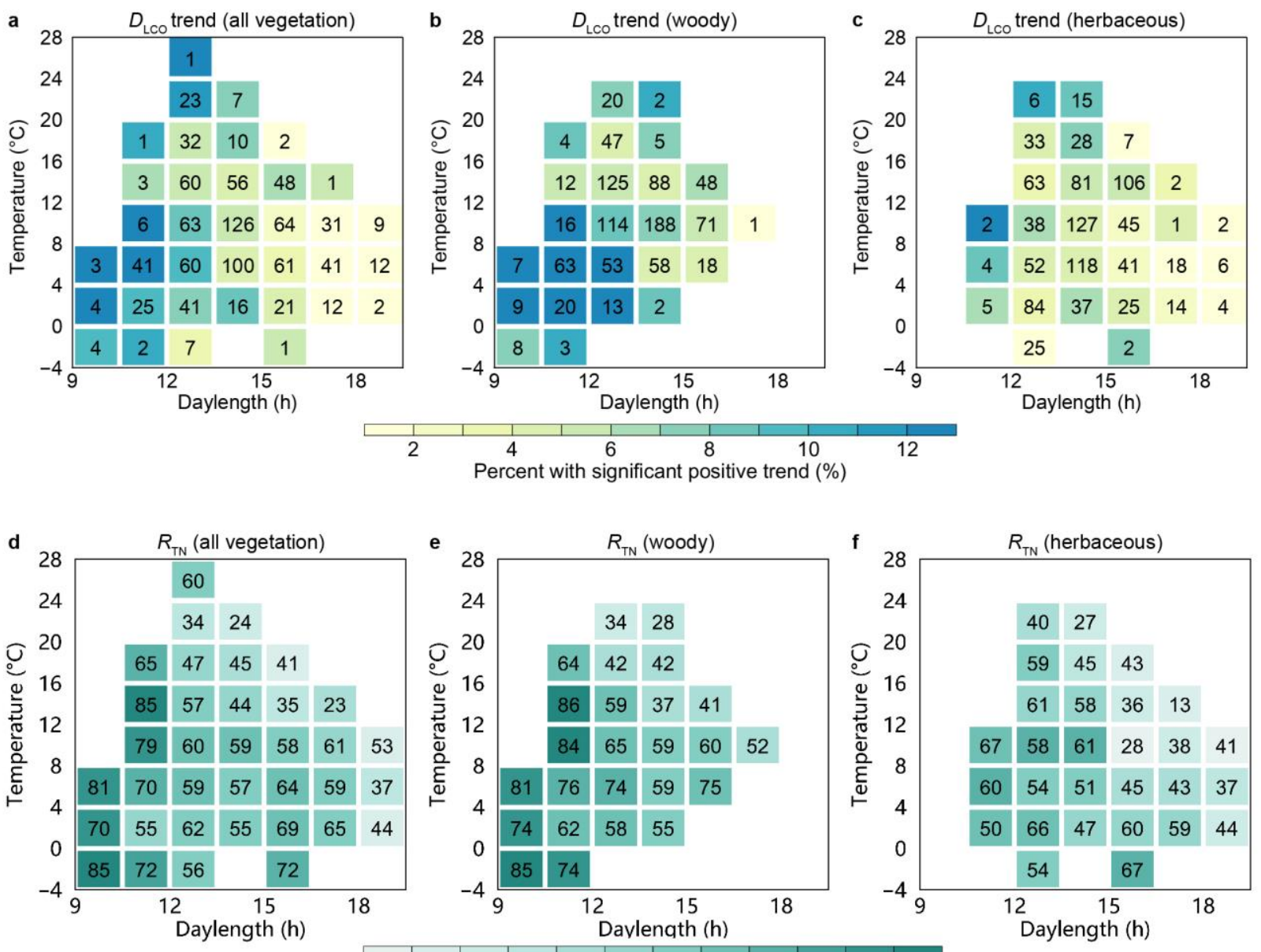

$$
\frac{1}{0.20}
$$$$
0.24
$$

Davlenath $(\mathrm{h})$

444 Fig. 5 Dependence of temporal trends in the timing of the onset of leaf coloration $\left(D_{\mathrm{LCO}}, \mathrm{a}-\mathrm{c}\right)$ 
and of the partial correlation coefficient $\left(R_{\mathrm{TN}}, \mathrm{d}-\mathrm{f}\right)$ between $D_{\mathrm{LCO}}$ and pre- $D_{\mathrm{LCO}}$ mean daily minimum temperature $\left(T_{\min }\right)$ on daylength and temperature at $D_{\text {LCO }}$ over the period 2000-2018. Daylength (indicated by the horizontal axis) was calculated for each pixel (location) at multiyear

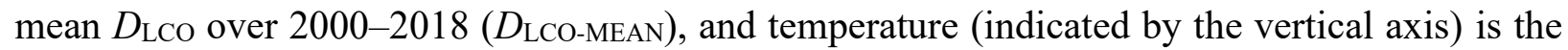
mean of daily minimum temperature in the month preceding $D_{\text {LCO-MEAN. a, All vegetation. Color }}$ indicates the percentage of area with significant $(P<0.05) D_{\text {LCO }}$ delays in each cell (i.e., a specific temperature $\times$ daylength combination), as indicated in the scale at the bottom. The number in each cell indicates the ratio (unit: \%o) of the area in each cell to the total area with $D_{\text {LCO }}$ retrieval (i.e., Northern Hemisphere from $30^{\circ} \mathrm{N}-75^{\circ} \mathrm{N}$ ). The temporal trends and their significances were determined with ordinary least squares regression and $t$-tests. $\mathrm{b}$ and $\mathrm{c}$, The same as (a) but for woody and herbaceous vegetation, respectively. d, All vegetation. Color indicates the average of the positive $R_{\mathrm{TN}}$, as indicated in the scale at the bottom. The number in each cell indicates the percentage of area with a positive correlation in each cell. e and $f$, The same as (d) but for woody and herbaceous vegetation, respectively. Each cell represents $4{ }^{\circ} \mathrm{C}$ of temperature and $1.5 \mathrm{~h}$ of daylength. Only cells where the ratio of the area of the cell to the total area is $>1 \%$ are represented. Woody and herbaceous vegetation are merged from Classes $1-6$ and Class 10, respectively, in the MODIS land-cover product (MCD12C1, Version 6) for 2009.

Although observational evidence is limited, experimental results have been reported for the photoperiodic induction of leaf senescence in several, mostly woody, species (Table S1). However, in those manipulative experiments, daylength was altered by several hours $(>4 \mathrm{~h}$, Table S1), which is more extreme than the natural conditions plants are likely to experience. Daylength depends only on the day of year and location. Because of the inter-annual limited variations in the timings of leaf coloration or senescence onset, the fluctuation in daylength under natural conditions is far less than that in manipulative experiments. Therefore, the role of photoperiod in leaf senescence identified under such experimental conditions does not necessarily apply to plants under natural conditions. The results in this study support experimental findings in wild plants at the biome and continental scales and show that 
473 photoperiod influences the onset of leaf coloration, which closely follows the initial of leaf 474 senescence.

475

476

477

478

479

480

481

482

483

484

485

486

487

488

489

490

491

492

493

494

495

496

497

498

\subsection{Implications}

Autumnal leaf senescence in preparation for overwintering is an evolutionary trade-off between the reallocation of leaf nutrients before leaf shed to reduce the risk of frost damage and the assimilation of carbon (Estiarte \& Peñuelas, 2015). The response of leaf senescence to an increase in temperature in autumn influences this trade-off. The absence of delays over time in the onset of leaf coloration and in the onset of decrease in maximum canopy photosynthetic capacity in response to climate warming, as observed in our study, may limit the detrimental effects of frost in autumn (Liu et al., 2018) and may also pose limited impacts on the start of the remobilization and resorption of nutrients (Estiarte \& Peñuelas, 2015). The stronger positive correlation between the advanced stage of leaf coloration and the $T_{\min }$ for an optimized period preceding that stage (Fig. 4 and Fig. S13), implies that climatic warming may help to extend the period from the onset to the end of leaf coloration in extensive areas across the middle and high northern latitudes (Fig. 6); this in turn may increase the efficiency of nitrogen resorption (Rennenberg et al., 2010) and increase the vegetation greenness in this period, which will modify on the surface energy balance through biophysical processes (Shen et al., 2015). The extended period of leaf coloration may also prolong the plant transpiration time and increase soil water consumption. The impact of autumn warming on net ecosystem productivity is dual, increasing both respiratory flux to the atmosphere (Piao et al., 2008) and forest gross primary photosynthesis (Keenan et al., 2014). The relatively static onset date of leaf coloration and its weak response to temperature would preclude the vegetation from fully using the potential increase in $\mathrm{CO}_{2}$ assimilation in early autumn induced by warming (Stinziano \& Way, 2017). Combined with a delay in the end of the season and a respiration increase due to warming, this suggests that additional warming will probably not result in a continuous increase in autumn $\mathrm{CO}_{2}$ assimilation. 


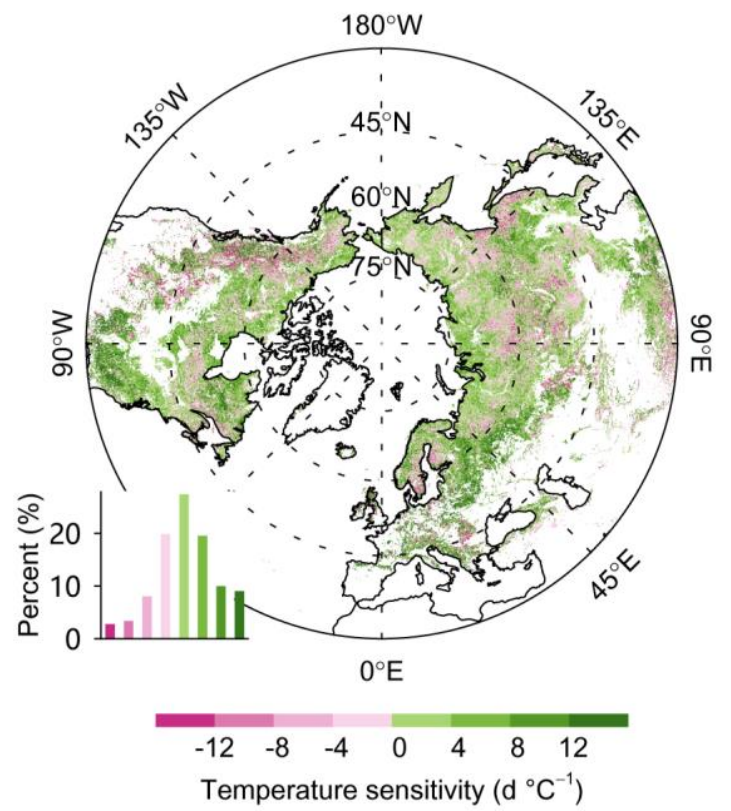

500 Fig. 6 Difference in temperature sensitivity between the end and onset of leaf coloration $\left(D_{\mathrm{LCE}}\right.$ 501 and $D_{\text {LCO }}$ ) over the period 2000-2018. The temperature sensitivity of $D_{\text {LCO }}$ is defined as the coefficient for pre- $D_{\mathrm{LCO}}$ mean daily minimum temperature $\left(T_{\min }\right)$ in a linear regression in which $D_{\mathrm{LCO}}$ is set as the dependent variable and pre- $D_{\mathrm{LCO}} T_{\min }$ and pre- $D_{\mathrm{LCO}}$ total precipitation are independent variables. The temperature sensitivity of $D_{\mathrm{LCE}}$ is calculated in a similar way. $D_{\mathrm{LCO}}$ and $D_{\mathrm{LCE}}$ are determined as the dates when NDVI decreases by $10 \%$ and $50 \%$, respectively, of its annual amplitude, based on a generalized sigmoid function fitted from the annual NDVI profile. The bar chart in the bottom-left corner shows the percentage of area for each interval of the temperature sensitivity indicated by the color scale at the bottom. Positive values (green) indicate that $D_{\mathrm{LCE}}$ is more sensitive to temperature than $D_{\mathrm{LCO}}$, whereas negative values (pink) indicate that $D_{\text {LCO }}$ is more sensitive to temperature than $D_{\text {LCE. }}$

\section{4 $\mid$ Concluding remarks}

In summary, satellite NDVI time series and ground-based phenological observations indicated no significant delay in the start of autumnal leaf coloration for most areas covered by natural vegetation over middle and high northern latitudes. Neither pre- $D_{\text {LCO }}$ temperature nor pre- $D_{\text {LCO }}$ precipitation significantly affected the interannual variations of the start of leaf coloration in most areas, indicating that the start of leaf senescence is triggered by photoperiod.

517 Interestingly, there was a weaker positive correlation between the start of autumnal leaf 
518 coloration and pre- $D_{\text {LCO }} T_{\min }$ for vegetation in regions with longer daylength, indicating strong 519 photoperiodic control of the start of leaf senescence. For vegetation with a given daylength at $520 D_{\text {LCO }}$ longer than $13.5 \mathrm{~h}$, the positive correlation between $D_{\mathrm{LCO}}$ and pre- $D_{\mathrm{LCO}} T_{\min }$ was slightly

521

522

523

524

525

526

527

528

529

530

531

532

533

534

535

536

537

538

539

540

541

542

543

544

545

546

547

548

549

550

551

552 stronger in colder areas, suggesting that there is strong selection pressure in harsher temperature environments on the timing of leaf coloration onset and that autumn warming could have a stronger delaying effect on leaf coloration onset in colder areas than in warmer areas. This study suggests that autumnal warming will not change the start date of leaf senescence, but it might slow the rate of senescence. A slower senescence speed possibly could extend the period of senescence and provide more time to reallocate nutrients and prepare for overwintering. Such changes could substantially affect carbon and nutrient cycles. Our study provides a foundation for understanding the complex relationships among nutrient cycling, vegetation growth, energy exchange, and climate change in autumn in temperate and boreal regions dominated by winter deciduous vegetation.

\section{Data Availability}

The data supporting the findings of this study are available through the links given in the paper.

\section{References}

Bauerle, W.L., Oren, R., Way, D.A., Qian, S.S., Stoy, P.C., Thornton, P.E., Bowden, J.D., Hoffman, F.M. \& Reynolds, R.F. (2012) Photoperiodic regulation of the seasonal pattern of photosynthetic capacity and the implications for carbon cycling. Proceedings of the National Academy of Sciences, 109, 8612-7.

Beck, P.S.A., Atzberger, C., Høgda, K.A., Johansen, B. \& Skidmore, A.K. (2006) Improved monitoring of vegetation dynamics at very high latitudes: A new method using MODIS NDVI. Remote Sensing of Environment, 100, 321-334.

Berman, E.E., Graves, T.A., Mikle, N.L., Merkle, J.A., Johnston, A.N. \& Chong, G.W. (2020) Comparative Quality and Trend of Remotely Sensed Phenology and Productivity Metrics across the Western United States. Remote Sensing, 12

Borthwick, H.A. \& Hendricks, S.B. (1960) Photoperiodism in Plants. Science, 132, 1223-1228.

Cao, R., Chen, Y., Shen, M., Chen, J., Zhou, J., Wang, C. \& Yang, W. (2018) A simple method to improve the quality of NDVI time-series data by integrating spatiotemporal information with the Savitzky-Golay filter. Remote Sensing of Environment, 217, 244-257.

Chen, J., Rao, Y., Shen, M., Wang, C., Zhou, Y., Ma, L., Tang, Y. \& Yang, X. (2016) A simple method for detecting phenological change from time series of vegetation index. IEEE Transactions on Geoscience and Remote Sensing, 54, 3436-3449.

China Meteorological Administration (1993) Observation criterion of agricultural meteorology. China Meteorological Press, Beijing (in Chinese). 
Delpierre, N., Dufrêne, E., Soudani, K., Ulrich, E., Cecchini, S., Boé, J. \& François, C. (2009) Modelling interannual and spatial variability of leaf senescence for three deciduous tree species in France. Agricultural and Forest Meteorology, 149, 938-948.

Elmore, A.J., Guinn, S.M., Minsley, B.J. \& Richardson, A.D. (2012) Landscape controls on the timing of spring, autumn, and growing season length in mid-Atlantic forests. Global Change Biology, 18, 656-674.

Estiarte, M. \& Peñuelas, J. (2015) Alteration of the phenology of leaf senescence and fall in winter deciduous species by climate change: effects on nutrient proficiency. Global Change Biology, 21, 1005-1017.

Estrella, N. \& Menzel, A. (2006) Responses of leaf colouring in four deciduous tree species to climate and weather in Germany. Climate Research, 32, 253-267.

Ford, K.R., Harrington, C.A. \& Clair, J.B.S. (2017) Photoperiod cues and patterns of genetic variation limit phenological responses to climate change in warm parts of species' range: Modeling diameter-growth cessation in coast Douglas-fir. Global Change Biology, 23, 3348-3362.

Fracheboud, Y., Luquez, V., Björkén, L., Sjödin, A., Tuominen, H. \& Jansson, S. (2009) The control of autumn senescence in European aspen. Plant Physiology, 149, 1982-1991.

Friedl, M. \& Sulla-Menashe, D. (2015) MCD12C1 MODIS/Terra+Aqua Land Cover Type Yearly L3 Global 0.05Deg CMG V006 In: NASA EOSDIS Land Processes DAAC. http://doi.org/10.5067/MODIS/MCD12C1.006

Fu, Y.H., Piao, S., Delpierre, N., Hao, F., Hänninen, H., Liu, Y., Sun, W., Janssens, I.A. \& Campioli, M. (2018) Larger temperature response of autumn leaf senescence than spring leaf-out phenology. Global Change Biology, 24, 2159-2168.

Fu, Y.H., Zhao, H., Piao, S., Peaucelle, M., Peng, S., Zhou, G., Ciais, P., Huang, M., Menzel, A., Penuelas, J., Song, Y., Vitasse, Y., Zeng, Z. \& Janssens, I.A. (2015) Declining global warming effects on the phenology of spring leaf unfolding. Nature, 526, 104-107.

Fu, Y.S.H., Campioli, M., Vitasse, Y., De Boeck, H.J., Van den Berge, J., AbdElgawad, H., Asard, H., Piao, S., Deckmyn, G. \& Janssens, I.A. (2014) Variation in leaf flushing date influences autumnal senescence and next year's flushing date in two temperate tree species. Proceedings of the National Academy of Sciences, 111, 7355-7360.

Gan, S.S. \& Amasino, R.M. (1997) Making sense of senescence - Molecular genetic regulation and manipulation of leaf senescence. Plant Physiology, 113, 313-319.

Ganguly, S., Friedl, M.A., Tan, B., Zhang, X. \& Verma, M. (2010) Land surface phenology from MODIS: Characterization of the Collection 5 global land cover dynamics product. Remote Sensing of Environment, 114, 1805-1816.

Garonna, I., De Jong, R., De Wit, A.J.W., Mücher, C.A., Schmid, B. \& Schaepman, M.E. (2014) Strong contribution of autumn phenology to changes in satellite-derived growing season length estimates across Europe (1982-2011). Global Change Biology, 20, 3457-3470.

Ge, Q.S., Wang, H.J., Rutishauser, T. \& Dai, J.H. (2015) Phenological response to climate change in China: a meta-analysis. Global Change Biology, 21, 265-274.

Gill, A.L., Gallinat, A.S., Sanders-DeMott, R., Rigden, A.J., Short Gianotti, D.J., Mantooth, J.A. \& Templer, P.H. (2015) Changes in autumn senescence in northern hemisphere deciduous trees: a meta-analysis of autumn phenology studies. Annals of Botany, 116, 875-888.

Gu, L., Post, W.M., Baldocchi, D.D., Black, T.A., Suyker, A.E., Verma, S.B., Vesala, T. \& Wofsy, S.C. (2009) Characterizing the seasonal dynamics of plant community photosynthesis across a range of vegetation types. Phenology of Ecosystem Processes (ed. by A. Noormets), pp. 35-58. Springer, 
New York, NY.

Hamner, K.C. (1940) Interrelation of light and darkness in photoperiod. Botanical Gazette, 101, 658-687.

Harris, I., Jones, P.D., Osborn, T.J. \& Lister, D.H. (2014) Updated high-resolution grids of monthly climatic observations - the CRU TS3.10 Dataset. International Journal of Climatology, 34, 623-642.

Howe, G.T., Hackett, W.P., Furnier, G.R. \& Klevorn, R.E. (1995) Photoperiodic responses of a northern and southern ecotype of black cottonwood. Physiologia Plantarum, 93, 695-708.

Jeganathan, C., Dash, J. \& Atkinson, P.M. (2014) Remotely sensed trends in the phenology of northern high latitude terrestrial vegetation, controlling for land cover change and vegetation type. Remote Sensing of Environment, 143, 154-170.

Jeong, S.J., Ho, C.H., Gim, H.J. \& Brown, M.E. (2011) Phenology shifts at start vs. end of growing season in temperate vegetation over the Northern Hemisphere for the period 1982-2008. Global Change Biology, 17, 2385-2399.

Keenan, T.F. \& Richardson, A.D. (2015) The timing of autumn senescence is affected by the timing of spring phenology: implications for predictive models. Global Change Biology, 21, 2634-2641.

Keenan, T.F., Gray, J., Friedl, M.A., Toomey, M., Bohrer, G., Hollinger, D.Y., Munger, J.W., O’Keefe, J., Schmid, H.P., Wing, I.S., Yang, B. \& Richardson, A.D. (2014) Net carbon uptake has increased through warming-induced changes in temperate forest phenology. Nature Climate Change, $\mathbf{4}$, 598-604.

Keskitalo, J., Bergquist, G., Gardeström, P. \& Jansson, S. (2005) A cellular timetable of autumn senescence. Plant Physiol, 139, 1635-1648.

Klosterman, S. \& Richardson, A.D. (2017) Observing Spring and Fall Phenology in a Deciduous Forest with Aerial Drone Imagery. Sensors (Basel), 17

Klosterman, S.T., Hufkens, K., Gray, J.M., Melaas, E., Sonnentag, O., Lavine, I., Mitchell, L., Norman, R., Friedl, M.A. \& Richardson, A.D. (2014) Evaluating remote sensing of deciduous forest phenology at multiple spatial scales using PhenoCam imagery. Biogeosciences, 11, 4305-4320.

Körner, C. (2007) Significance of temperature in plant life. Plant Growth and Climate Change (ed. by J.I.L. Morison and M.D. Morecroft), pp. 48-69.

Körner, C. \& Basler, D. (2010) Response-warming, photoperiods, and tree phenology. Science, 329, 278-278.

Körner, C. \& Hiltbrunner, E. (2018) The 90 ways to describe plant temperature. Perspectives in Plant Ecology, Evolution and Systematics, 30, 16-21.

Leblans, N.I.W., Sigurdsson, B.D., Vicca, S., Fu, Y.S., Penuelas, J. \& Janssens, I.A. (2017) Phenological responses of Icelandic subarctic grasslands to short-term and long-term natural soil warming. Global Change Biology, 23, 4932-4945.

Lim, P.O., Kim, H.J. \& Nam, H.G. (2007) Leaf Senescence. Annual Review of Plant Biology, 58, 115-136.

Liu, Q., Fu, Y.H., Zhu, Z., Liu, Y., Liu, Z., Huang, M., Janssens, I.A. \& Piao, S. (2016) Delayed autumn phenology in the Northern Hemisphere is related to change in both climate and spring phenology. Global Change Biology, 22, 3702-3711.

Liu, Q., Piao, S., Janssens, I.A., Fu, Y., Peng, S., Lian, X., Ciais, P., Myneni, R.B., Penuelas, J. \& Wang, T. (2018) Extension of the growing season increases vegetation exposure to frost. Nature Communications, 9, 426.

Lukasová, V., Bucha, T., Škvareninová, J. \& Škvarenina, J. (2019) Validation and Application of European Beech Phenological Metrics Derived from MODIS Data along an Altitudinal Gradient. Forests, 10, 60.

Mariën, B., Balzarolo, M., Dox, I., Leys, S., Lorène, M.J., Geron, C., Portillo-Estrada, M., AbdElgawad, H., 
Asard, H., Campioli, M., Mariën, B., Balzarolo, M., Dox, I., Leys, S., Lorène, M.J., Geron, C., Portillo Estrada, M., AbdElgawad, H., Asard, H. \& Campioli, M. (2019) Detecting the onset of autumn leaf senescence in deciduous forest trees of the temperate zone. New Phytologist, 224, 166-176.

Melaas, E.K., Friedl, M.A. \& Zhu, Z. (2013) Detecting interannual variation in deciduous broadleaf forest phenology using Landsat TM/ETM+ data. Remote Sensing of Environment, 132, 176-185.

Menzel, A., Yuan, Y., Matiu, M., Sparks, T., Scheifinger, H., Gehrig, R. \& Estrella, N. (2020) Climate change fingerprints in recent European plant phenology. Global Change Biology, 26, 2599-2612.

Myneni, R.B., Keeling, C.D., Tucker, C.J., Asrar, G. \& Nemani, R.R. (1997) Increased plant growth in the northern high latitudes from 1981 to 1991. Nature, 386, 698-702.

Nagai, S., Nasahara, K.N., Muraoka, H., Akiyama, T. \& Tsuchida, S. (2010) Field experiments to test the use of the normalized-difference vegetation index for phenology detection. Agricultural and Forest Meteorology, 150, 152-160.

Nezval, O., Krejza, J., Světlík, J., Šigut, L. \& Horáček, P. (2020) Comparison of traditional ground-based observations and digital remote sensing of phenological transitions in a floodplain forest. Agricultural and Forest Meteorology, 291

Pastorello, G.Z., Papale, D., Chu, H., Trotta, C., Agarwal, D.A., Canfora, E., Baldocchi, D.D. \& Torn, M.S. (2017) A new data set to keep a sharper eye on land-air exchanges. In: Eos

Paus, E., Nilsen, J. \& Junttila, O. (1986) Bud dormancy and vegetative growth in Salix-Polaris as affected by temperature and photoperiod. Polar Biology, 6, 91-95.

Peñuelas, J., Rutishauser, T. \& Filella, I. (2009) Phenology Feedbacks on Climate Change. Science, 324, 887-888.

Piao, S., Liu, Q., Chen, A., Janssens, I.A., Fu, Y., Dai, J., Liu, L., Lian, X., Shen, M. \& Zhu, X. (2019) Plant phenology and global climate change: Current progresses and challenges. Global Change Biology, 25, 1922-1940.

Piao, S., Ciais, P., Friedlingstein, P., Peylin, P., Reichstein, M., Luyssaert, S., Margolis, H., Fang, J., Barr, A., Chen, A., Grelle, A., Hollinger, D.Y., Laurila, T., Lindroth, A., Richardson, A.D. \& Vesala, T. (2008) Net carbon dioxide losses of northern ecosystems in response to autumn warming. Nature, 451, 49-52.

Ren, J., Campbell, J. \& Shao, Y. (2017) Estimation of SOS and EOS for Midwestern US Corn and Soybean Crops. Remote Sensing, 9

Rennenberg, H., Wildhagen, H. \& Ehlting, B. (2010) Nitrogen nutrition of poplar trees. Plant Biology, 12, 275-291.

Richardson, A.D., Hufkens, K., Milliman, T. \& Frolking, S. (2018) Intercomparison of phenological transition dates derived from the PhenoCam Dataset V1.0 and MODIS satellite remote sensing. Scientific Reports, 8

Richardson, A.D., Keenan, T.F., Migliavacca, M., Ryu, Y., Sonnentag, O. \& Toomey, M. (2013) Climate change, phenology, and phenological control of vegetation feedbacks to the climate system. Agricultural and Forest Meteorology, 169, 156-173.

Sen, P.K. (1968) Estimates of the Regression Coefficient Based on Kendall's Tau. Journal of the American Statistical Association, 63, 1379-1389.

Seyednasrollah, B., Young, A.M., Hufkens, K., Milliman, T., Friedl, M.A., Frolking, S. \& Richardson, A.D. (2019a) Tracking vegetation phenology across diverse biomes using Version 2.0 of the PhenoCam Dataset. Sci Data, 6, 222.

Seyednasrollah, B., Young, A.M., Hufkens, K., Milliman, T., Friedl, M.A., Frolking, S., Richardson, A.D., Abraha, M., Allen, D.W., Apple, M., Arain, M.A., Baker, J., Baker, J.M., Baldocchi, D., Bernacchi, 
C.J., Bhattacharjee, J., Blanken, P., Bosch, D.D., Boughton, R., Boughton, E.H., Brown, R.F., Browning, D.M., Brunsell, N., Burns, S.P., Cavagna, M., Chu, H., Clark, P.E., Conrad, B.J., Cremonese, E., Debinski, D., Desai, A.R., Diaz-Delgado, R., Duchesne, L., Dunn, A.L., Eissenstat, D.M., El-Madany, T., Ellum, D.S.S., Ernest, S.M., Esposito, A., Fenstermaker, L., Flanagan, L.B., Forsythe, B., Gallagher, J., Gianelle, D., Griffis, T., Groffman, P., Gu, L., Guillemot, J., Halpin, M., Hanson, P.J., Hemming, D., Hove, A.A., Humphreys, E.R., Jaimes-Hernandez, A., Jaradat, A.A., Johnson, J., Keel, E., Kelly, V.R., Kirchner, J.W., Kirchner, P.B., Knapp, M., Krassovski, M., Langvall, O., Lanthier, G., Maire, G.I., Magliulo, E., Martin, T.A., McNeil, B., Meyer, G.A., Migliavacca, M., Mohanty, B.P., Moore, C.E., Mudd, R., Munger, J.W., Murrell, Z.E., Nesic, Z., Neufeld, H.S., O'Halloran, T.L., Oechel, W., Oishi, A.C., Oswald, W.W., Perkins, T.D., Reba, M.L., Rundquist, B., Runkle, B.R., Russell, E.S., Sadler, E.J., Saha, A., Saliendra, N.Z., Schmalbeck, L., Schwartz, M.D., Scott, R.L., Smith, E.M., Sonnentag, O., Stoy, P., Strachan, S., Suvocarev, K., Thom, J.E., Thomas, R.Q., Van den berg, A.K., Vargas, R., Verfaillie, J., Vogel, C.S., Walker, J.J., Webb, N., Wetzel, P., Weyers, S., Whipple, A.V., Whitham, T.G., Wohlfahrt, G., Wood, J.D., Wolf, S., Yang, J., Yang, X., Yenni, G., Zhang, Y., Zhang, Q. \& Zona, D. (2019b) PhenoCam Dataset v2.0: Vegetation Phenology from Digital Camera Imagery, 2000-2018. In. ORNL Distributed Active Archive Center

Shen, M., Tang, Y., Desai, A.R., Gough, C. \& Chen, J. (2014) Can EVI-derived land-surface phenology be used as a surrogate for phenology of canopy photosynthesis? International Journal of Remote Sensing, 35, 1162-1174.

Shen, M.G., Piao, S.L., Jeong, S.J., Zhou, L.M., Zeng, Z.Z., Ciais, P., Chen, D.L., Huang, M.T., Jin, C.S., Li, L.Z.X., Li, Y., Myneni, R.B., Yang, K., Zhang, G.X., Zhang, Y.J. \& Yao, T.D. (2015) Evaporative cooling over the Tibetan Plateau induced by vegetation growth. Proceedings of the National Academy of Sciences, 112, 9299-9304.

Soudani, K., Delpierre, N., Berveiller, D., Hmimina, G., Pontailler, J.-Y., Seureau, L., Vincent, G. \& Dufrêne, É. (2020) A survey of proximal methods for monitoring leaf phenology in temperate deciduous forests. Biogeosciences Discuss. [preprint], https://doi.org/10.5194/bg-2020-389, in review,

Soudani, K., Hmimina, G., Delpierre, N., Pontailler, J.Y., Aubinet, M., Bonal, D., Caquet, B., de Grandcourt, A., Burban, B., Flechard, C., Guyon, D., Granier, A., Gross, P., Heinesh, B., Longdoz, B., Loustau, D., Moureaux, C., Ourcival, J.M., Rambal, S., Saint André, L. \& Dufrêne, E. (2012) Ground-based Network of NDVI measurements for tracking temporal dynamics of canopy structure and vegetation phenology in different biomes. Remote Sensing of Environment, 123, 234-245.

Stinziano, J.R. \& Way, D.A. (2017) Autumn photosynthetic decline and growth cessation in seedlings of white spruce are decoupled under warming and photoperiod manipulations. Plant Cell and Environment, 40, 1296-1316.

Tang, J., Körner , C., Muraoka, H., Piao, S., Shen, M., Thackeray, S.J. \& Yang, X. (2016) Emerging opportunities and challenges in phenology: a review. Ecosphere, 7, e01436.

Theil, H. (1992) A rank-invariant method of linear and polynomial regression analysis. Henri Theil's Contributions to Economics and Econometrics: Econometric Theory and Methodology (ed. by B. Raj and J. Koerts), pp. 345-381. Springer Netherlands, Dordrecht.

Thomas, H. \& Stoddart, J.L. (1980) Leaf Senescence. Annual Review of Plant Physiology and Plant Molecular Biology, 31, 83-111.

Vermote, E.F. (2015) MOD09CMG MODIS/Terra Surface Reflectance Daily L3 Global 0.05Deg CMG V006. In: NASA EOSDIS Land Processes DAAC 
Viovy, N. (2018) CRUNCEP Version 7 - Atmospheric Forcing Data for the Community Land Model. In: Research Data Archive at the National Center for Atmospheric Research, Computational and Information Systems Laboratory, Boulder CO.

Wang, C. \& Zhu, K. (2019) Misestimation of growing season length due to inaccurate construction of satellite vegetation index time series. IEEE Geoscience and Remote Sensing Letters, 16, 1185-1189.

White, M.A., Thornton, P.E. \& Running, S.W. (1997) A continental phenology model for monitoring vegetation responses to interannual climatic variability. Global Biogeochemical Cycles, 11, 217-234.

Wingate, L., Ogée, J., Cremonese, E., Filippa, G., Mizunuma, T., Migliavacca, M., Moisy, C., Wilkinson, M., Moureaux, C., Wohlfahrt, G., Hammerle, A., Hörtnagl, L., Gimeno, C., Porcar-Castell, A., Galvagno, M., Nakaji, T., Morison, J., Kolle, O., Knohl, A., Kutsch, W., Kolari, P., Nikinmaa, E., Ibrom, A., Gielen, B., Eugster, W., Balzarolo, M., Papale, D., Klumpp, K., Köstner, B., Grünwald, T., Joffre, R., Ourcival, J.M., Hellstrom, M., Lindroth, A., George, C., Longdoz, B., Genty, B., Levula, J., Heinesch, B., Sprintsin, M., Yakir, D., Manise, T., Guyon, D., Ahrends, H., Plaza-Aguilar, A., Guan, J.H. \& Grace, J. (2015) Interpreting canopy development and physiology using a European phenology camera network at flux sites. Biogeosciences, 12, 5995-6015.

Xu, C., Liu, H., Williams, A.P., Yin, Y. \& Wu, X. (2016) Trends toward an earlier peak of the growing season in Northern Hemisphere mid-latitudes. Global Change Biology, 22, 2852-2860.

Yang, X., Tang, J. \& Mustard, J.F. (2014) Beyond leaf color: Comparing camera-based phenological metrics with leaf biochemical, biophysical, and spectral properties throughout the growing season of a temperate deciduous forest. Journal of Geophysical Research: Biogeosciences, 119, 181-191.

Yu, H., Luedeling, E. \& Xu, J. (2010) Winter and spring warming result in delayed spring phenology on the Tibetan Plateau. Proceedings of the National Academy of Sciences, 107, 22151-22156.

Zhang, X. (2015) Reconstruction of a complete global time series of daily vegetation index trajectory from long-term AVHRR data. Remote Sensing of Environment, 156, 457-472.

Zhang, X., Tarpley, D. \& Sullivan, J.T. (2007) Diverse responses of vegetation phenology to a warming climate. Geophysical Research Letters, 34

Zhang, X., Friedl, M.A., Schaaf, C.B., Strahler, A.H., Hodges, J.C., Gao, F., Reed, B.C. \& Huete, A. (2003) Monitoring vegetation phenology using MODIS. Remote Sensing of Environment, 84, 471-475.

Zhang, X., Jayavelu, S., Liu, L., Friedl, M.A., Henebry, G.M., Liu, Y., Schaaf, C.B., Richardson, A.D. \& Gray, J. (2018) Evaluation of land surface phenology from VIIRS data using time series of PhenoCam imagery. Agricultural and Forest Meteorology, 256-257, 137-149.

Zhao, B., Donnelly, A. \& Schwartz, M.D. (2020) Evaluating autumn phenology derived from field observations, satellite data, and carbon flux measurements in a northern mixed forest, USA. International Journal of Biometeorology, 64, 713-727.

Zohner, C.M., Benito, B.M., Svenning, J.-C. \& Renner, S.S. (2016) Day length unlikely to constrain climate-driven shifts in leaf-out times of northern woody plants. Nature Climate Change, $\mathbf{6}$, 1120-1123. 


\section{Supplementary Information for}

3

4 Warming does not delay the start of autumnal leaf coloration but slows its progress rate 5

6 This PDF file includes:

7

$8 \quad$ Figures $\mathrm{S} 1$ to $\mathrm{S} 25$

$9 \quad$ Tables $\mathrm{S} 1$ to S8

10 Supplementary Methods

11 Supplementary References 


\section{Supplementary Figures}

14

15

a in situ observations in China

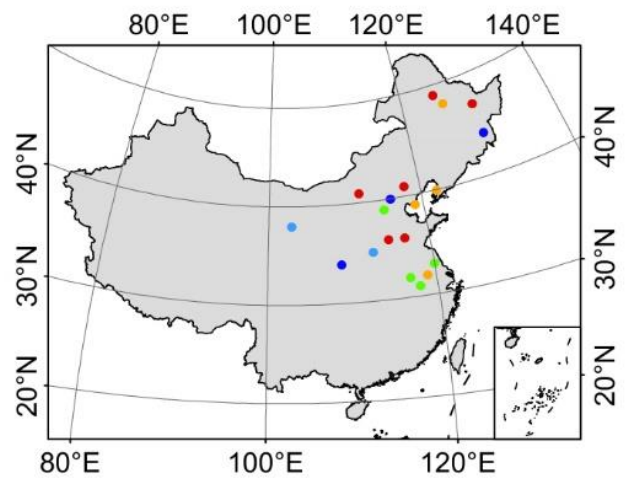

Species number

$\bullet \leq 10 \cdot 11-15 \cdot 16-20 \cdot 21-25 \cdot 26-30 \cdot>30$

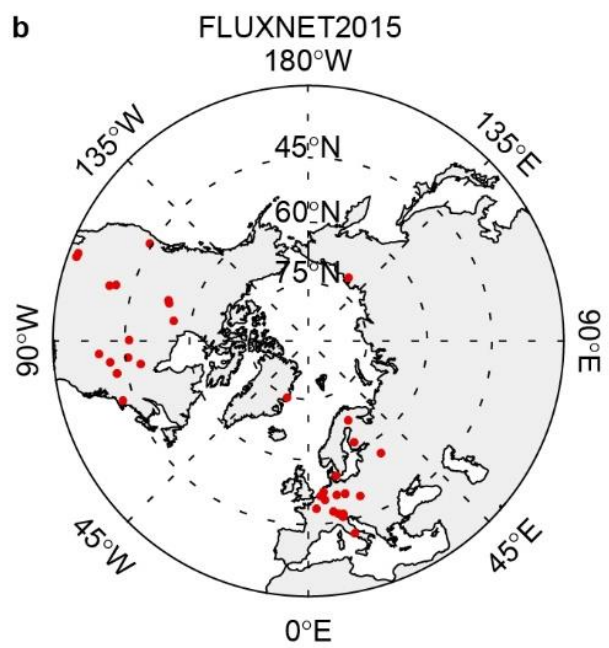

17 Figure S1. Locations of the sites of in situ observations used in this study. a, phenological observation 18 sites in China. b, FLUXNET2015 flux tower sites. 


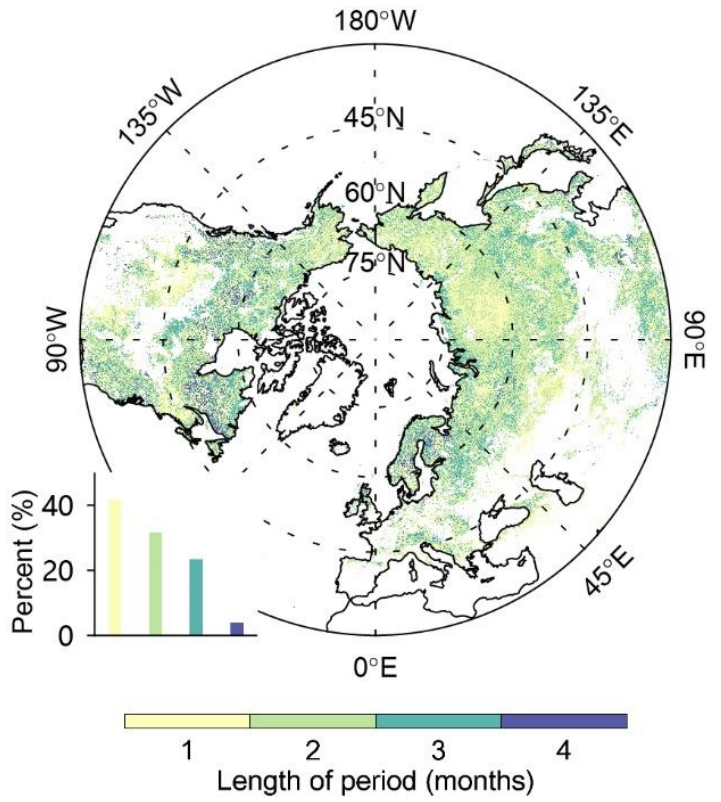

21 Figure S2. Spatial pattern of the length of the pre- $D_{\mathrm{LCO}}$ period for mean daily minimum temperature

$22\left(T_{\min }\right)$. The bar chart shows the percentage of area for each interval of the length of the pre- $D_{\mathrm{LCO}}$ period, 23 with the length indicated by the color scale at the bottom. 


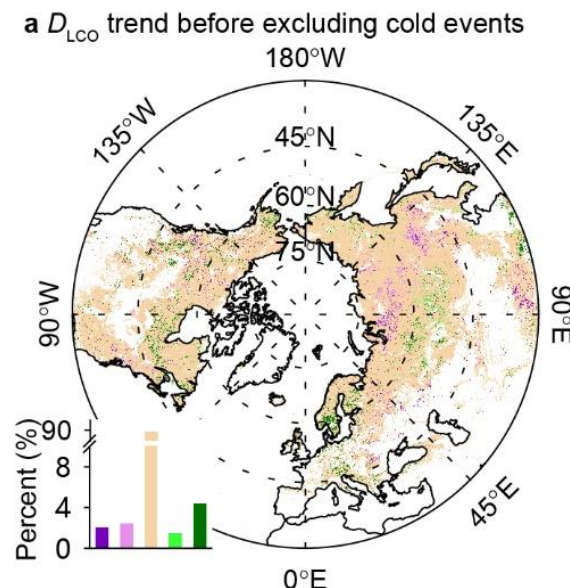

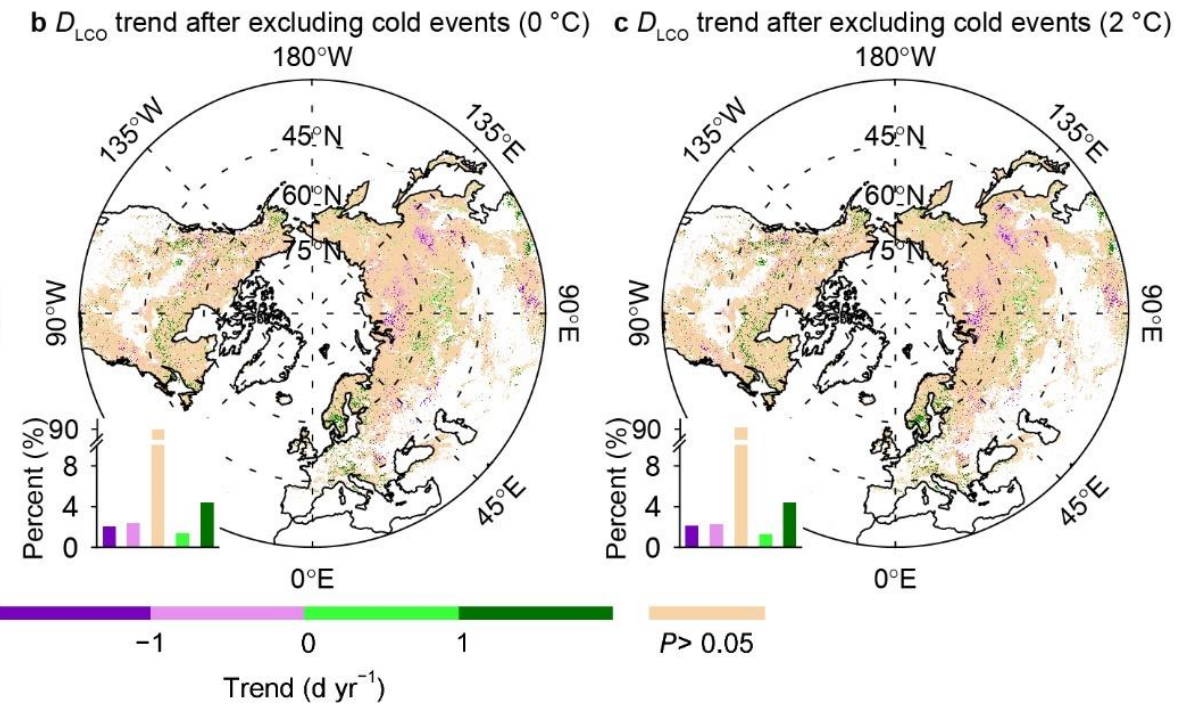

Figure S3. Temporal trends in timing of the onset of leaf coloration $\left(D_{\mathrm{LCO}}\right)$, retrieved from satellite images over the period 2000-2016 before (a) and after (b and c) the exclusion of years with cold events before $D_{\text {LCO }}$. Cold events were determined mainly by using a threshold-based method with daily minimum temperatures of $0{ }^{\circ} \mathrm{C}(\mathrm{b})$ or $2{ }^{\circ} \mathrm{C}(\mathrm{c})$. The bar chart in each panel shows the percentage of area within each interval of the significant $(P<0.05)$ temporal trends and the percentage of area with nonsignificant trends, indicated by the color scale at the bottom. The percentage for each interval of the trend (positive and negative trend values refer to significantly delayed and advanced $D_{\text {LCO }}$, respectively) is provided in Table S5. D $D_{\text {LCO }}$ is defined as the date when NDVI decreases by $10 \%$ of its annual amplitude in autumn, on the basis of a generalized sigmoid function fitted from the annual NDVI profile. Significant temporal trends were determined by using $t$-tests at $P<0.05$ and ordinary least squares regression between $D_{\text {LCO }}$ and the respective years. Pixels dominated by croplands or with low vegetation coverage, weak seasonality, or peak NDVI in October-April were discarded. 

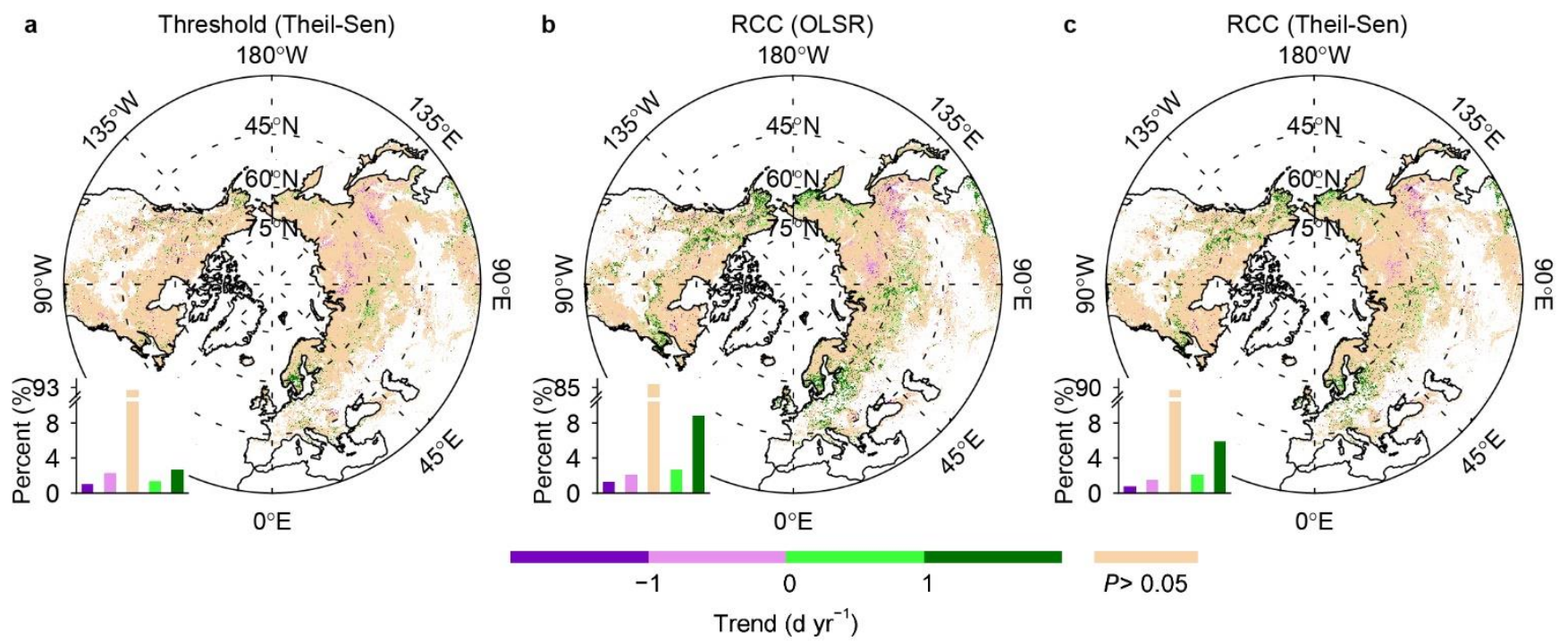

Figure S4. Temporal trends in timing of the onset of leaf coloration ( $\left.D_{\mathrm{LCO}}\right)$, retrieved from satellite

41 images over the period 2000-2018. The bar chart in each panel shows the percentage of area within each 42 interval of the significant $(P<0.05)$ temporal trends and the percentage of area with nonsignificant 43 trends, indicated by the color scale at the bottom. Positive and negative trend values refer to significantly 44 delayed and advanced $D_{\text {LCO }}$, respectively. $D_{\text {LCO }}$ in (a) was defined as the date when NDVI decreased by $4510 \%$ of its annual amplitude in each autumn (threshold), on the basis of a generalized sigmoid function 46 fitted from the annual NDVI profile. $D_{\mathrm{LCO}}$ in (b) and (c) was determined as the date when the rate of 47 change of the curvature (RCC) of a double logistic-function-fitted NDVI curve reached its first local 48 minimum value in the descending period. In (a) and (c), significant temporal trends were determined by 49 using Mann-Kendall tests at $P<0.05$ and a Theil-Sen estimator between $D_{\mathrm{LCO}}$ and the respective years; 50 in (b), significant temporal trends were determined by using $t$-tests at $P<0.05$ and ordinary least squares 51 regression (OLSR) between $D_{\text {LCO }}$ and respective years. Pixels dominated by croplands or with low 52 vegetation coverage, weak seasonality, or peak NDVI in October-April were discarded. 


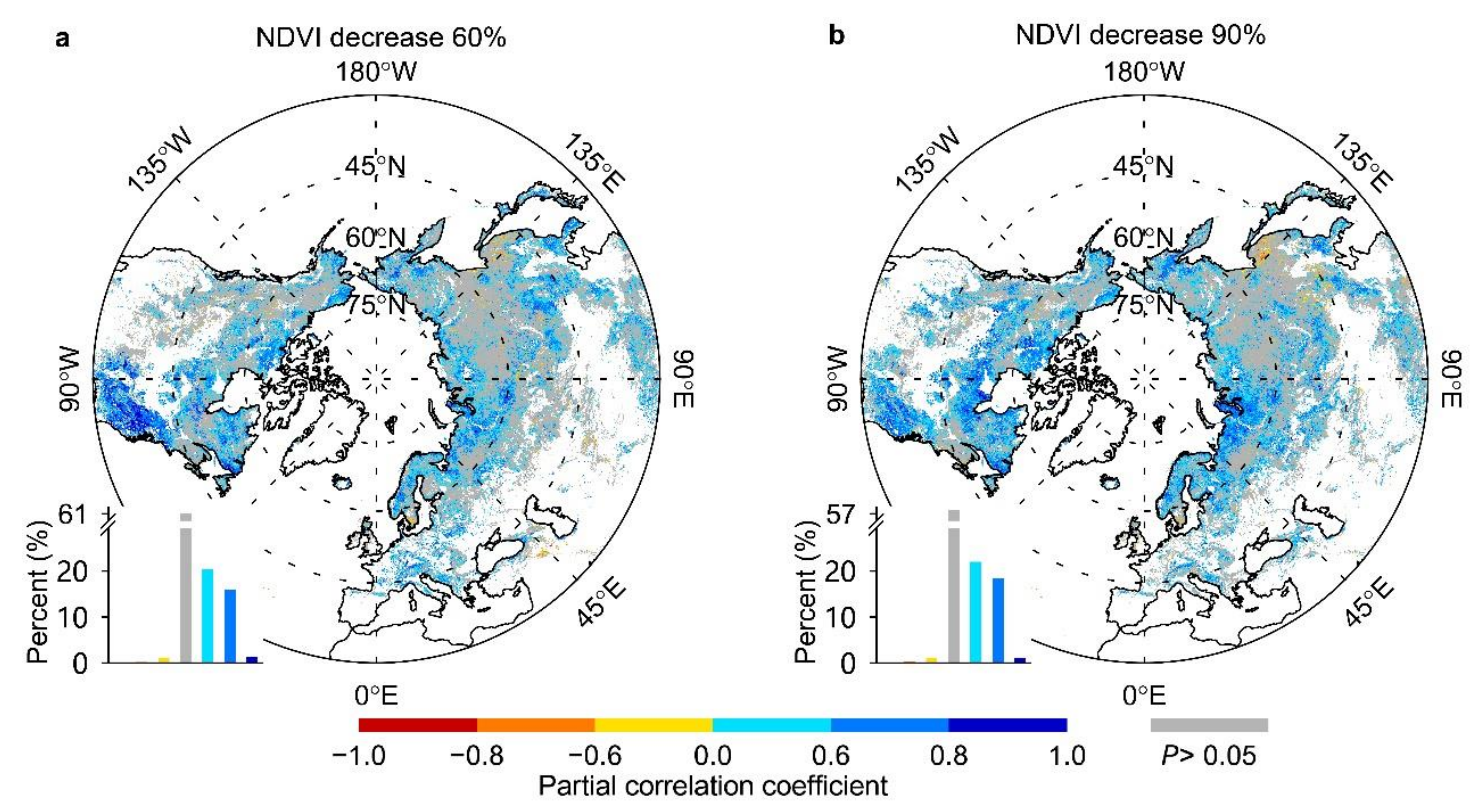

53

54 Figure S5. Spatial pattern of the partial correlation coefficient between the timing of the end of leaf 55 coloration $\left(D_{\mathrm{LCE}}\right)$ and pre- $D_{\mathrm{LCE}} T_{\min }$ over the period 2000-2018. $D_{\mathrm{LCE}}$ was determined as the date when 56 NDVI drops by 60\% (a) and 90\% (b), respectively. The bar chart in the bottom-left corner shows the 57 percentage of area for each interval of the partial correlation coefficient, with the coefficient values 58 indicated by the color scale at the bottom. Non-significant correlations $(P>0.05)$ are in gray. 


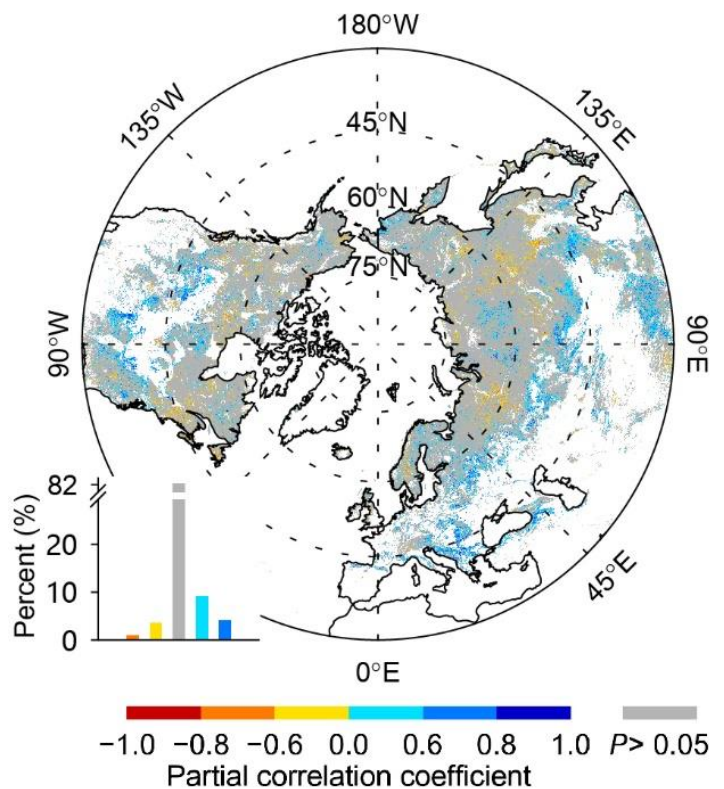

62 Figure S6. Spatial pattern of the partial correlation coefficient between the timing of onset of leaf 63 coloration $\left(D_{\mathrm{LCO}}\right)$ and pre- $D_{\mathrm{LCO}}$ total precipitation over the period 2000-2018. The bar chart in the 64 bottom-left corner shows the percentage of area for each interval of the partial correlation coefficient, 65 with the coefficient values indicated by the color scale at the bottom. Non-significant correlations $(P>$ 660.05 ) are in gray, and the percentage for each interval is provided in Table 1. 

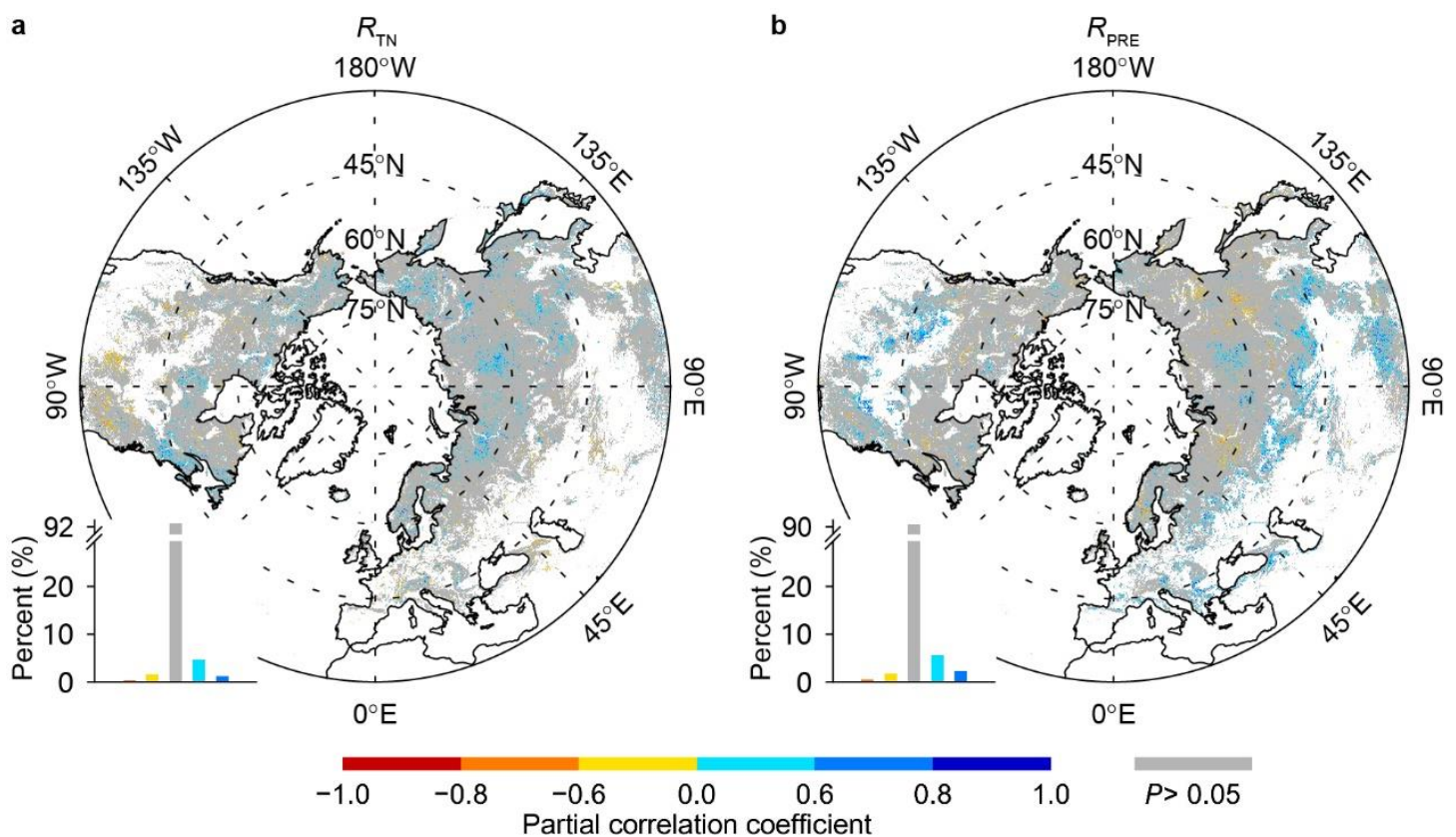

68

Figure S7. Spatial pattern of the partial correlation coefficient between the timing of onset of leaf coloration $\left(D_{\mathrm{LCO}}\right)$ and pre- $D_{\mathrm{LCO}}\left(1\right.$ month preceding the multiyear mean $\left.D_{\mathrm{LCO}}\right)$ climatic factors over the period 2000-2018. a, Spatial pattern of the partial correlation coefficient $\left(R_{\mathrm{TN}}\right)$ between $D_{\mathrm{LCO}}$ and pre$D_{\text {LCO }}$ mean daily minimum temperature $\left(T_{\min }\right)$ while controlling for the corresponding total precipitation. b, Spatial pattern of the partial correlation coefficient $\left(R_{\mathrm{PRE}}\right)$ between $D_{\mathrm{LCO}}$ and pre- $D_{\mathrm{LCO}}$ total precipitation while controlling for the corresponding $T_{\min }$. The bar chart in each panel shows the percentage of area for each interval of the partial correlation coefficient, with the coefficient value indicated by the color scale at the bottom. Non-significant correlations $(P>0.05)$ are in gray. 


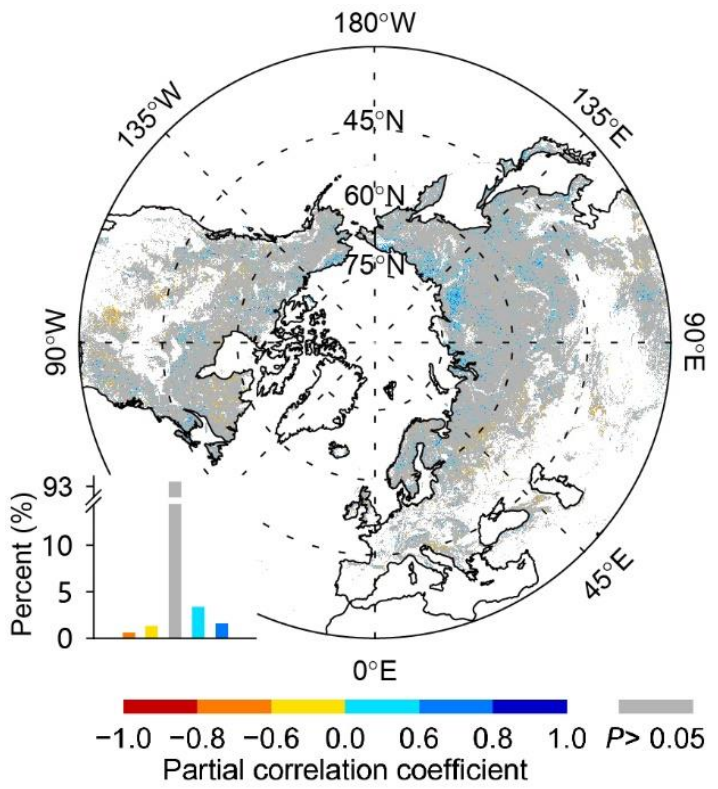

79 Figure S8. Spatial pattern of the partial correlation coefficient between the timing of onset of leaf 80 coloration $\left(D_{\mathrm{LCO}}\right)$ and pre- $D_{\mathrm{LCO}}\left(15\right.$ days preceding the multiyear mean $\left.D_{\mathrm{LCO}}\right)$ mean daily minimum 81 temperature while controlling for the corresponding total precipitation over the period 2000-2016. The 82 bar chart shows the percentage of area for each interval of partial correlation coefficient, with the 83 coefficient value indicated by the color scale at the bottom. Non-significant correlations $(P>0.05)$ are in 84 gray. Daily minimum temperature was extracted from the CRU-NCEP 7.2 6-hourly dataset and 85 determined as the minimum value of the four 6-hourly minimum temperature values for each day. 


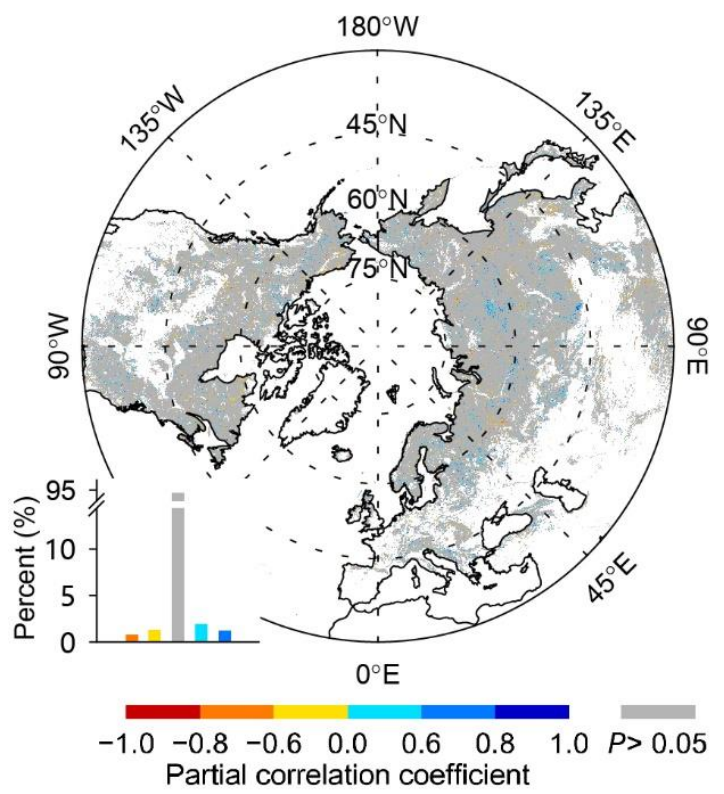

88 Figure S9. Spatial pattern of the partial correlation coefficient between the timing of the onset of leaf 89 coloration $\left(D_{\mathrm{LCO}}\right)$ and the lowest daily minimum temperature $\left(T_{\min }\right)$ during the 15 days before the 90 multiyear mean $D_{\mathrm{LCO}}$, with the concurrent mean $T_{\min }$ (mean of the remaining $14 T_{\min }$ values after 91 removal of the lowest $T_{\min }$ during the period) and total precipitation as control variables over the period 92 2000-2016. The bar chart shows the percentage of area for each interval of the partial correlation 93 coefficient $(P<0.05)$, with the coefficient indicated by the color scale at the bottom. Non-significant 94 correlations $(P>0.05)$ are in gray. Daily minimum temperature was extracted from the CRUNCEP 7.2 95 6-hourly dataset and determined as the minimum value of the four 6-hourly minimum temperature 96 values for each day. 

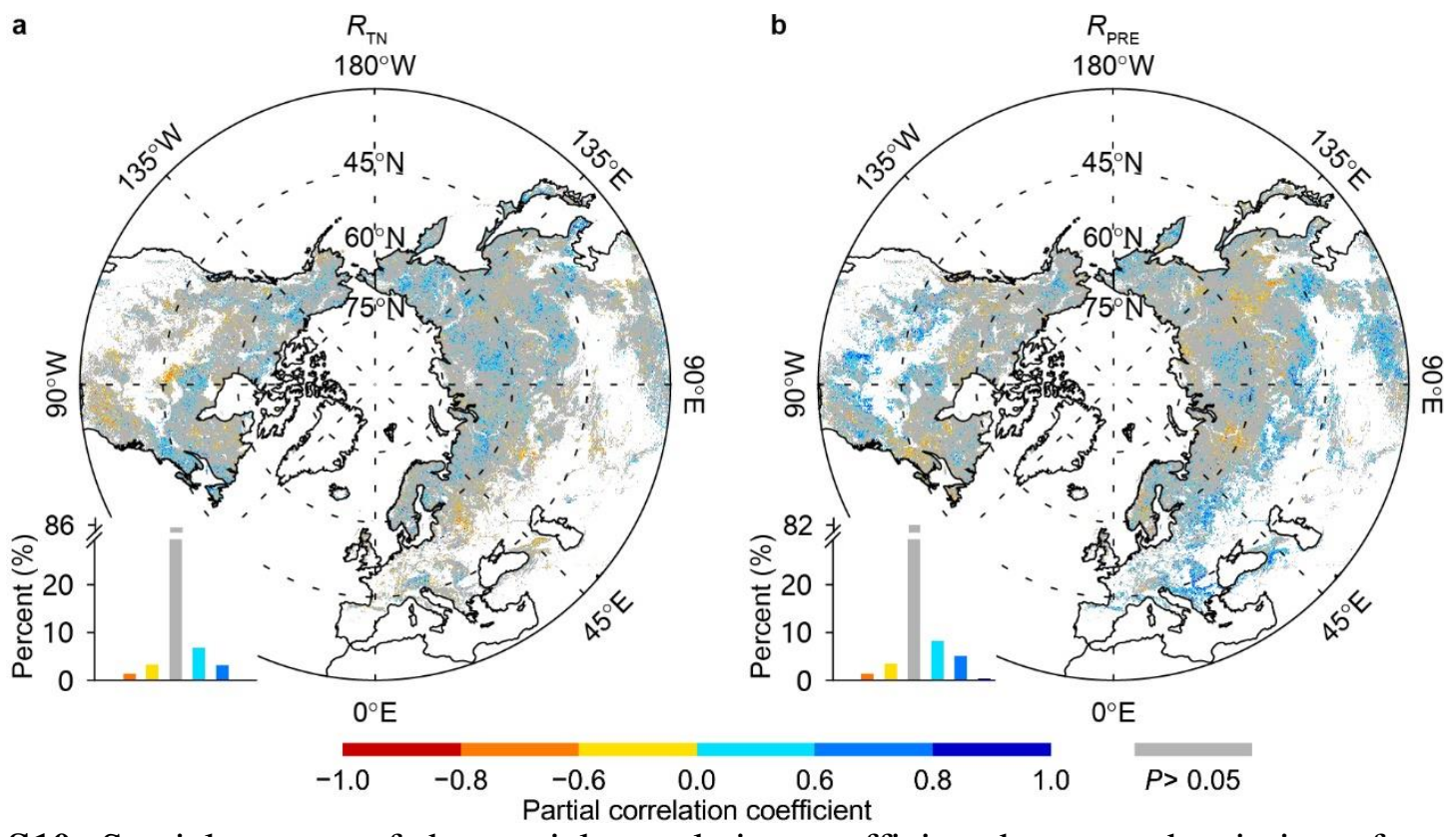

99 Figure S10. Spatial pattern of the partial correlation coefficient between the timing of onset of leaf 100 coloration $\left(D_{\mathrm{LCO}}\right)$ and pre- $D_{\mathrm{LCO}}$ climatic factors, with green-up onset date as an extra control variable 101 over the period 2000-2018. a, Spatial pattern of the partial correlation coefficient $\left(R_{\mathrm{TN}}\right)$ between $D_{\mathrm{LCO}}$ 102 and pre- $D_{\text {LCO }}$ mean daily minimum temperature $\left(T_{\min }\right)$ while controlling for the corresponding total 103 precipitation and green-up onset date. b, Spatial pattern of the partial correlation coefficient $\left(R_{\mathrm{PRE}}\right)$ 104 between $D_{\mathrm{LCO}}$ and pre- $D_{\mathrm{LCO}}$ total precipitation while controlling for the corresponding $T_{\min }$ and green-up 105 onset date. The bar chart in each panel shows the percentage of area for each interval of the partial 106 correlation coefficient, with the coefficient value indicated by the color scale at the bottom. Non107 significant correlations $(P>0.05)$ are in gray. 

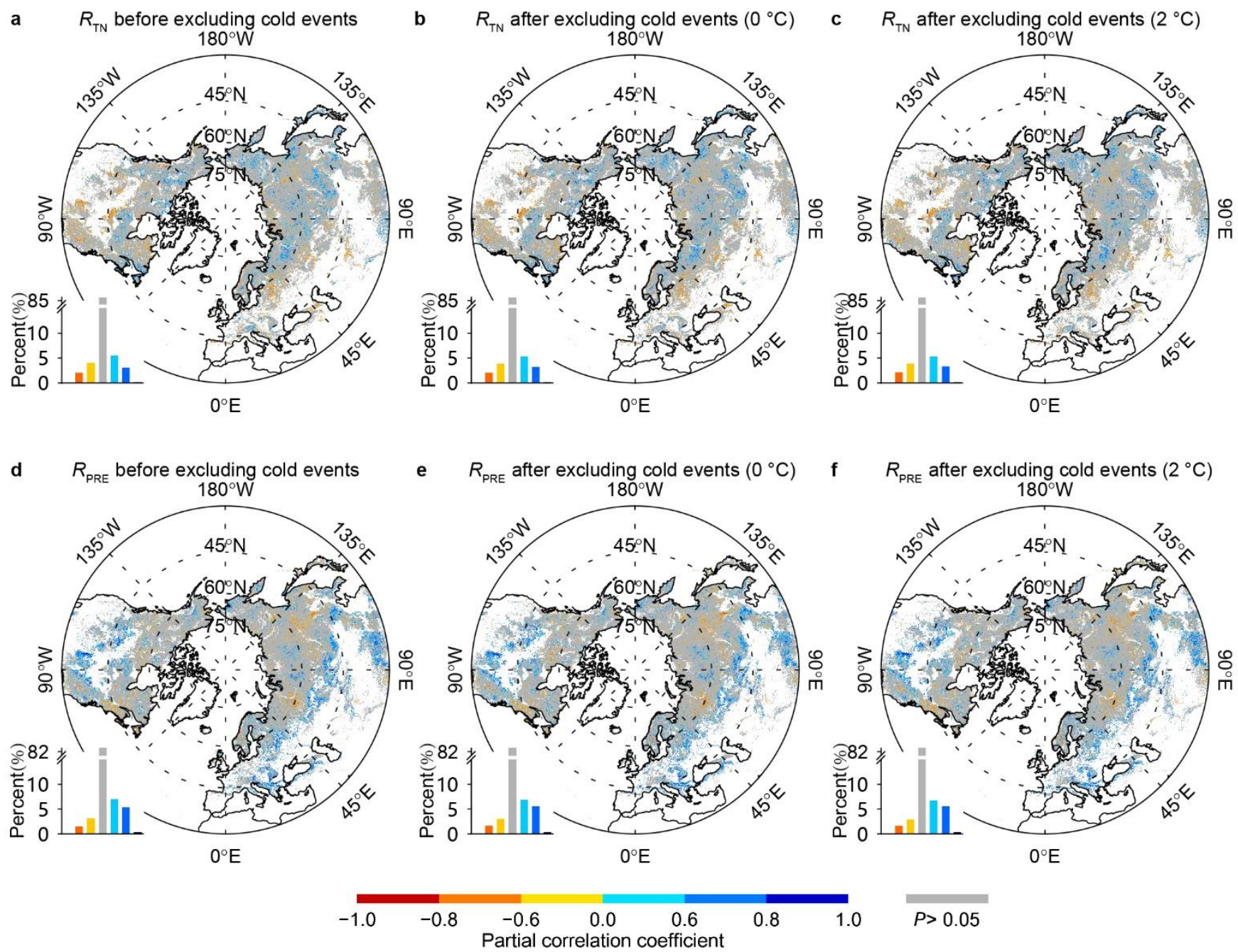

110 Figure S11. Spatial pattern of the partial correlation coefficient between the timing of onset of leaf

111 coloration $\left(D_{\mathrm{LCO}}\right)$ and pre- $D_{\mathrm{LCO}}$ climatic factors over the period 2000-2016 before and after the

112 exclusion of years with cold events before $D_{\mathrm{LCO}}$. a-c, Spatial pattern of the partial correlation coefficient

$113\left(R_{\mathrm{TN}}\right)$ between $D_{\mathrm{LCO}}$ and pre- $D_{\mathrm{LCO}}$ mean daily minimum temperature $\left(T_{\min }\right)$ before (a) and after (b and $\left.\mathrm{c}\right)$

114 the exclusion of years with cold events. $d-f$, The same as $(a-c)$, but for the partial correlation between

$115 D_{\mathrm{LCO}}$ and pre- $D_{\mathrm{LCO}}$ total precipitation $\left(R_{\mathrm{PRE}}\right)$. The bar chart in each panel shows the percentage of area

116 for each interval of the partial correlation coefficient, with the coefficient value indicated by the color

117 scale at the bottom. Non-significant correlations $(P>0.05)$ are in gray, and the percentage for each

118 interval is provided in Table S7. Cold events were determined mainly by using a threshold-based

119 method with a daily minimum temperature of $0{ }^{\circ} \mathrm{C}\left(\mathrm{b}\right.$ and e) or $2{ }^{\circ} \mathrm{C}(\mathrm{c}$ and $\mathrm{f})$. 


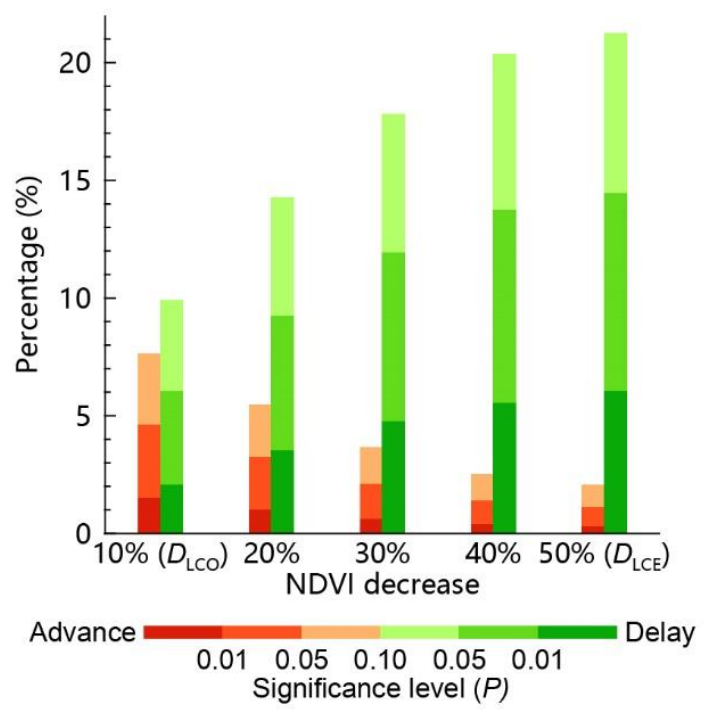

122 Figure S12. Percentage of area with significant temporal trends in the timing of different stages of leaf 123 coloration, as retrieved from satellite images. Significance levels of the temporal trends were determined 124 by using $t$-tests for ordinary least squares regression over the period 2000-2018 at middle and high 125 northern latitudes $\left(30^{\circ} \mathrm{N}-75^{\circ} \mathrm{N}\right)$. The timings of the different stages of leaf coloration were defined as 126 the dates when NDVI decreased by $10 \%$ (i.e., $D_{\mathrm{LCO}}$ ), $20 \%, 30 \%, 40 \%$, or $50 \%$ (i.e., $D_{\mathrm{LCE}}$ ) of its annual 127 amplitude in autumn, on the basis of a generalized sigmoid function fitted from the annual NDVI profile. 

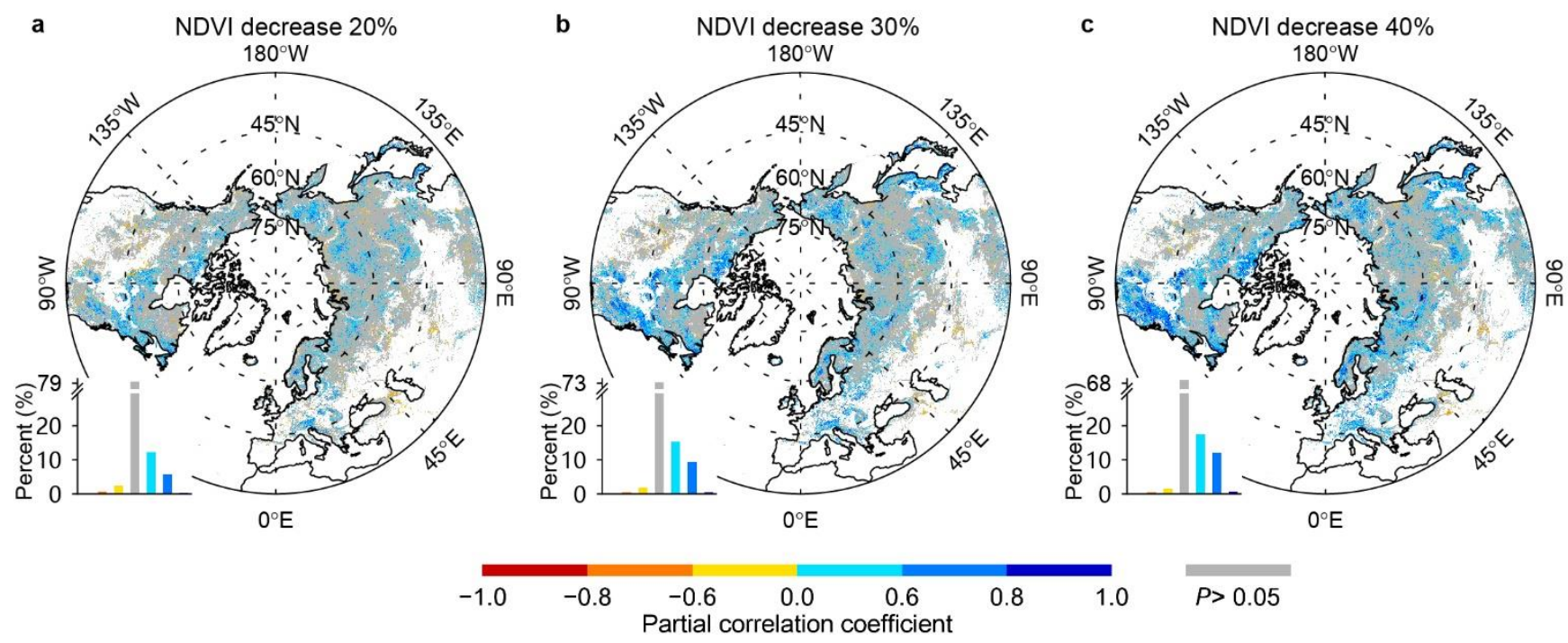

Figure S13. Spatial pattern of the partial correlation coefficient between the timing of different stages of 132 leaf coloration and the mean daily minimum temperature for an optimized period preceding each stage 133 for 2000-2018. The timings of different stages of leaf coloration are determined as the first dates when 134 NDVI decreased by $20 \%$ (a), $30 \%$ (b), or $40 \%$ (c) of its annual amplitude in autumn. The bar chart in 135 each panel shows the percentage of area for each interval of the partial correlation coefficient, with the 136 coefficient value indicated by the color scale at the bottom. Non-significant correlations $(P>0.05)$ are in 137 gray. 


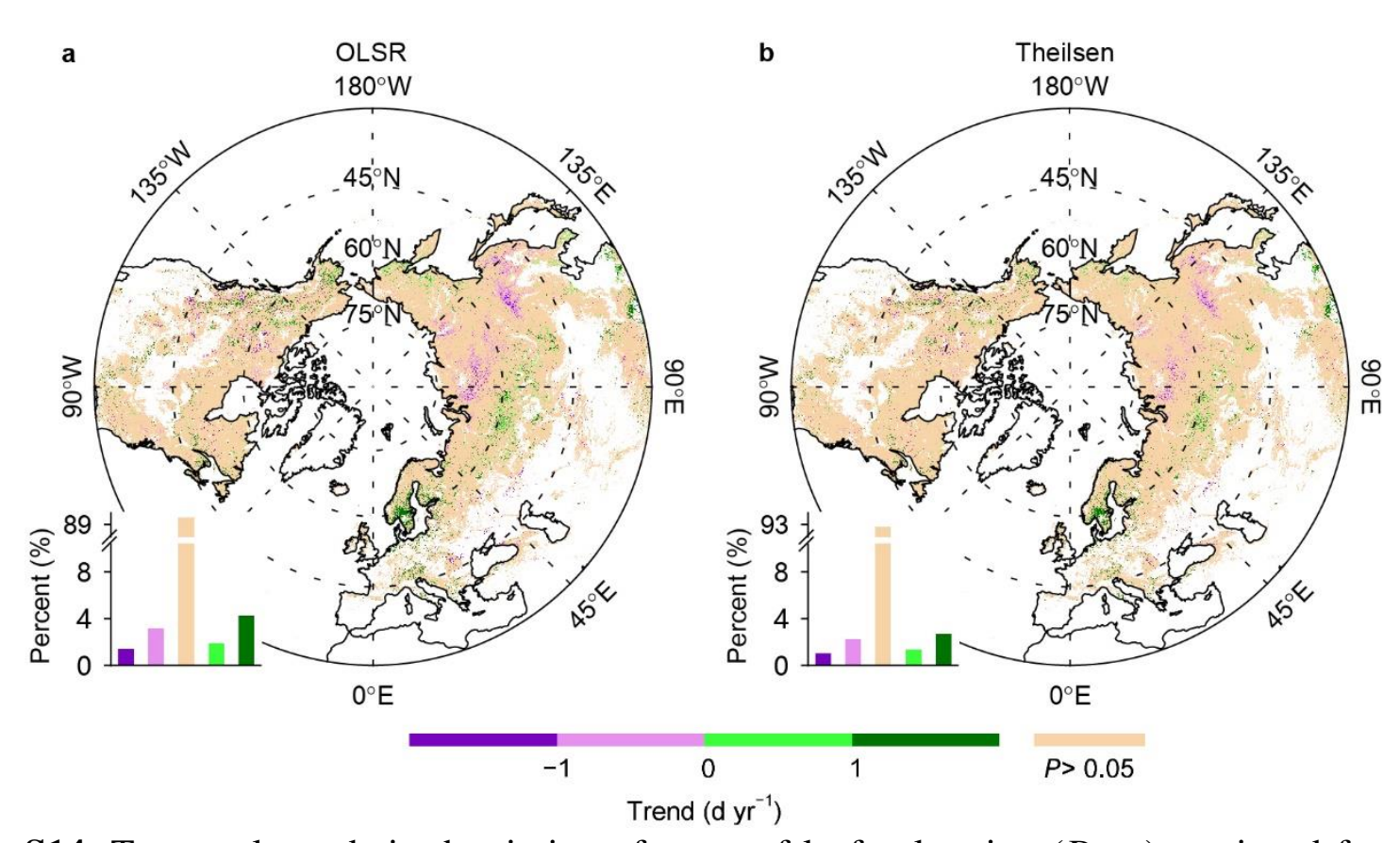

141

Figure S14. Temporal trends in the timing of onset of leaf coloration $\left(D_{\mathrm{LCO}}\right)$, retrieved from satellite images for 2000-2018. The bar chart in each panel shows the percentage of area within each interval of the significant $(P<0.05)$ temporal trends and the percentage of area with nonsignificant trends, indicated by the color scale at the bottom. Positive and negative trend values refer to significantly delayed and advanced $D_{\mathrm{LCO}}$, respectively. For the pixels identified as deciduous broadleaved forests, $D_{\text {LCO }}$ was defined as the date when NDVI decreased by $10 \%$ of its annual amplitude from 1 August on the basis of a generalized sigmoid function fitted from the annual NDVI profile; the maximum value used to determine the annual amplitude was defined as the mean value of the upper quartile of the fitted

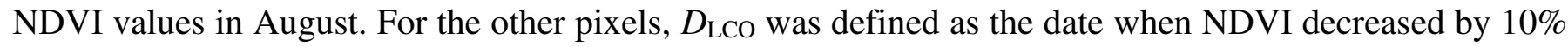
of its annual amplitude; the maximum value of the fitted curve was used to determine the annual amplitude. In (a), significant temporal trends were determined by using $t$-tests at $P<0.05$ and OLSR between $D_{\mathrm{LCO}}$ and the respective years. In (b), significant temporal trends were determined by using Mann-Kendall tests at $P<0.05$ and a Theil-Sen estimator between $D_{\mathrm{LCO}}$ and the respective years. Pixels dominated by croplands or with low vegetation coverage, weak seasonality, or peak NDVI in OctoberApril were discarded. 

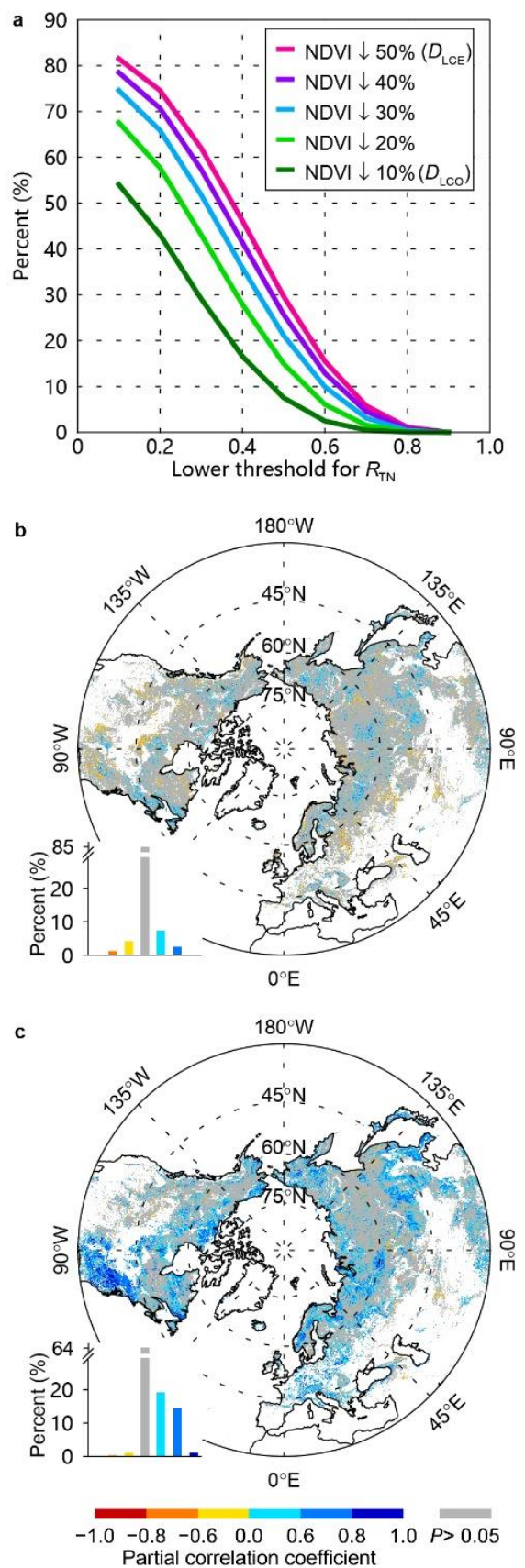

Figure S15. Relationships between the timing of different stages of leaf coloration, as retrieved from satellite images, and the mean daily minimum temperature $\left(T_{\min }\right)$ for an optimized period preceding the respective stage over the period 2000-2018. a, Percentage of area for which the partial correlation coefficient $\left(R_{\mathrm{TN}}\right)$ between the timing of a certain stage of leaf coloration (defined by NDVI decrease) and $T_{\min }$ for an optimized period preceding the stage was higher than a certain threshold indicated by the horizontal axis. For example, $R_{\mathrm{TN}}$ for the onset of leaf coloration ( $D_{\mathrm{LCO}}, 10 \%$ decrease in NDVI) is higher than 0.2 in about $40 \%$ of the area. b, Spatial pattern of the partial correlation coefficient between 
$166 D_{\mathrm{LCO}}$ and pre- $D_{\mathrm{LCO}} T_{\min }$. c, Spatial pattern of the partial correlation coefficient between timing of the end 167 of leaf coloration ( $D_{\mathrm{LCE}}, 50 \%$ decrease in NDVI) and pre- $D_{\mathrm{LCE}} T_{\min }$. For pixels identified as deciduous 168 broadleaved forests, $D_{\text {LCO }}$ was defined as the date when NDVI decreased by $10 \%$ of its annual 169 amplitude from 1 August on the basis of a generalized sigmoid function fitted from the annual NDVI 170 profile. The maximum value used to determine the annual amplitude was defined as the mean value of 171 the upper quartile of the fitted NDVI values in August. For the other pixels, $D_{\mathrm{LCO}}$ was defined as the 172 date when NDVI decreased by $10 \%$ of its annual amplitude; the maximum value of the fitted curve was 173 used to determine the annual amplitude. The bar charts in (b) and (c) show the percentage of area for 174 each interval of the partial correlation coefficient $(P<0.05)$, with the coefficient indicated by the color 175 scale at the bottom. Nonsignificant correlations $(P>0.05)$ are in gray. Pixels dominated by croplands or 176 with low vegetation coverage, weak seasonality, or peak NDVI in October-April were discarded. 

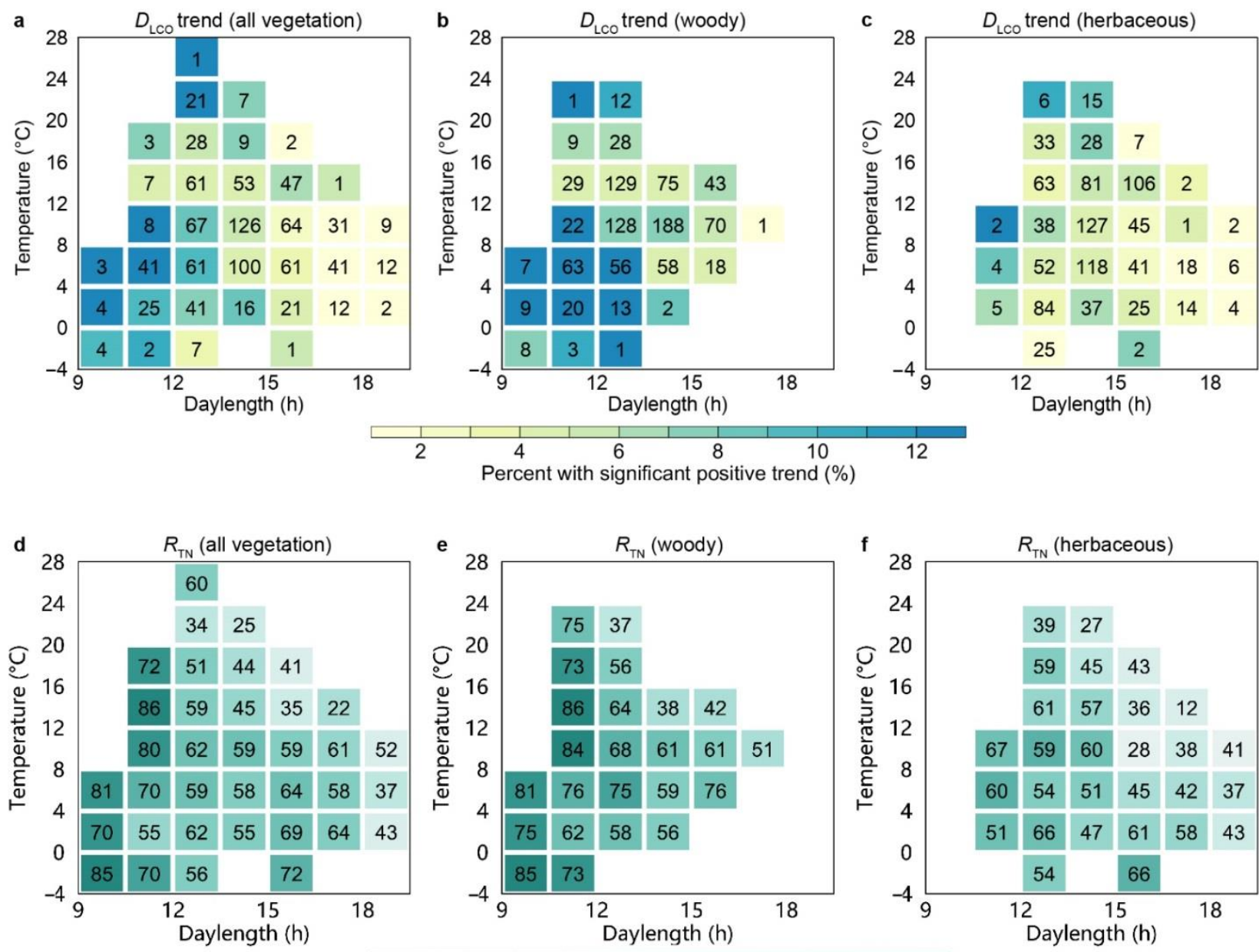

178 $\begin{array}{cccc}0.24 & 0.28 & 0.32 & 0.36 \\ \text { Average correlation coefficient }\end{array}$

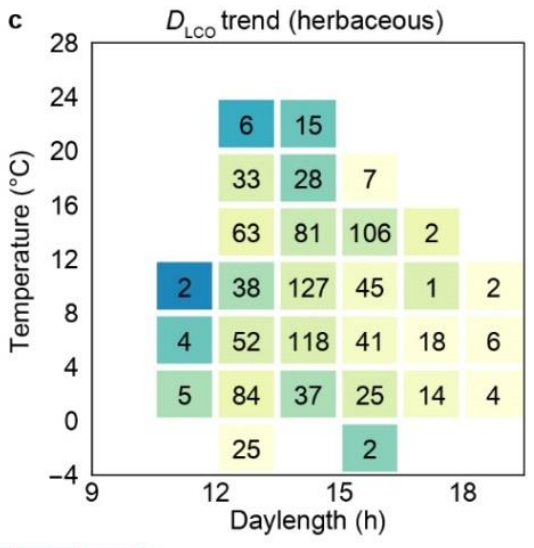

Figure S16. Dependence of temporal trends in the timing of onset of leaf coloration $\left(D_{\mathrm{LCO}}, \mathrm{a}-\mathrm{c}\right)$ and of the partial correlation coefficient $\left(R_{\mathrm{TN}}, \mathrm{d}-\mathrm{f}\right)$ between $D_{\mathrm{LCO}}$ and pre- $D_{\mathrm{LCO}}$ mean daily minimum temperature $\left(T_{\min }\right)$ on daylength and temperature at $D_{\text {LCO }}$ over the period 2000-2018. Daylength (indicated by the horizontal axis) was calculated for each pixel (location) at multiyear mean $D_{\text {LCo over }}$

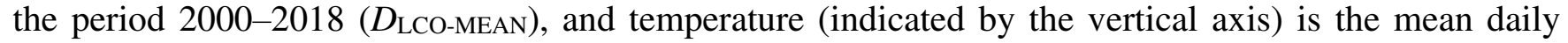

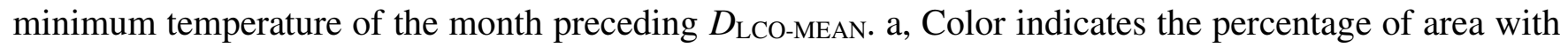
significant $(P<0.05) D_{\text {LCO }}$ delays in each cell (i.e., a specific temperature $\times$ daylength combination), as indicated by the color scale at the bottom. The number in each cell indicates the ratio (unit: \%o) of the area in each cell to the total area with $D_{\text {LCO }}$ retrieval (i.e., Northern Hemisphere from $30^{\circ} \mathrm{N}-75^{\circ} \mathrm{N}$ ). The temporal trends and their significances were determined by ordinary least squares regression and $t$-tests. b and c, The same as (a) but for woody and herbaceous vegetation, respectively. d, Color indicates the average of the positive $R_{\mathrm{TN}}$. The number indicates the percentage of area with a positive correlation in each cell, as indicated by the color scale at the bottom. e and f, The same as (d) but for woody and 
192 herbaceous vegetation, respectively. For the pixels identified as deciduous broadleaved forests, $D_{\text {LCO }}$ 193 was defined as the date when NDVI decreased by $10 \%$ of its annual amplitude from 1 August on the 194 basis of a generalized sigmoid function fitted from the annual NDVI profile. The maximum value used 195 to determine the annual amplitude was defined as the mean value of the upper quartile of the fitted 196 NDVI values in August. For the other pixels, $D_{\text {LCO }}$ was defined as the date when NDVI decreased by $10 \%$ 197 of its annual amplitude; the maximum value of the fitted curve was used to determine the annual 198 amplitude. Each cell represents $4{ }^{\circ} \mathrm{C}$ of temperature and $1.5 \mathrm{~h}$ of daylength. Only cells where the ratio of 199 the area of the cell to the total area is $>1 \%$ are represented. Woody and herbaceous vegetation are 200 merged from Classes 1-6 and Class 10, respectively, in the MODIS land-cover product (MCD12C1, 201 Version 6) for 2009. 


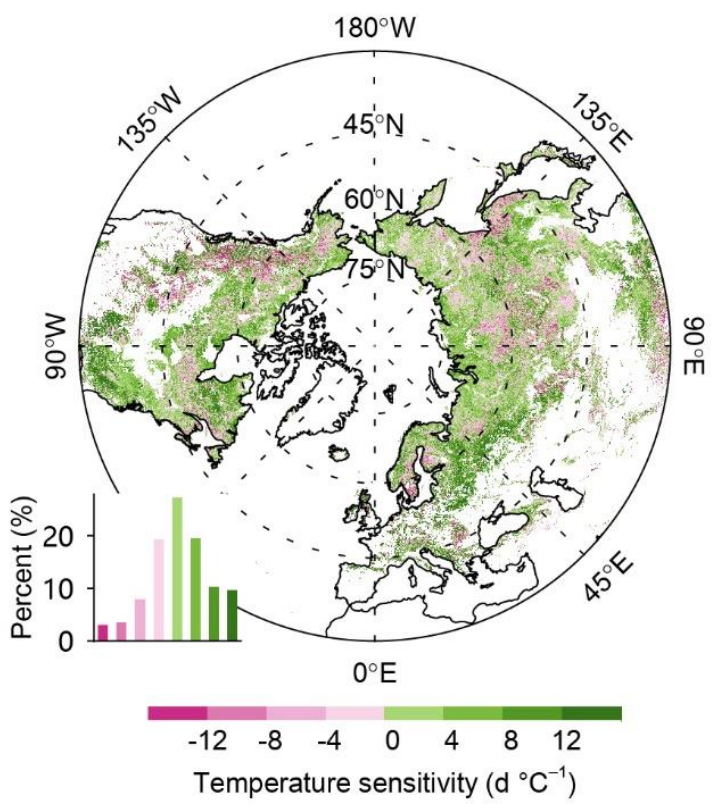

Figure S17. Difference in temperature sensitivity between the end and the onset of leaf coloration $\left(D_{\mathrm{LCE}}\right.$ and $D_{\text {LCO }}$ ) over the period 2000-2018. The temperature sensitivity of $D_{\text {LCO }}$ was defined as the coefficient for pre- $D_{\mathrm{LCO}}$ mean daily minimum temperature $\left(T_{\min }\right)$ in a linear regression in which $D_{\mathrm{LCO}}$ was set as the dependent variable and pre- $D_{\mathrm{LCO}} T_{\min }$ and pre- $D_{\mathrm{LCO}}$ total precipitation were independent variables. The temperature sensitivity of $D_{\mathrm{LCE}}$ was calculated in a similar way. $D_{\mathrm{LCO}}$ and $D_{\mathrm{LCE}}$ were determined as the dates when NDVI decreased by $10 \%$ and 50\%, respectively, of its annual amplitude based on a generalized sigmoid function fitted from the annual NDVI profile. For the pixels identified as deciduous broadleaved forests, $D_{\text {LCO }}$ was defined as the date when NDVI decreased by $10 \%$ of its

213 NDVI profile. The maximum value used to determine the annual amplitude was defined as the mean 214 value of the upper quartile of the fitted NDVI values in August. For the other pixels, $D_{\text {LCo }}$ was defined 215 as the date when NDVI decreased by $10 \%$ of its annual amplitude; the maximum value of the fitted curve was used to determine the annual amplitude. The bar chart in the bottom-left corner shows the 217 percentage of area for each interval of the temperature sensitivity indicated by the color scale at the 218 bottom. Negative values (pink) indicate that $D_{\mathrm{LCO}}$ was more sensitive than $D_{\mathrm{LCE}}$ to temperature. 


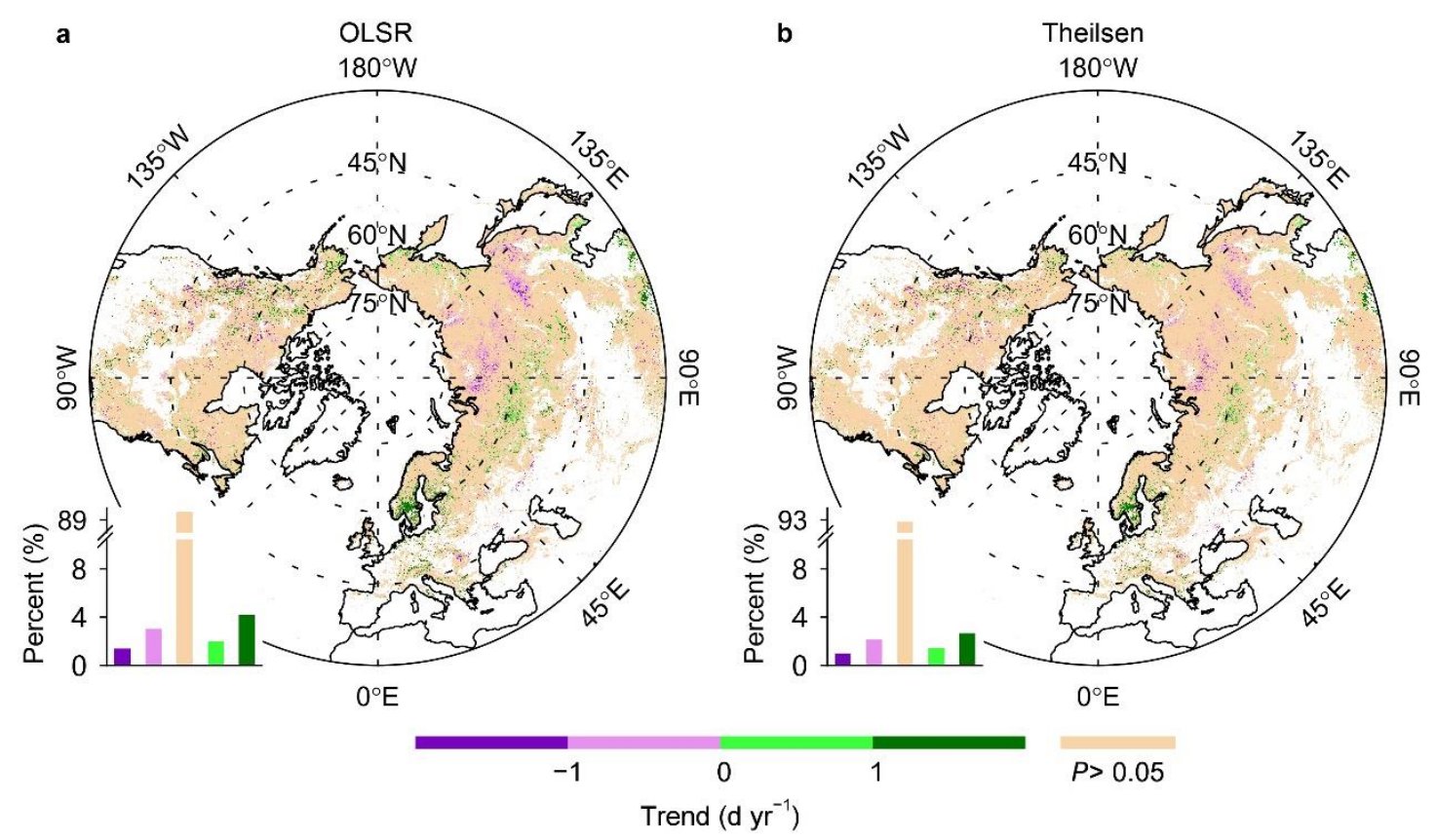

Figure S18. Temporal trends in the timing of onset of leaf coloration $\left(D_{\mathrm{LCO}}\right)$, as retrieved from satellite 222 images for the period 2000-2018. The bar chart in each panel shows the percentage of area within each 223 interval of the significant $(P<0.05)$ temporal trends and the percentage of area with nonsignificant 224 trends, indicated by the color scale at the bottom. Positive and negative trend values refer to significantly 225 delayed and advanced $D_{\mathrm{LCO}}$, respectively. For the pixels identified as deciduous broadleaved forests, $226 D_{\text {LCO }}$ was defined as the date when NDVI decreased by $10 \%$ of its annual amplitude from 16 August, on 227 the basis of a generalized sigmoid function fitted from the annual NDVI profile. The maximum value 228 used to determine the annual amplitude was defined as the mean value of the upper quartile of the fitted 229 NDVI values in the second half of August. For the other pixels, $D_{\text {LCO }}$ was defined as the date when 230 NDVI decreased by $10 \%$ of its annual amplitude; the maximum value of the fitted curve was used to 231 determine the annual amplitude. In (a), significant temporal trends were determined by using $t$-tests at $P$ $232<0.05$ and OLSR between $D_{\text {LCO }}$ and respective years. In (b), significant temporal trends were 233 determined by using Mann-Kendall tests at $P<0.05$ and a Theil-Sen estimator between $D_{\text {LCO }}$ and the 234 respective years. Pixels dominated by croplands or with low vegetation coverage, weak seasonality, or 235 peak NDVI in October-April were discarded. 

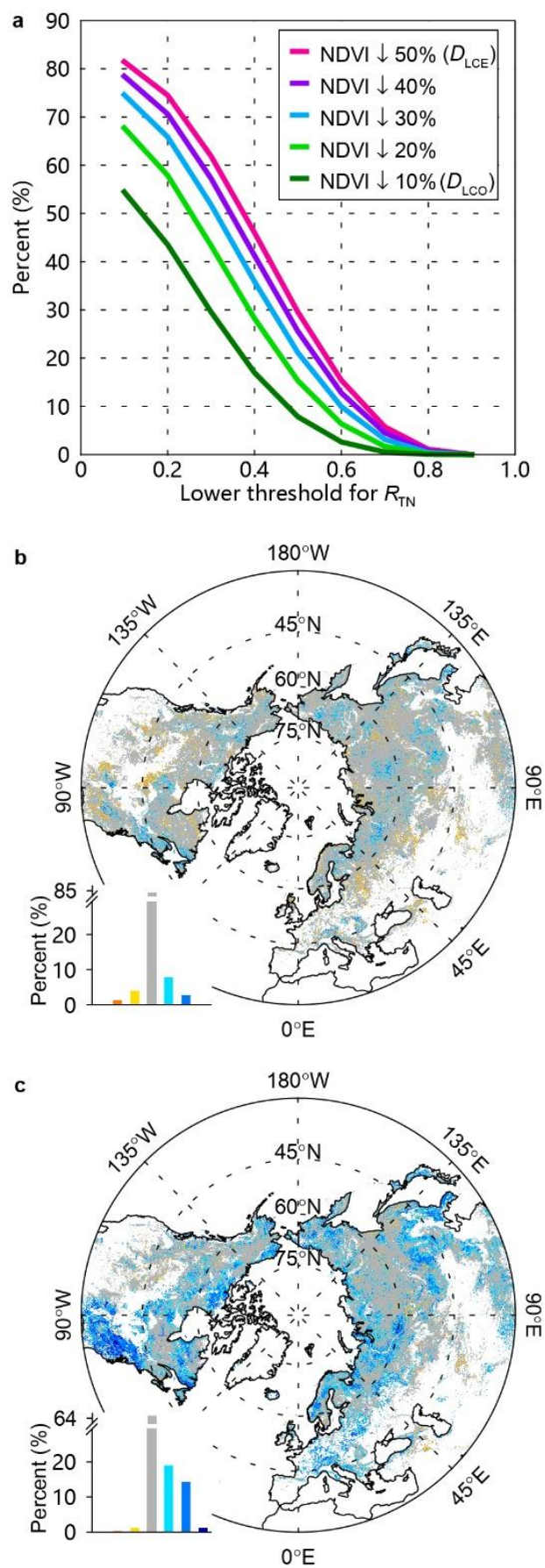

239 satellite images, and the mean daily minimum temperature $\left(T_{\min }\right)$ for an optimized period preceding the 240 respective stage over the period 2000-2018. a, Percentage of area for which the partial correlation 241 coefficient $\left(R_{\mathrm{TN}}\right)$ between the timing of a given stage of leaf coloration (defined by NDVI decrease) and $242 T_{\min }$ for an optimized period preceding the stage was higher than a given threshold, indicated by the 
243 horizontal axis. For example, $R_{\mathrm{TN}}$ for the onset of leaf coloration ( $D_{\mathrm{LCO}}, 10 \%$ decrease in NDVI) is 244 higher than 0.2 in about $40 \%$ of the area. b, Spatial pattern of the partial correlation coefficient between $245 D_{\mathrm{LCO}}$ and pre- $D_{\mathrm{LCO}} T_{\min }$. c, Spatial pattern of the partial correlation coefficient between timing of the end 246 of leaf coloration ( $D_{\mathrm{LCE}}, 50 \%$ decrease in NDVI) and pre- $D_{\mathrm{LCE}} T_{\min }$. For the pixels identified as 247 deciduous broadleaved forests, $D_{\text {LCo }}$ was defined as the date when NDVI decreased by $10 \%$ of its 248 annual amplitude from 16 August, on the basis of a generalized sigmoid function fitted from the annual 249 NDVI profile. The maximum value used to determine the annual amplitude was defined as the mean 250 value of the upper quartile of the fitted NDVI values in the second half of August. For the other pixels, $251 D_{\text {LCO }}$ was defined as the date when NDVI decreased by $10 \%$ of its annual amplitude; the maximum 252 value of the fitted curve was used to determine the annual amplitude. The bar charts in (b) and (c) show 253 the percentage of area for each interval of the partial correlation coefficient $(P<0.05)$, with the 254 coefficient indicated by the color scale at the bottom. Non-significant correlations $(P>0.05)$ are in gray. 255 Pixels dominated by croplands or with low vegetation coverage, weak seasonality, or peak NDVI in 256 October-April were discarded. 

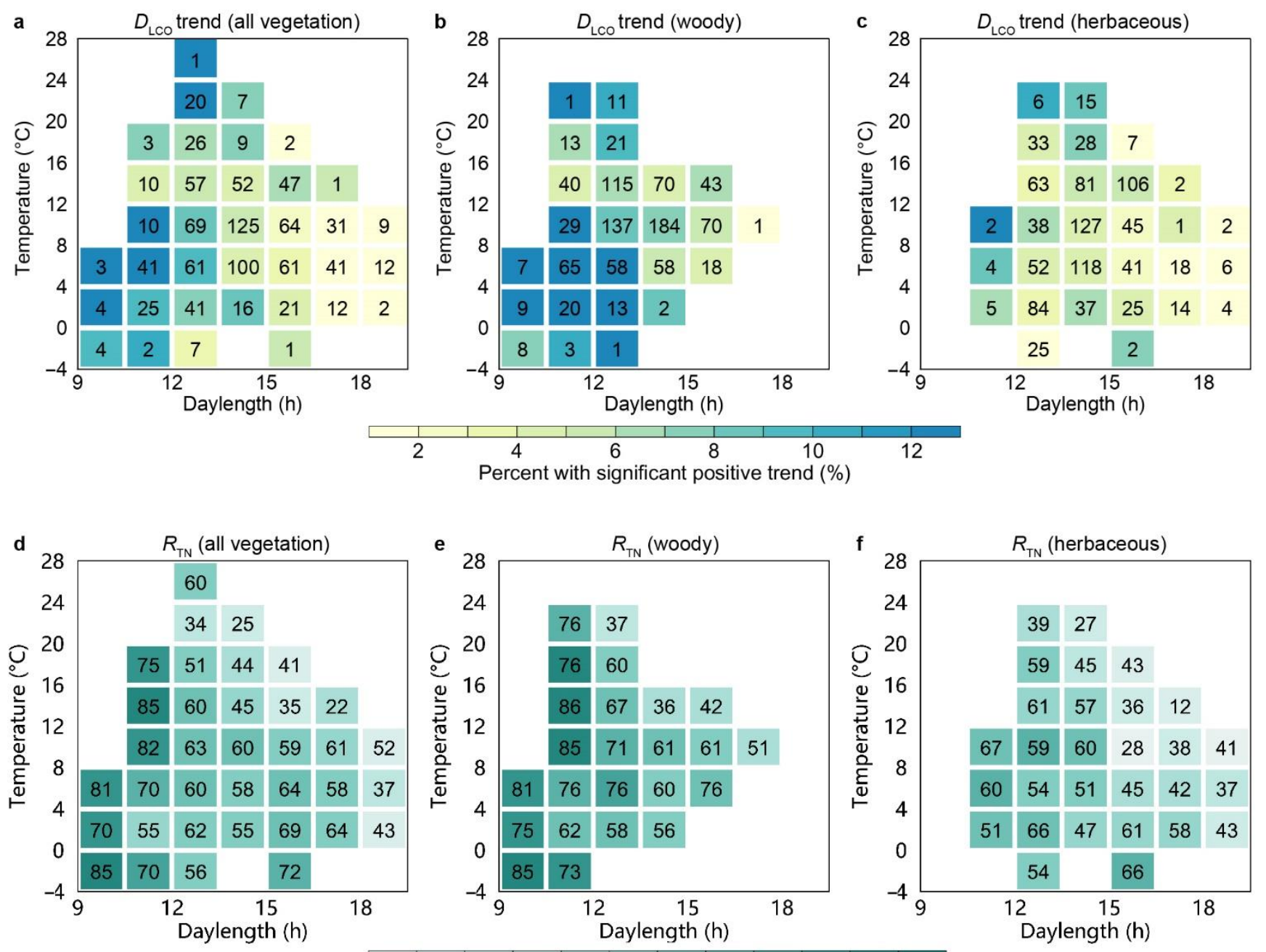

0.20

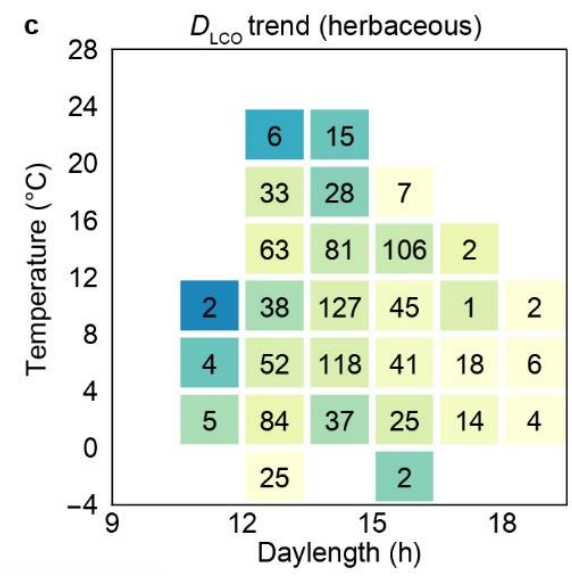


271 percentage of area with a positive correlation in each cell. e and f, The same as (d) but for woody and 272 herbaceous vegetation, respectively. For the pixels identified as deciduous broadleaved forests, $D_{\text {LCO }}$ 273 was defined as the date when NDVI decreased by $10 \%$ of its annual amplitude from 16 August, on the 274 basis of a generalized sigmoid function fitted from the annual NDVI profile. The maximum value used 275 to determine the annual amplitude was defined as the mean value of the upper quartile of the fitted 276 NDVI values in the second half of August. For the other pixels, $D_{\text {LCO }}$ was defined as the date when 277 NDVI decreased by $10 \%$ of its annual amplitude; the maximum value of the fitted curve was used to 278 determine the annual amplitude. Each cell represents $4{ }^{\circ} \mathrm{C}$ of temperature and $1.5 \mathrm{~h}$ of daylength. Only 279 cells where the ratio of the area of the cell to the total area is $>1 \%$ are represented. Woody and 280 herbaceous vegetation are merged from Classes 1-6 and Class 10, respectively, in the MODIS land281 cover product (MCD12C1, Version 6) for 2009. 


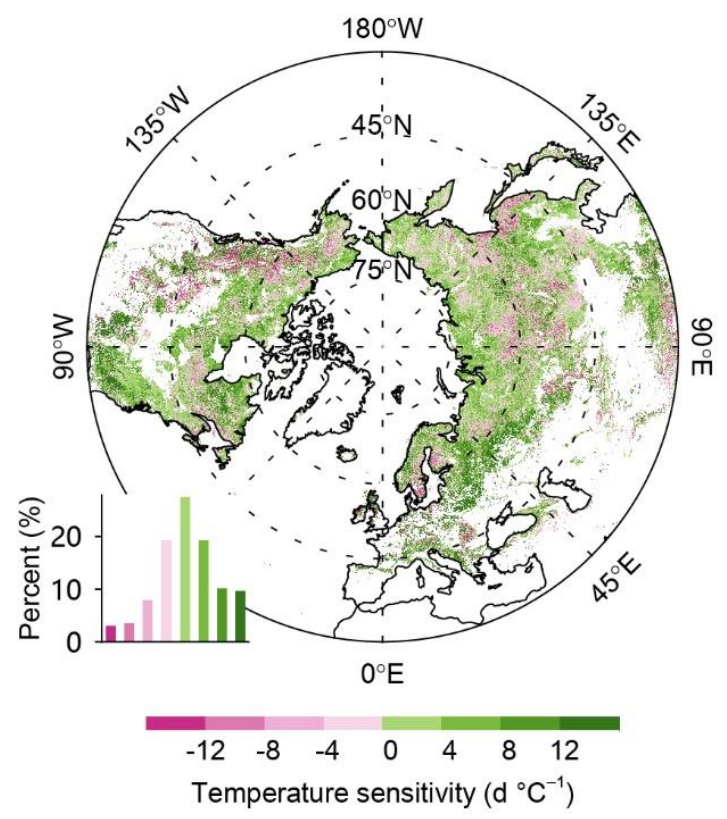

Figure S21. Difference in temperature sensitivity between the end and the onset of leaf coloration $\left(D_{\mathrm{LCE}}\right.$ and $D_{\text {LCO }}$ ) over the period 2000-2018. The temperature sensitivity of $D_{\text {LCO was }}$ defined as the coefficient for pre- $D_{\mathrm{LCO}}$ mean daily minimum temperature $\left(T_{\mathrm{min}}\right)$ in the linear regression in which $D_{\mathrm{LCO}}$ was set as the dependent variable and pre- $D_{\mathrm{LCO}} T_{\min }$ and pre- $D_{\mathrm{LCO}}$ total precipitation were independent variables. 292 deciduous broadleaved forests, $D_{\text {LCO }}$ was defined as the date when NDVI decreased by $10 \%$ of its 293 annual amplitude from 16 August, on the basis of a generalized sigmoid function fitted from the annual 294 NDVI profile, The maximum value used to determine the annual amplitude was defined as the mean 295 value of the upper quartile of the fitted NDVI values in the second half of August. For the other pixels, $296 D_{\text {LCO }}$ was defined as the date when NDVI decreased by $10 \%$ of its annual amplitude; the maximum 297 value of the fitted curve was used to determine the annual amplitude. The bar chart in the bottom-left 298 corner shows the percentage of area for each interval of the temperature sensitivity indicated by the 299 color scale at the bottom. Negative values (pink) indicate that $D_{\text {LCO }}$ was more sensitive than $D_{\text {LCE }}$ to 300 temperature. 


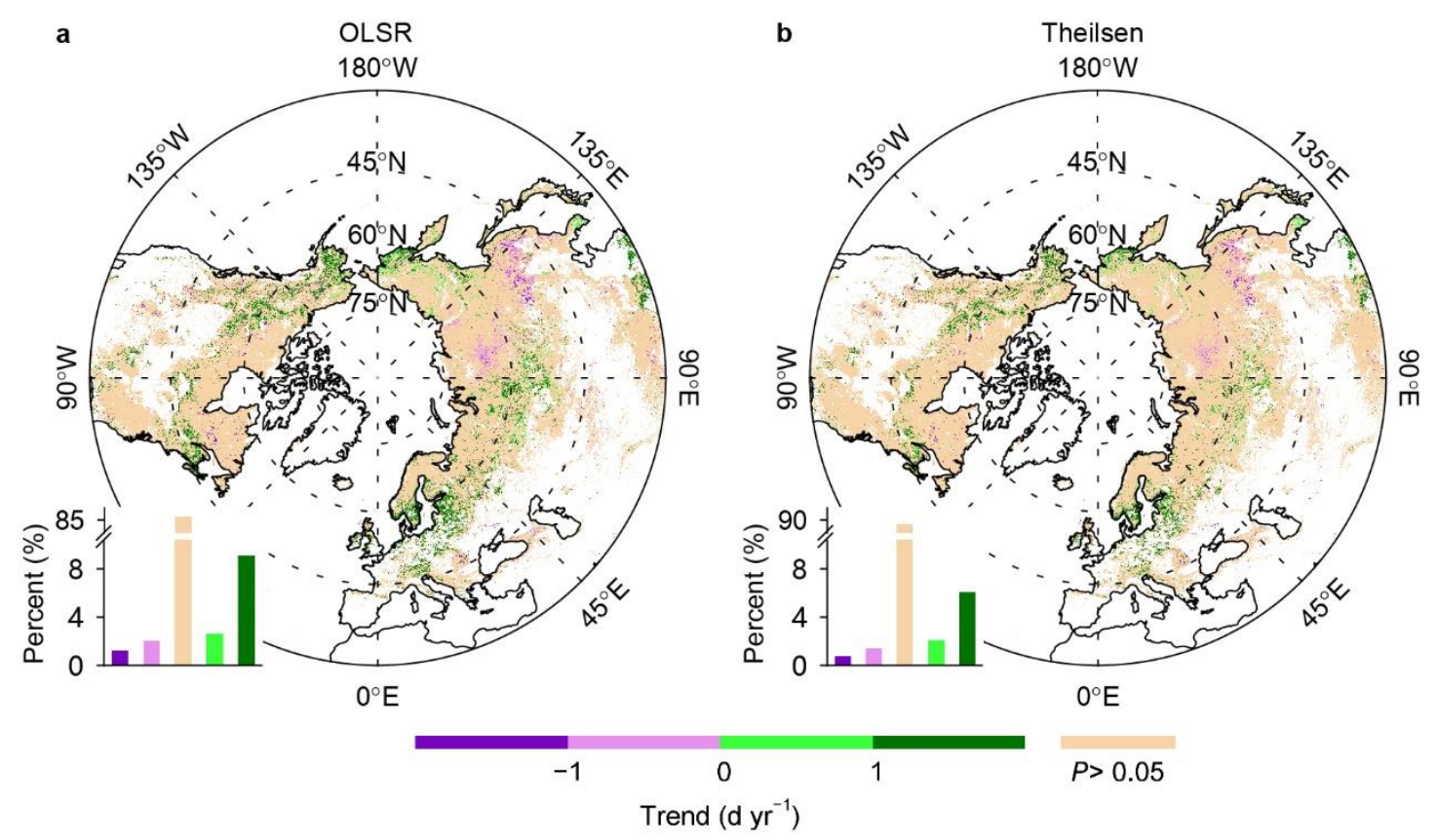

Figure S22. Temporal trends in the timing of onset of leaf coloration $\left(D_{\mathrm{LCO}}\right)$, as retrieved from satellite 304 images for 2000-2018. The bar chart in each panel shows the percentage of area within each interval of 305 the significant $(P<0.05)$ temporal trends and the percentage of area with nonsignificant trends, 306 indicated by the color scale at the bottom. Positive and negative trend values refer to significantly 307 delayed and advanced $D_{\mathrm{LCO}}$, respectively. $D_{\mathrm{LCO}}$ was determined as the date when the rate of change of 308 the curvature (RCC) of the fitted NDVI curve reached its first local minimum value in the descending 309 period. For the pixels identified as deciduous broadleaved forests, the fitting function was a modified 310 double logistic function that considered summer NDVI green-down (Elmore et al., 2012), whereas the 311 fitting function was a double logistic function for the other pixels(Beck et al., 2006). In (a), significant 312 temporal trends were determined by using $t$-tests at $P<0.05$ and OLSR between $D_{\text {LCo }}$ and the respective 313 years. In (b), significant temporal trends were determined by using Mann-Kendall tests at $P<0.05$ and a 314 Theil-Sen estimator between $D_{\mathrm{LCO}}$ and the respective years. Pixels dominated by croplands or with low 315 vegetation coverage, weak seasonality, or peak NDVI in October-April were discarded. 

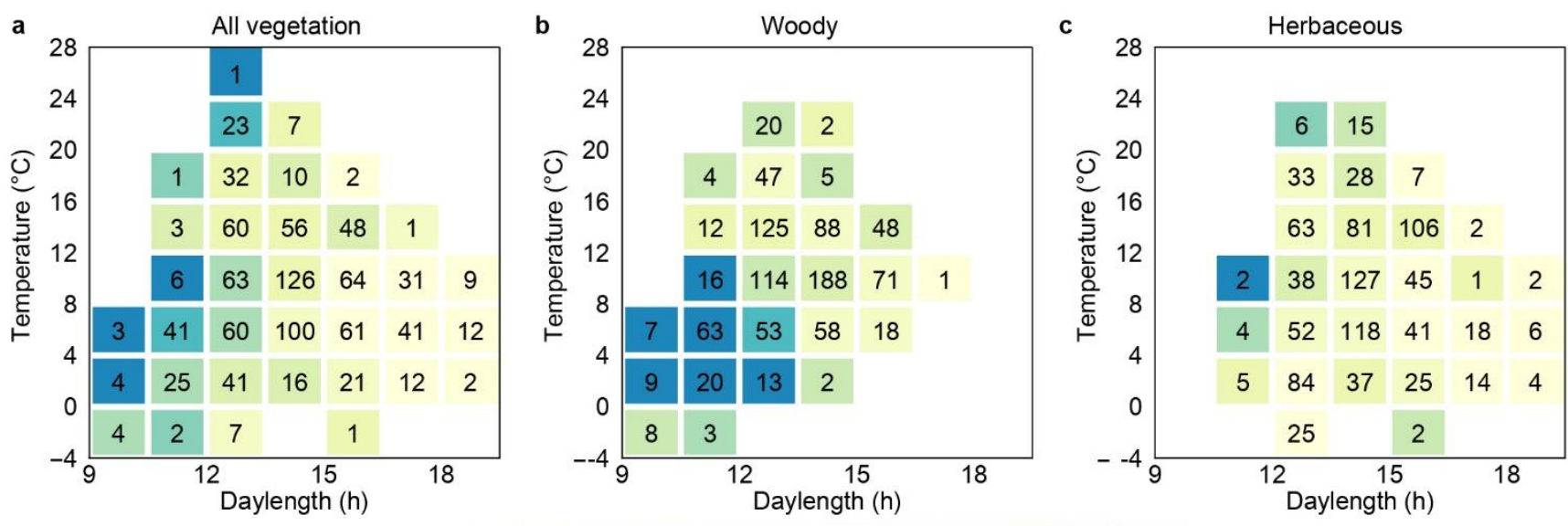

316

Figure S23. Dependence of temporal trends in the timing of onset of leaf coloration $\left(D_{\mathrm{LCO}}\right)$ on daylength and temperature at $D_{\text {LCO }}$ over the period 2000-2018 for all (a), woody (b), and herbaceous (c) vegetation. The daylength (indicated by the horizontal axis) was calculated for each pixel (location) at

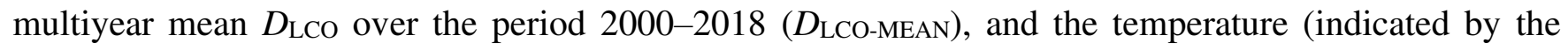
vertical axis) is the mean daily minimum temperature of the month preceding $D_{\text {LCO-MEAn. a, Color }}$ indicates the percentage of area with significant $(P<0.05) D_{\text {LCO }}$ delays in each cell (i.e., a specific temperature $\times$ daylength combination), as indicated by the color scale at the bottom. The number in each cell indicates the ratio (unit: \%) of the area in each cell to the total area with $D_{\text {LCo }}$ retrieval (i.e., Northern Hemisphere from $30^{\circ} \mathrm{N}-75^{\circ} \mathrm{N}$ ). Temporal trends and their significances were determined by using the Theil-Sen estimator and Mann-Kendall tests. b and c, The same as (a), but for woody and herbaceous vegetation, respectively. Each cell represents $4{ }^{\circ} \mathrm{C}$ of temperature and $1.5 \mathrm{~h}$ of daylength. Only cells where the ratio of the area of the cell to the total area is $>1 \%$ are represented. Woody and herbaceous vegetation are merged from Classes 1-6 and Class 10, respectively, in the MODIS landcover product (MCD12C1, Version 6) for 2009. 

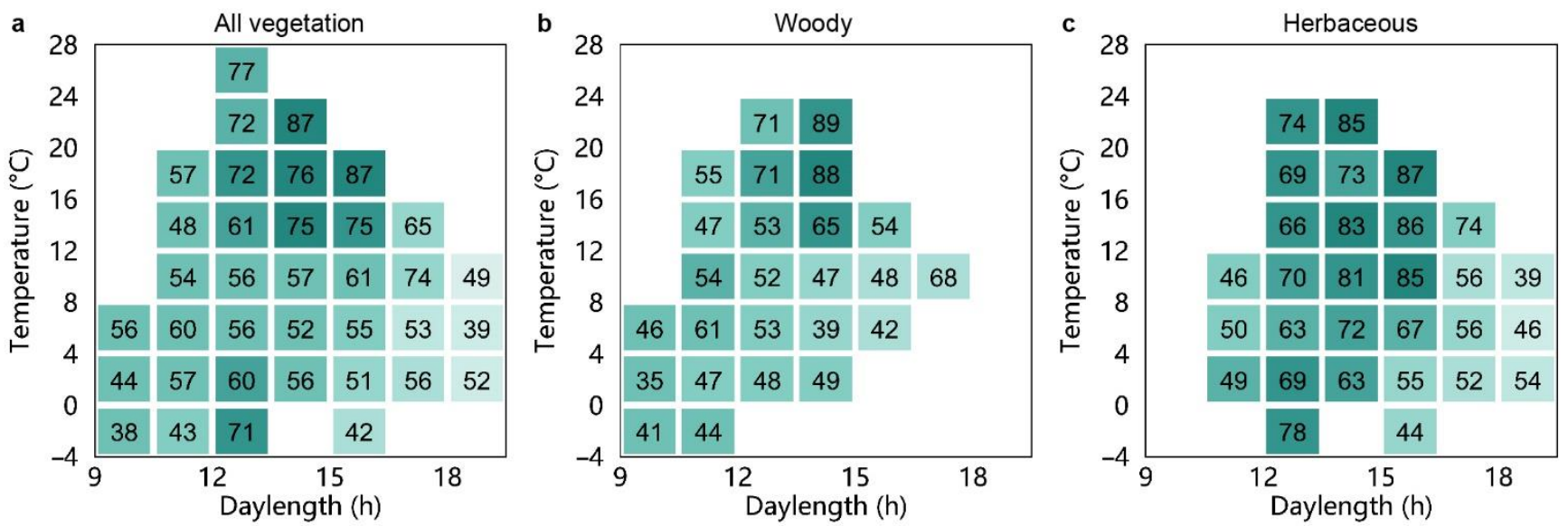

Figure S24. Dependence of the partial correlation coefficient $\left(R_{\mathrm{PRE}}\right)$ between the timing of onset of leaf 334 coloration $\left(D_{\mathrm{LCO}}\right)$ and pre- $D_{\mathrm{LCO}}$ total precipitation on daylength and temperature at $D_{\mathrm{LCO}}$ over the period 335 2000-2018 for all (a), woody (b), and herbaceous (c) vegetation. Daylength (indicated by the horizontal 336 axis) was calculated for each pixel (location) at multiyear mean $D_{\text {LCO }}$ over the period 2000-2018 (DLCO337 MEAN), and temperature (indicated by the vertical axis) is the mean daily minimum temperature of the

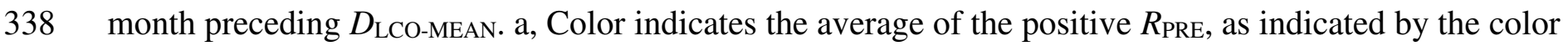
339 scale at the bottom. The number indicates the percentage of area with a positive correlation in each cell 340 (i.e., a specific temperature $\times$ daylength combination); $b$ and $c$, The same as (a), but for woody and 341 herbaceous vegetation, respectively. Each cell represents $4{ }^{\circ} \mathrm{C}$ of temperature and $1.5 \mathrm{~h}$ of daylength. 342 Only cells where the ratio of the area of the cell to the total area is $>1 \%$ are represented. Woody and 343 herbaceous vegetation are merged from Classes 1-6, and Class 10 in the MODIS land-cover product 344 (MCD12C1, Version 6) for 2009. 

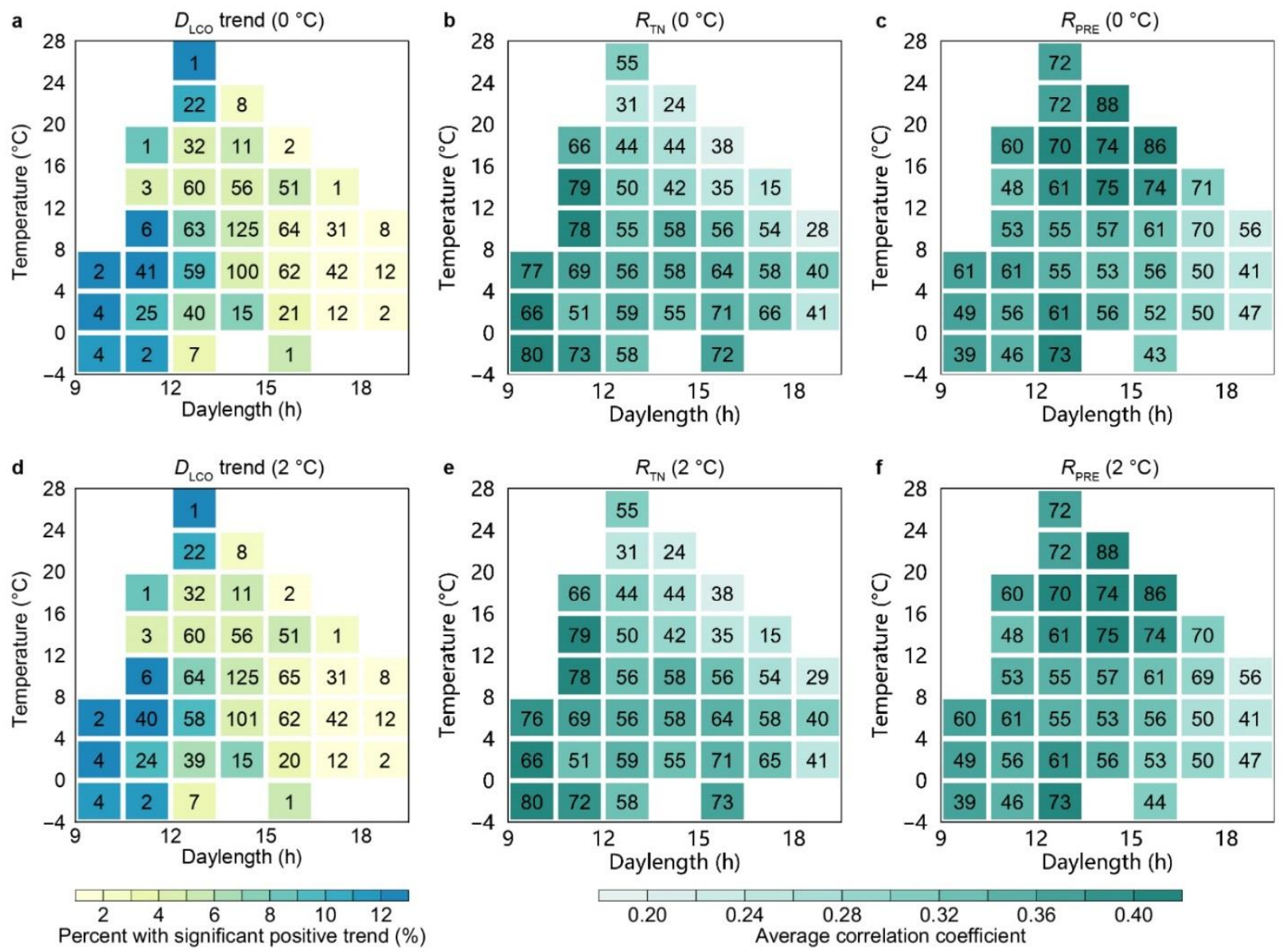

Figure S25. Dependence of temporal trends in the timing of onset of leaf coloration $\left(D_{\mathrm{LCO}}\right.$, a and d), of the partial correlation coefficient $\left(R_{\mathrm{TN}}, \mathrm{b}\right.$ and e) between $D_{\mathrm{LCO}}$ and pre- $D_{\mathrm{LCO}}$ mean daily minimum temperature, and of the partial correlation coefficient ( $R_{\mathrm{PRE}}, \mathrm{c}$ and f) between $D_{\mathrm{LCO}}$ and pre- $D_{\mathrm{LCO}}$ total precipitation on daylength and temperature at $D_{\text {LCO }}$ over the period 2000-2016 after the exclusion of years with cold events before $D_{\mathrm{LCO}}$. Daylength (indicated by the horizontal axis) was calculated for each pixel (location) at multiyear mean $D_{\text {LCO }}$ over the period 2000-2016 ( $D_{\text {LCO-MEAN), and temperature }}$

353 (indicated by the vertical axis) is the mean daily minimum temperature of the month preceding $D_{\text {LCO- }}$ 354 MEAN. Cold events were determined mainly by using a threshold-based method with a daily minimum temperature of $0{ }^{\circ} \mathrm{C}(\mathrm{a}-\mathrm{c})$ or $2{ }^{\circ} \mathrm{C}(\mathrm{d}-\mathrm{f})$. a and $\mathrm{d}$, Color indicates the percentage of area with significant

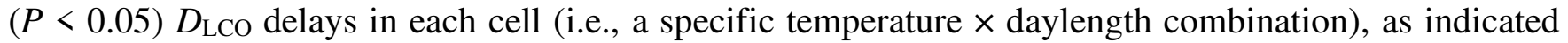
by the color scale at the bottom. The number in each cell indicates the ratio (unit: \%o) of the area in each cell to the total area with $D_{\mathrm{LCO}}$ retrieval (i.e., Northern Hemisphere from $30^{\circ} \mathrm{N}-75^{\circ} \mathrm{N}$ ). b and e, Color indicates the average of the positive $R_{\mathrm{TN}}$, as indicated by the color scale at the bottom. The number indicates the percentage of area with a positive correlation in each cell. $\mathrm{c}$ and $\mathrm{f}$, The same as (b and e),

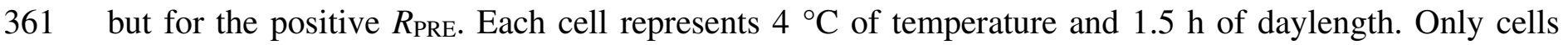
where the ratio of the area of the cell to the total area is $>1 \%$ are represented. 
Supplementary Tables

Table S1. Experiments on photoperiodic control of plant growth.

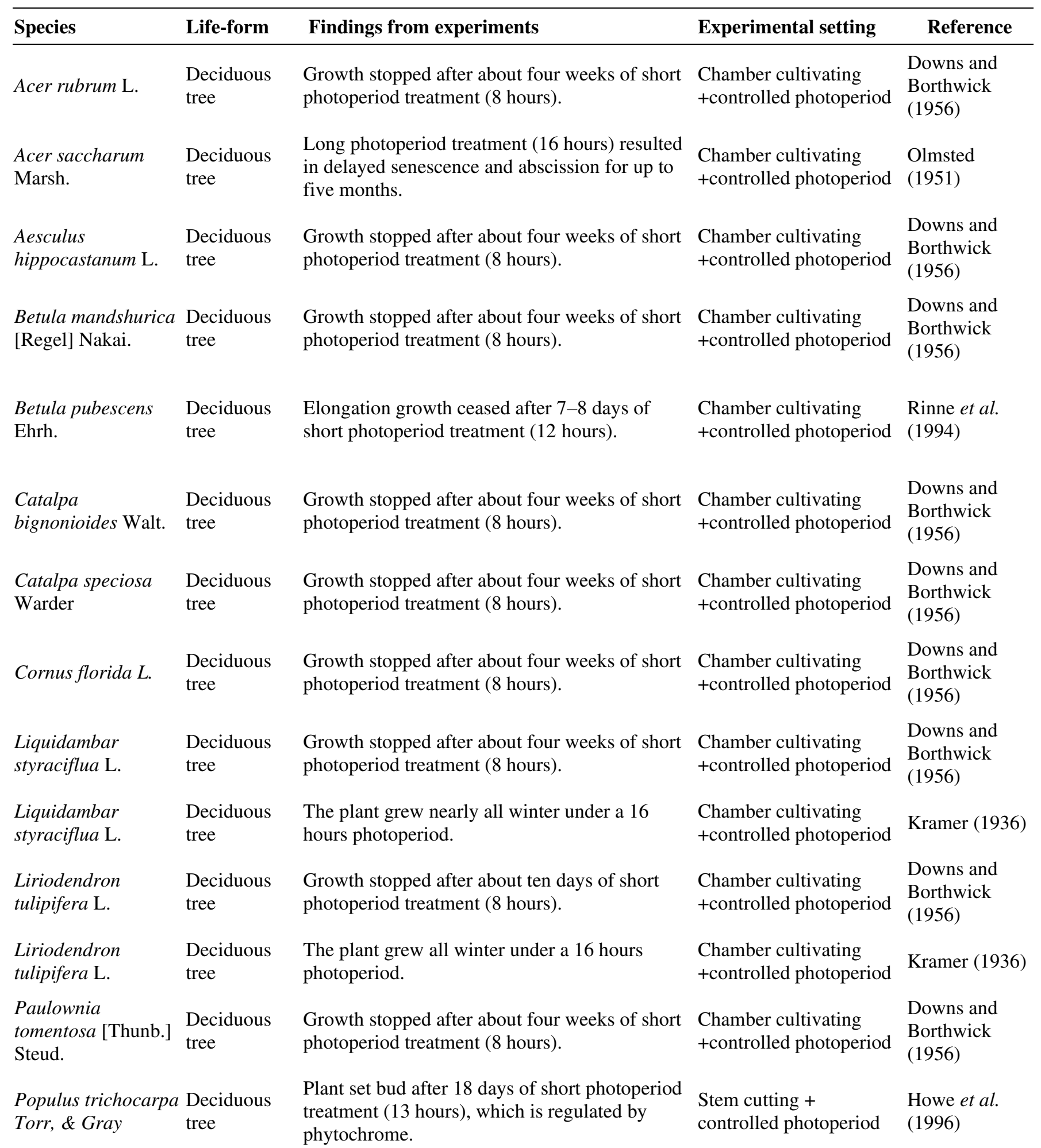




\begin{tabular}{|c|c|c|c|c|}
\hline Species & Life-form & Findings from experiments & Experimental setting & Reference \\
\hline $\begin{array}{l}\text { Populus tremula } x \\
\text { tremuloides }\end{array}$ & $\begin{array}{l}\text { Deciduous } \\
\text { tree }\end{array}$ & $\begin{array}{l}\text { When plants are shifted from long days ( } 16 \\
\text { hours) to short days ( } 8 \text { hours), they respond by } \\
\text { growth cessation and bud set after } 32 \text { days. }\end{array}$ & $\begin{array}{l}\text { Chamber cultivating } \\
+ \text { controlled photoperiod }\end{array}$ & $\begin{array}{l}\text { Böhlenius et } \\
\text { al. (2006) }\end{array}$ \\
\hline Ulmus americana $\mathrm{L}$. & $\begin{array}{l}\text { Deciduous } \\
\text { tree }\end{array}$ & $\begin{array}{l}\text { Growth stopped after about twenty weeks of } \\
\text { short photoperiod treatment ( } 8 \text { hours). }\end{array}$ & $\begin{array}{l}\text { Chamber cultivating } \\
\text { +controlled photoperiod }\end{array}$ & $\begin{array}{l}\text { Downs and } \\
\text { Borthwick } \\
(1956)\end{array}$ \\
\hline $\begin{array}{l}\text { Picea abies (L.) } \\
\text { Karst. }\end{array}$ & $\begin{array}{l}\text { Evergreen } \\
\text { tree }\end{array}$ & $\begin{array}{l}\text { Growth cessation occurred within two weeks } \\
\text { after exposure to short photoperiods }(\leq 15 \\
\text { hours). }\end{array}$ & $\begin{array}{l}\text { Chamber cultivating } \\
\text { +controlled photoperiod }\end{array}$ & Heide (1974) \\
\hline $\begin{array}{l}\text { Picea glauca } \\
\text { (Moench) Voss }\end{array}$ & $\begin{array}{l}\text { Evergreen } \\
\text { tree }\end{array}$ & $\begin{array}{l}\text { Growth cessation occurred after five weeks of } \\
\text { short photoperiod treatment ( } 8 \text { hours) under } \\
\text { warm temperature conditions. }\end{array}$ & $\begin{array}{l}\text { Chamber cultivating } \\
\text { +controlled photoperiod }\end{array}$ & $\begin{array}{l}\text { Hamilton et al. } \\
\text { (2016) }\end{array}$ \\
\hline Pinus sylvestris $L$. & $\begin{array}{l}\text { Evergreen } \\
\text { tree }\end{array}$ & $\begin{array}{l}\text { Northern populations grown under } 50^{\circ} \mathrm{N} \\
\text { photoperiod (shorter) stopped growth earlier } \\
\text { than that under } 60^{\circ} \mathrm{N} \text { photoperiod (longer). }\end{array}$ & $\begin{array}{l}\text { Chamber cultivating } \\
\text { +controlled photoperiod }\end{array}$ & $\begin{array}{l}\text { Oleksyn et al. } \\
\text { (1992) }\end{array}$ \\
\hline Pinus sylvestris L. & $\begin{array}{l}\text { Evergreen } \\
\text { tree }\end{array}$ & $\begin{array}{l}\text { Growth stopped after about four weeks of short } \\
\text { photoperiod treatment ( } 8 \text { hours). }\end{array}$ & $\begin{array}{l}\text { Chamber cultivating } \\
\text { +controlled photoperiod }\end{array}$ & $\begin{array}{l}\text { Downs and } \\
\text { Borthwick } \\
(1956)\end{array}$ \\
\hline $\begin{array}{l}\text { Pinus virginiana } \\
\text { Mill. }\end{array}$ & $\begin{array}{l}\text { Evergreen } \\
\text { tree }\end{array}$ & $\begin{array}{l}\text { Growth stopped after about four weeks of short } \\
\text { photoperiod treatment ( } 8 \text { hours). }\end{array}$ & $\begin{array}{l}\text { Chamber cultivating } \\
\text { +controlled photoperiod }\end{array}$ & $\begin{array}{l}\text { Downs and } \\
\text { Borthwick } \\
\text { (1956) }\end{array}$ \\
\hline Salix pentandra L. & $\begin{array}{l}\text { Deciduous } \\
\text { small tree or } \\
\text { shrub }\end{array}$ & $\begin{array}{l}\text { Short photoperiod ( } \leq 22 \text { hours for a northern } \\
\text { ecotype and } \leq 15 \text { hours for a southern ecotype) } \\
\text { induced apical growth cessation. }\end{array}$ & $\begin{array}{l}\text { Chamber cultivating } \\
+ \text { controlled photoperiod }\end{array}$ & Junttila (1980) \\
\hline Salix polaris L. & $\begin{array}{l}\text { Deciduous } \\
\text { small tree or } \\
\text { shrub }\end{array}$ & $\begin{array}{l}\text { Leaf abscission in the arctic ecotype was } \\
\text { stimulated by short photoperiod when grown at } \\
15^{\circ} \mathrm{C} \text {. }\end{array}$ & $\begin{array}{l}\text { Collected with roots }+ \\
\text { controlled photoperiod }\end{array}$ & $\begin{array}{l}\text { Paus et al. } \\
(1986)\end{array}$ \\
\hline Syringa vulgaris L. & $\begin{array}{l}\text { Deciduous } \\
\text { small tree or } \\
\text { shrub }\end{array}$ & $\begin{array}{l}\text { Photosynthetic efficiency has a more consistent } \\
\text { relationship with photoperiod than with } \\
\text { temperature. }\end{array}$ & $\begin{array}{l}\text { Observation under } \\
\text { natural conditions }\end{array}$ & $\begin{array}{l}\text { Aikio et al. } \\
\text { (2019) }\end{array}$ \\
\hline
\end{tabular}




\begin{tabular}{|c|c|c|c|c|}
\hline Species & Life-form & Findings from experiments & Experimental setting & Reference \\
\hline $\begin{array}{l}\text { Hibiscus rosa- } \\
\text { sinensis } \mathrm{L} \text {. }\end{array}$ & $\begin{array}{l}\text { Evergreen } \\
\text { small tree or } \\
\text { shrub }\end{array}$ & $\begin{array}{l}\text { Leaves under long photoperiod treatment ( } 16 \\
\text { hours) spend ten more days to complete } \\
\text { senescence than that under short photoperiod } \\
\text { treatment ( } 8 \text { hours). }\end{array}$ & $\begin{array}{l}\text { Leaves cutting }+ \\
\text { controlled photoperiod }\end{array}$ & $\begin{array}{l}\text { Misra and } \\
\text { Biswal (1973) }\end{array}$ \\
\hline Hibiscus syriacus L. & $\begin{array}{l}\text { Deciduous } \\
\text { shrub }\end{array}$ & $\begin{array}{l}\text { Short photoperiod ( } 8 \text { hours) induced dormancy } \\
\text { while long photoperiod ( } 16 \text { hours) delayed } \\
\text { dormancy and resulted in considerable winter } \\
\text { injury }\end{array}$ & $\begin{array}{l}\text { Chamber cultivating } \\
+ \text { controlled photoperiod }\end{array}$ & $\begin{array}{l}\text { Davidson } \\
(1957)\end{array}$ \\
\hline $\begin{array}{l}\text { Weigela florida A. } \\
\text { DC. }\end{array}$ & $\begin{array}{l}\text { Deciduous } \\
\text { shrub }\end{array}$ & $\begin{array}{l}\text { Short photoperiod ( } 8 \text { hours) induced dormancy } \\
\text { while long photoperiod ( } 16 \text { hours) delayed } \\
\text { dormancy and resulted in considerable winter } \\
\text { injury. }\end{array}$ & $\begin{array}{l}\text { Chamber cultivating } \\
\text { +controlled photoperiod }\end{array}$ & $\begin{array}{l}\text { Davidson } \\
\text { (1957) }\end{array}$ \\
\hline $\begin{array}{l}\text { Rhododendron } \\
\text { catawbiense Michx. }\end{array}$ & $\begin{array}{l}\text { Evergreen } \\
\text { shrub }\end{array}$ & $\begin{array}{l}\text { Short photoperiod ( } 8 \text { hours) induced dormancy } \\
\text { while long photoperiod ( } 16 \text { hours) delayed } \\
\text { dormancy and resulted in considerable winter } \\
\text { injury. }\end{array}$ & $\begin{array}{l}\text { Chamber cultivating } \\
+ \text { controlled photoperiod }\end{array}$ & $\begin{array}{l}\text { Davidson } \\
\text { (1957) }\end{array}$ \\
\hline $\begin{array}{l}\text { Cucurbita pepo } \\
\text { Linn. }\end{array}$ & Herbaceous & $\begin{array}{l}\text { After three months of growth, much larger } \\
\text { percentage of mesophyll cell death was detected } \\
\text { in short photoperiod ( } 9 \text { hours) than that in long } \\
\text { photoperiod ( } 18 \text { hours). }\end{array}$ & $\begin{array}{l}\text { Chamber cultivating } \\
\text { +controlled photoperiod }\end{array}$ & $\begin{array}{l}\text { Wang et al. } \\
(2002)\end{array}$ \\
\hline $\begin{array}{l}\text { Sedum telephium L. } \\
\text { subsp. maximum } \\
\text { (L.) Krocker }\end{array}$ & Herbaceous & $\begin{array}{l}\text { After eight weeks of growth, plants in long } \\
\text { photoperiod ( } 24 \text { hours) elongated rapidly while } \\
\text { those in short photoperiod ( } 10 \text { hours) became } \\
\text { dormant. }\end{array}$ & $\begin{array}{l}\text { Chamber cultivating } \\
\text { +controlled photoperiod }\end{array}$ & Heide (2001) \\
\hline $\begin{array}{l}\text { Vitis labruscana } \\
\text { Bailey }\end{array}$ & Herbaceous & $\begin{array}{l}\text { Cane elongation was less in response to short } \\
\text { photoperiod treatments ( } 12 \text { or } 13 \text { hours), as } \\
\text { compared to natural photoperiod ( } 13.7 \text { or } 14.3 \\
\text { hours). }\end{array}$ & $\begin{array}{l}\text { Stem cutting }+ \\
\text { controlled photoperiod }\end{array}$ & $\begin{array}{l}\text { Fennell and } \\
\text { Hoover (1991) }\end{array}$ \\
\hline Vitis riparia Michx. & Herbaceous & $\begin{array}{l}\text { Cane elongation was less in response to short } \\
\text { photoperiod treatments ( } 12 \text { or } 13 \text { hours), as } \\
\text { compared to natural photoperiod ( } 13.7 \text { or } 14.3 \\
\text { hours). }\end{array}$ & $\begin{array}{l}\text { Stem cutting }+ \\
\text { controlled photoperiod }\end{array}$ & $\begin{array}{l}\text { Fennell and } \\
\text { Hoover (1991) }\end{array}$ \\
\hline
\end{tabular}


368 Table S2. In situ observations in China used in this study.

\begin{tabular}{ccccccc}
\hline Site Name & Latitude & Longitude & Species number & Start year & End year & Year length \\
\hline Nunkiang & 49 & 125 & 5 & $1975 \pm 0$ & $1993 \pm 4$ & $17 \pm 4$ \\
Wudalianchi & 48 & 126 & 11 & $1976 \pm 3$ & $1995 \pm 3$ & $18 \pm 3$ \\
Kiamusze & 47 & 130 & 6 & $1981 \pm 1$ & $1996 \pm 0$ & $16 \pm 1$ \\
Minqin & 38 & 103 & 29 & $1981 \pm 1$ & $1996 \pm 1$ & $12 \pm 1$ \\
Hohhot & 41 & 112 & 10 & $1981 \pm 2$ & $1996 \pm 1$ & $13 \pm 2$ \\
Mutankiang & 44 & 130 & 41 & $1980 \pm 2$ & $1996 \pm 2$ & $13 \pm 2$ \\
Beijing & 40 & 116 & 42 & $1972 \pm 1$ & $1994 \pm 3$ & $20 \pm 4$ \\
Chengteh & 41 & 118 & 5 & $1983 \pm 2$ & $1996 \pm 0$ & $12 \pm 1$ \\
Qinhuangdao & 39 & 119 & 15 & $1980 \pm 0$ & $1993 \pm 0$ & $13 \pm 1$ \\
Gaizhou & 40 & 122 & 12 & $1979 \pm 1$ & $1996 \pm 0$ & $17 \pm 1$ \\
Yixian & 39 & 115 & 17 & $1980 \pm 0$ & $1993 \pm 0$ & $12 \pm 1$ \\
Liaocheng & 36 & 115 & 5 & $1974 \pm 4$ & $1993 \pm 2$ & $15 \pm 3$ \\
Tyan & 36 & 117 & 5 & $1974 \pm 0$ & $1986 \pm 0$ & $11 \pm 0$ \\
Sian & 34 & 109 & 33 & $1977 \pm 3$ & $1994 \pm 3$ & $15 \pm 3$ \\
Luoyang & 35 & 113 & 27 & $1977 \pm 4$ & $1996 \pm 1$ & $18 \pm 4$ \\
Yancheng & 33 & 120 & 19 & $1981 \pm 4$ & $1996 \pm 0$ & $15 \pm 3$ \\
Zhengjiang & 32 & 119 & 15 & $1976 \pm 3$ & $1993 \pm 2$ & $17 \pm 3$ \\
Hefei & 32 & 117 & 19 & $1979 \pm 1$ & $1995 \pm 1$ & $17 \pm 2$ \\
Wuhu & 31 & 118 & 16 & $1982 \pm 1$ & $1996 \pm 0$ & $13 \pm 1$ \\
\hline
\end{tabular}


371 Table S3. FLUXNET2015 flux tower sites used in this study.

\begin{tabular}{|c|c|c|c|c|c|}
\hline Fluxnet ID & Vegetation type & Latitude & Longitude & Year range & Reference \\
\hline BE-Bra & Mixed Forests & 51.31 & 4.52 & $\begin{array}{l}\text { 1999-2002,2004- } \\
2014\end{array}$ & Janssens (2016) \\
\hline BE-Vie & Mixed Forests & 50.31 & 6.00 & 1996-2014 & De Ligne et al. (2016) \\
\hline CA-Gro & Mixed Forests & 48.22 & -82.16 & $2003-2013$ & McCaughey (2016) \\
\hline CA-Man & Evergreen Needleleaf Forest & 55.88 & -98.48 & $\begin{array}{l}1994-2004,2006- \\
2008\end{array}$ & Amiro (2016) \\
\hline CA-Oas & Mixed Forests & 53.63 & -106.20 & $1996-2010$ & Black (2016b) \\
\hline CA-Obs & Evergreen Needleleaf Forest & 53.99 & -105.12 & $1999-2010$ & Black (2016a) \\
\hline CA-TP3 & Mixed Forests & 42.71 & -80.35 & $2003-2014$ & Arain (2016b) \\
\hline CA-TP4 & Mixed Forests & 42.71 & -80.36 & $2002-2014$ & Arain (2016a) \\
\hline CH-Dav & Evergreen Needleleaf Forest & 46.82 & 9.86 & $1997-2014$ & Hörtnagl et al. (2016b) \\
\hline CH-Lae & Mixed Forests & 47.48 & 8.37 & 2004-2014 & Hörtnagl et al. (2016a) \\
\hline CZ-BK1 & Evergreen Needleleaf Forest & 49.50 & 18.54 & 2004-2014 & Šigut et al. (2016) \\
\hline DE-Gri & Mixed Forests & 50.95 & 13.51 & 2004-2014 & Bernhofer et al. (2016b) \\
\hline DE-Hai & Mixed Forests & 51.08 & 10.45 & $2000-2012$ & Knohl et al. (2016) \\
\hline DE-Tha & Evergreen Needleleaf Forest & 50.96 & 13.57 & $1996-2014$ & Bernhofer et al. (2016a) \\
\hline DK-Sor & Deciduous Broadleaf Forest & 55.49 & 11.64 & 1996-2014 & Ibrom and Pilegaard (2016) \\
\hline DK-ZaH & Open Shrublands & 74.47 & -20.55 & $\begin{array}{l}2000-2010,2012- \\
2014\end{array}$ & Lund et al. (2016) \\
\hline FI-Hyy & Evergreen Needleleaf Forest & 61.85 & 24.30 & $1996-2014$ & Mammarella et al. (2016) \\
\hline FI-Sod & Evergreen Needleleaf Forest & 67.36 & 26.64 & $2001-2014$ & Aurela et al. (2016) \\
\hline FR-Fon & Deciduous Broadleaf Forest & 48.48 & 2.78 & $2005-2014$ & Berveiller et al. (2016) \\
\hline IT-Col & Deciduous Broadleaf Forest & 41.85 & 13.59 & $\begin{array}{l}1997-2002,2004- \\
2014\end{array}$ & Matteucci (2016) \\
\hline IT-Lav & Evergreen Needleleaf Forest & 45.96 & 11.28 & 2003-2014 & Gianelle et al. (2016b) \\
\hline IT-MBo & Grasslands & 46.01 & 11.05 & $2003-2013$ & Gianelle et al. (2016a) \\
\hline IT-Ren & Evergreen Needleleaf Forest & 46.59 & 11.43 & $\begin{array}{l}1999,2002- \\
2003,2005-2013\end{array}$ & Minerbi and Montagnani (2016) \\
\hline NL-Loo & Evergreen Needleleaf Forest & 52.17 & 5.74 & 1996-2014 & Moors and Elbers (2016) \\
\hline RU-Cok & Open Shrublands & 70.83 & 147.49 & $2003-2013$ & Dolman et al. (2016) \\
\hline RU-Fyo & Mixed Forests & 56.46 & 32.92 & $1998-2014$ & Varlagin et al. (2016) \\
\hline US-GLE & Evergreen Needleleaf Forest & 41.36 & -106.24 & $2005-2014$ & Massman (2016) \\
\hline US-Ha1 & Mixed Forests & 42.54 & -72.17 & $1992-2012$ & Munger (2016) \\
\hline US-MMS & Deciduous Broadleaf Forest & 39.32 & -86.41 & $1999-2014$ & Novick and Phillips (2016) \\
\hline US-Me2 & Evergreen Needleleaf Forest & 44.45 & -121.56 & $2002-2014$ & Law (2016) \\
\hline US-NR1 & Evergreen Needleleaf Forest & 40.03 & -105.55 & 1999-2014 & Blanken (2016) \\
\hline US-Oho & Deciduous Broadleaf Forest & 41.55 & -83.84 & $2004-2013$ & Chen (2016) \\
\hline US-PFa & Mixed Forests & 45.95 & -90.27 & $1996-2014$ & Desai (2016) \\
\hline US-SRM & Open Shrublands & 31.82 & -110.87 & $2004-2014$ & Scott $(2016 a)$ \\
\hline US-UMB & Deciduous Broadleaf Forest & 45.56 & -84.71 & $2000-2014$ & Gough et al. (2016) \\
\hline US-Wkg & Grasslands & 31.74 & -109.94 & 2004-2014 & Scott $(2016 b)$ \\
\hline
\end{tabular}


373 Table S4. Proportions of years with cold events before $D_{\mathrm{LCO}}$ (for satellite and in situ observations) and

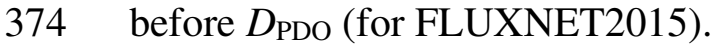

\begin{tabular}{cccc}
\hline Metrics & $\begin{array}{c}\text { Satellite } D_{\text {LCO }} \\
(2000-2016)\end{array}$ & $\begin{array}{c}\text { in situ } D_{\text {LCO }} \\
\text { China }\end{array}$ & $\begin{array}{c}\text { FLUXNET2015 } \\
D_{\text {PDO }}\end{array}$ \\
\hline Proportion $(\%)$ of years with cold events $\left({ }^{\circ} \mathrm{C}\right)$ & 1 & 2 & 1 \\
\hline Proportion $(\%)$ of years with cold events $\left(2{ }^{\circ} \mathrm{C}\right)$ & 2 & 3 & 1 \\
\hline
\end{tabular}

$375 D_{\mathrm{PDO}}$, timing of onset of the decrease in maximum canopy photosynthetic capacity in autumn; $D_{\mathrm{LCO}}$, timing of onset of leaf 376 coloration in autumn. Cold events were determined mainly by using a threshold-based method with a daily minimum 377 temperature of $0^{\circ} \mathrm{C}$ or $2{ }^{\circ} \mathrm{C}$. 
379 Table S5. Percentage of time series for each interval of the temporal trend in $D_{\mathrm{LCO}}$ before and after the 380 exclusion of years with cold events.

\begin{tabular}{|c|c|c|c|c|c|c|c|}
\hline \multirow{2}{*}{ Metrics } & \multirow{2}{*}{$\begin{array}{l}\text { Number of } \\
\text { time-series }\end{array}$} & \multirow{2}{*}{ Cold events } & \multicolumn{4}{|c|}{ Interval of significant temporal trend $\left(\mathrm{d} \mathrm{y}^{-1}\right)(P<0.05)$} & \multirow{2}{*}{$P>0.05$} \\
\hline & & & $<-1$ & {$[-1,0)$} & $(0,1]$ & $>1$ & \\
\hline \multirow{3}{*}{$\begin{array}{c}\text { Satellite } D_{\text {LCO }} \\
(2000-2016)\end{array}$} & \multirow{3}{*}{$2.01 \times 10^{6}$} & Not excluded & 2 & 2 & 2 & 4 & 90 \\
\hline & & Excluded $\left(0{ }^{\circ} \mathrm{C}\right)$ & 2 & 2 & 2 & 4 & 90 \\
\hline & & Excluded $\left(2{ }^{\circ} \mathrm{C}\right)$ & 2 & 2 & 1 & 5 & 90 \\
\hline \multirow{3}{*}{$\begin{array}{l}\text { in situ } D_{\mathrm{LCO}} \\
\text { China }\end{array}$} & \multirow{3}{*}{326} & Not excluded & 12 & 4 & 4 & 6 & 74 \\
\hline & & Excluded $\left(0{ }^{\circ} \mathrm{C}\right)$ & 12 & 4 & 5 & 6 & 73 \\
\hline & & Excluded $\left(2{ }^{\circ} \mathrm{C}\right)$ & 12 & 3 & 5 & 7 & 73 \\
\hline
\end{tabular}

$381 D_{\mathrm{LCO}}$, timing of onset of leaf coloration in autumn. Temporal trends were determined by using the ordinary least squares 382 regression between $D_{\mathrm{LCO}}$ and the respective years, with $t$-tests. Only time series with at least 10 continuous years of data after exclusion of years with cold events were included. Cold events were determined mainly by using a threshold-based method with a daily minimum temperature of $0{ }^{\circ} \mathrm{C}$ or $2{ }^{\circ} \mathrm{C}$. Data in the farthest right column indicate the percentage of area or time386 
387 Table S6. Percentage of time series for each interval of the temporal trend in $D_{\mathrm{LCO}}$.

\begin{tabular}{|c|c|c|c|c|c|c|}
\hline \multirow{2}{*}{ Metrics } & \multirow{2}{*}{$\begin{array}{l}\text { Number of } \\
\text { time-series }\end{array}$} & \multicolumn{4}{|c|}{ Interval of significant temporal trend $\left(\mathrm{d} \mathrm{y}^{-1}\right)(P<0.05)$} & \multirow{2}{*}{$P>0.05$} \\
\hline & & $<-1$ & {$[-1,0)$} & $(0,1]$ & $>1$ & \\
\hline $\begin{array}{c}\text { Satellite } D_{\text {LCO }} \\
(2000-2018)\end{array}$ & $2.07 \times 10^{6}$ & 1 & 2 & 1 & 3 & 93 \\
\hline in situ $D_{\mathrm{LCO}}$ China & 332 & 8 & 2 & 3 & 3 & 84 \\
\hline
\end{tabular}

$388 D_{\mathrm{LCO}}$, timing of the onset of leaf coloration in autumn. Temporal trends were determined by using the Theil-Sen estimator 389 between $D_{\mathrm{LCO}}$ and the respective years, with Mann-Kendall tests. Data in the farthest right column indicate the percentage of 390 area or time-series with a non-significant trend.

391 
Table S7. Percentage of correlations between $D_{\mathrm{LCO}}$ or $D_{\mathrm{PDO}}$ and each climate factor for each interval of the partial correlation coefficient before and after the exclusion of years with cold events.

\begin{tabular}{|c|c|c|c|c|c|c|c|c|c|}
\hline \multirow{2}{*}{ Metrics } & \multirow{2}{*}{$\begin{array}{l}\text { Climatic } \\
\text { Factor }\end{array}$} & \multirow{2}{*}{ Cold Events } & \multicolumn{6}{|c|}{ Interval of the partial correlation coefficient $(P<0.05)$} & \multirow{2}{*}{$P>0.05$} \\
\hline & & & $\overline{[-1.0,-0.8)[-0 .}$ & $8,-0.6)$ & {$[-0.6,0)$} & $(0,0.6]$ & $(0.6,0.8]$ & $(0.8,1.0]$ & \\
\hline \multirow{6}{*}{$\begin{array}{l}\text { Satellite } D_{\text {LCO }} \\
\text { (2000-2016) }\end{array}$} & \multirow{3}{*}{ Temperature } & Not excluded & 0 & 2 & 4 & 5 & 3 & 0 & 86 \\
\hline & & Excluded $\left(0^{\circ} \mathrm{C}\right)$ & 0 & 2 & 4 & 5 & 3 & 0 & 86 \\
\hline & & Excluded $\left(2^{\circ} \mathrm{C}\right)$ & 0 & 2 & 4 & 5 & 3 & 0 & 86 \\
\hline & \multirow{3}{*}{ Precipitation } & Not excluded & 0 & 2 & 3 & 7 & 5 & 0 & 83 \\
\hline & & Excluded $\left(0^{\circ} \mathrm{C}\right)$ & 0 & 2 & 3 & 7 & 5 & 0 & 83 \\
\hline & & Excluded $\left(2^{\circ} \mathrm{C}\right)$ & 0 & 2 & 3 & 7 & 5 & 0 & 83 \\
\hline \multirow{6}{*}{$\begin{array}{l}\text { in situ } D_{\mathrm{LCO}} \\
\text { China }\end{array}$} & \multirow{3}{*}{ Temperature } & Not excluded & 0 & 2 & 3 & 4 & 8 & 1 & 82 \\
\hline & & Excluded $\left(0^{\circ} \mathrm{C}\right)$ & 0 & 2 & 2 & 4 & 9 & 1 & 82 \\
\hline & & Excluded $\left(2^{\circ} \mathrm{C}\right)$ & 0 & 2 & 2 & 4 & 9 & 1 & 82 \\
\hline & \multirow{3}{*}{ Precipitation } & Not excluded & 0 & 3 & 3 & 4 & 5 & 0 & 85 \\
\hline & & Excluded $\left(0^{\circ} \mathrm{C}\right)$ & 0 & 4 & 3 & 3 & 6 & 0 & 84 \\
\hline & & Excluded $\left(2^{\circ} \mathrm{C}\right)$ & 0 & 4 & 3 & 3 & 6 & 0 & 84 \\
\hline \multirow{6}{*}{$\begin{array}{c}\text { FLUXNET2015 } \\
D_{\mathrm{PDO}}\end{array}$} & \multirow{6}{*}{ Precipitation } & Not excluded & 0 & 5 & 3 & 0 & 3 & 0 & 89 \\
\hline & & Excluded $\left(0^{\circ} \mathrm{C}\right)$ & 0 & 5 & 3 & 0 & 0 & 0 & 92 \\
\hline & & Excluded $\left(2^{\circ} \mathrm{C}\right)$ & 0 & 5 & 3 & 0 & 0 & 0 & 92 \\
\hline & & Not excluded & 0 & 6 & 0 & 8 & 3 & 5 & 78 \\
\hline & & Excluded $\left(0^{\circ} \mathrm{C}\right)$ & 0 & 6 & 0 & 8 & 3 & 5 & 78 \\
\hline & & Excluded $\left(2^{\circ} \mathrm{C}\right)$ & 0 & 6 & 0 & 8 & 3 & 5 & 78 \\
\hline
\end{tabular}

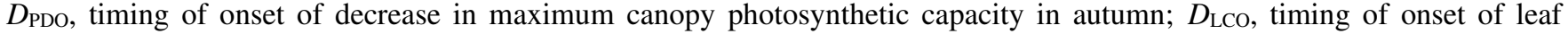
coloration in autumn. The relationships between $D_{\mathrm{LCO}}$ (or $D_{\mathrm{PDO}}$ ) and temperature were determined by using a partial correlation analysis between $D_{\mathrm{LCO}}$ (or $D_{\mathrm{PDO}}$ ) and pre- $D_{\mathrm{LCO}}$ (or pre- $D_{\mathrm{PDO}}$ ) mean daily minimum temperature, with concurrent total precipitation as the control variable. The relationships between $D_{\mathrm{LCO}}$ (or $D_{\mathrm{PDO}}$ ) and pre- $D_{\mathrm{LCO}}$ (or pre- $D_{\mathrm{PDO}}$ ) precipitation were determined similarly. Cold events were determined mainly by using a threshold-based method with a daily minimum temperature of $0{ }^{\circ} \mathrm{C}$ or $2{ }^{\circ} \mathrm{C}$. Data in the farthest right column indicate the percentage of area or time-series with a nonsignificant correlation. 
402 Table S8. Percentage of correlations between $D_{\mathrm{LCO}}$ or $D_{\mathrm{PDO}}$ and each climate factor for each interval of 403 the partial correlation coefficient.

\begin{tabular}{|c|c|c|c|c|c|c|c|c|}
\hline \multirow{2}{*}{$\begin{array}{l}\text { Climatic } \\
\text { factor }\end{array}$} & \multirow{2}{*}{ Metrics } & \multicolumn{6}{|c|}{ Interval of the partial correlation coefficient $(P<0.05)$} & \multirow{2}{*}{$P>0.05$} \\
\hline & & $\overline{[-1.0,-0.8)}$ & {$[-0.8,-0.6)$} & {$[-0.6,0)$} & $(0,0.6]$ & $(0.6,0.8]$ & $(0.8,1.0]$ & \\
\hline \multirow{2}{*}{ Temperature } & FLUXNET2015 $D_{\mathrm{PDO}}$ & 0 & 7 & 0 & 0 & 3 & 0 & 90 \\
\hline & Satellite $D_{\mathrm{LCO}}$ & 0 & 4 & 3 & 3 & 3 & 0 & 87 \\
\hline \multirow{2}{*}{ Precipitation } & FLUXNET2015 $D_{\mathrm{PDO}}$ & 0 & 7 & 0 & 0 & 3 & 7 & 83 \\
\hline & Satellite $D_{\mathrm{LCO}}$ & 0 & 0 & 0 & 0 & 7 & 0 & 93 \\
\hline
\end{tabular}

$404 D_{\mathrm{PDO}}$, timing of onset of decrease in maximum canopy photosynthetic capacity in autumn; $D_{\mathrm{LCO}}$, timing of onset of leaf 405 coloration in autumn. The relationships between $D_{\mathrm{LCO}}$ (or $D_{\mathrm{PDO}}$ ) and temperature were determined by using a partial 406 correlation analysis between $D_{\mathrm{LCO}}$ (or $D_{\mathrm{PDO}}$ ) and pre- $D_{\mathrm{LCO}}$ (or pre- $D_{\mathrm{PDO}}$ ) mean daily minimum temperature, with concurrent total precipitation as the control variable. The relationships between $D_{\mathrm{LCO}}$ (or $D_{\mathrm{PDO}}$ ) and pre- $D_{\mathrm{LCO}}$ (or pre- $D_{\mathrm{PDO}}$ ) precipitation were determined similarly. Only sites with at least 10 continuous years of valid data for both $D_{\mathrm{LCO}}$ and $D_{\mathrm{PDO}}$ were included. Data in the farthest right column indicate the percentage of area or time-series with a non-significant correlation. To make the satellite $D_{\mathrm{LCO}}$ and FLUXNET2015 $D_{\mathrm{PDO}}$ more comparable, MOD09A1 with a spatial resolution of $500 \mathrm{~m}$ was used for 


\section{Supplementary Methods}

\section{Preparation of high quality 5-day NDVI time series}

The quality of the daily surface reflectance data from MOD09CMG was unsatisfactory owing to 416 cloud contamination (Vermote, 2015), so we used the 5-day maximum value composite approach 417 (Zhang, 2015), combined with a Savitzky-Golay filter (Cao et al., 2018), to produce a high-quality 418 NDVI time series before determining $D_{\mathrm{LCO}}$. Details of the data preprocessing are given in the following 419 text.

420 1) Calculating daily NDVI. We calculated the daily NDVI time series with the quality flag from 421 surface reflectance in the red and near-infrared bands as $N D V I=(N I R-R E D) /(N I R+R E D)$. The 422 quality flags for daily NDVI were derived from the two quality bands (i.e., Internal CM and State QA) 423 of the reflectance product MOD09CMG (Vermote et al., 2015). We determined four types of conditions 424 that corresponded to the assigned quality flags: 1) clear, 2) uncertain, 3) snowy, and 4) cloudy (with 425 deteriorating data quality), according to Cao et al. (2018) These were subsequently used in the Savitzky426 Golay filtering (Cao et al., 2018). To be precise, the quality flag was set to "cloudy" if the cloud state in 427 either Internal CM or State QA was labeled as "yes" or "cloudy or mixed"; the quality flag was set to 428 "snowy" if the snow/ice flag in State QA was labeled as "yes"; and the quality flag was set to "uncertain" 429 if the cloud state in State QA was not set (assumed clear). All the other data flags were set to "clear" 430 (see the index table below). In addition, considering that the NDVI value of a vegetation pixel ranged 431 from -0.2 to 1.0 , NDVI data outside this range were treated as gaps in the NDVI time series.

\begin{tabular}{cccc}
\hline $\begin{array}{c}\text { Quality flag of } \\
\text { daily NDVI }\end{array}$ & $\begin{array}{c}\text { MOD35 snow/ice flag in } \\
\text { State QA }\end{array}$ & $\begin{array}{c}\text { Cloud state in } \\
\text { State QA }\end{array}$ & $\begin{array}{c}\text { Cloud state in } \\
\text { Internal CM }\end{array}$ \\
\hline clear & no & clear & no \\
uncertain & no & not set (assumed clear) & no \\
snowy & yes & clear or not set (assumed & no \\
& - & clear) & - \\
cloudy & - & cloudy or mixed & yes \\
\hline
\end{tabular}

"No" and "yes" in the snow/ice flag indicate absence and presence of snow or ice, respectively; "no" and "yes" in the internal CM indicate absence and presence of cloud, respectively; "-" means no specific snow/ice or cloud state was required.

2) Determining the background NDVI value for each pixel. The background value represents the annual minimum NDVI during winter (December-February), in which NDVI was expected to be stable 436 for winter deciduous vegetation if there was no snow/ice or cloud contamination. The background NDVI 437 value was calculated as the mean of high winter NDVI values, because snow/ice or cloud contamination 
438 decreases NDVI owing to the uncertainties in the snow/ice and cloud flags (Beck et al., 2006). To obtain 439 high winter NDVI values for a given pixel, we first calculated a time series of winter NDVI higher than 4400.10 (snow-contaminated NDVI is usually lower than 0.10 ). The high winter NDVI values were 441 expected to be higher than the 50th percentile of this time series of winter NDVI and lower than the 442 mean +2 SD of this time series of winter NDVI. In some cases, there would be no winter NDVI values 443 higher than 0.10; for these cases the background NDVI value was set at 0.10 .

444 3) Compositing the 5-day NDVI time series from daily NDVI time series. The daily NDVI time445 series were aggregated to a 5-day composite as follows: if there were one or more NDVI values meeting 446 the quality level (i.e., the quality flag is "clear" in step 1) within the 5-day period, the median value was 447 used as the composite value to reduce noise, and the composite value was flagged as "clear". If no 448 acceptable NDVI data were found in the 5-day period, the maximum value was used as the composite 449 value (see Figure SM1), and the composite value was flagged as the corresponding daily quality flag of 450 the maximum value.
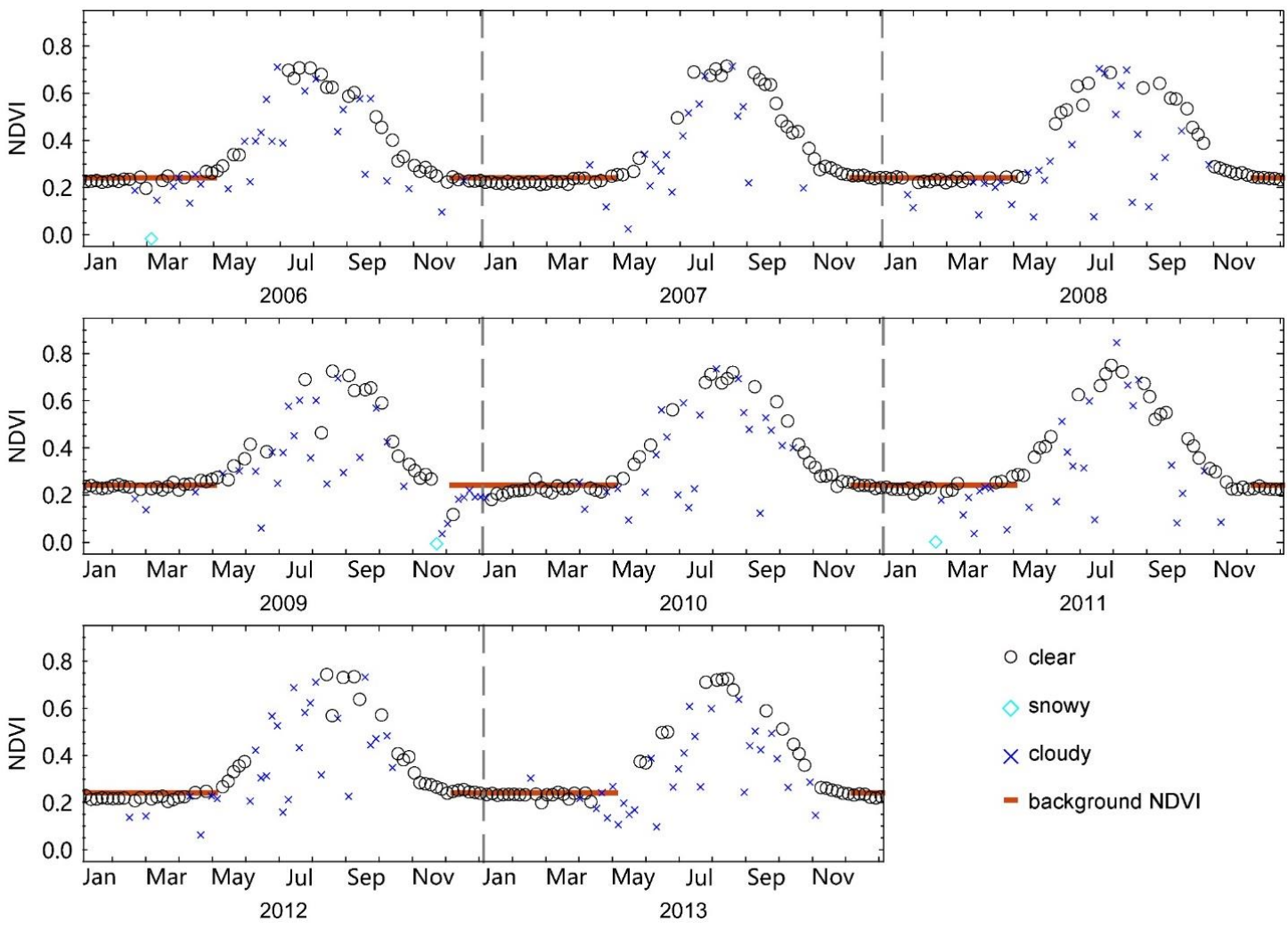

O clear

$\diamond$ snowy

$\times$ cloudy

- background NDVI

452 Figure SM1. An example $\left(31.325^{\circ} \mathrm{N}, 98.125^{\circ} \mathrm{E}\right)$ showing composite 5-day NDVI time series from 453 daily NDVI time series. 
4) Eliminating snow cover contamination in NDVI data. NDVI values in winter (DecemberFebruary) were all replaced by the background NDVI value, and their flag was set to "clear", meaning that those NDVI values were not changed in the Savitzky-Golay filtering. In the other three seasons (March-November), the NDVI values lower than this background NDVI value were then substituted for the latter one (see Figure SM2) and their flag values were set to "cloudy".
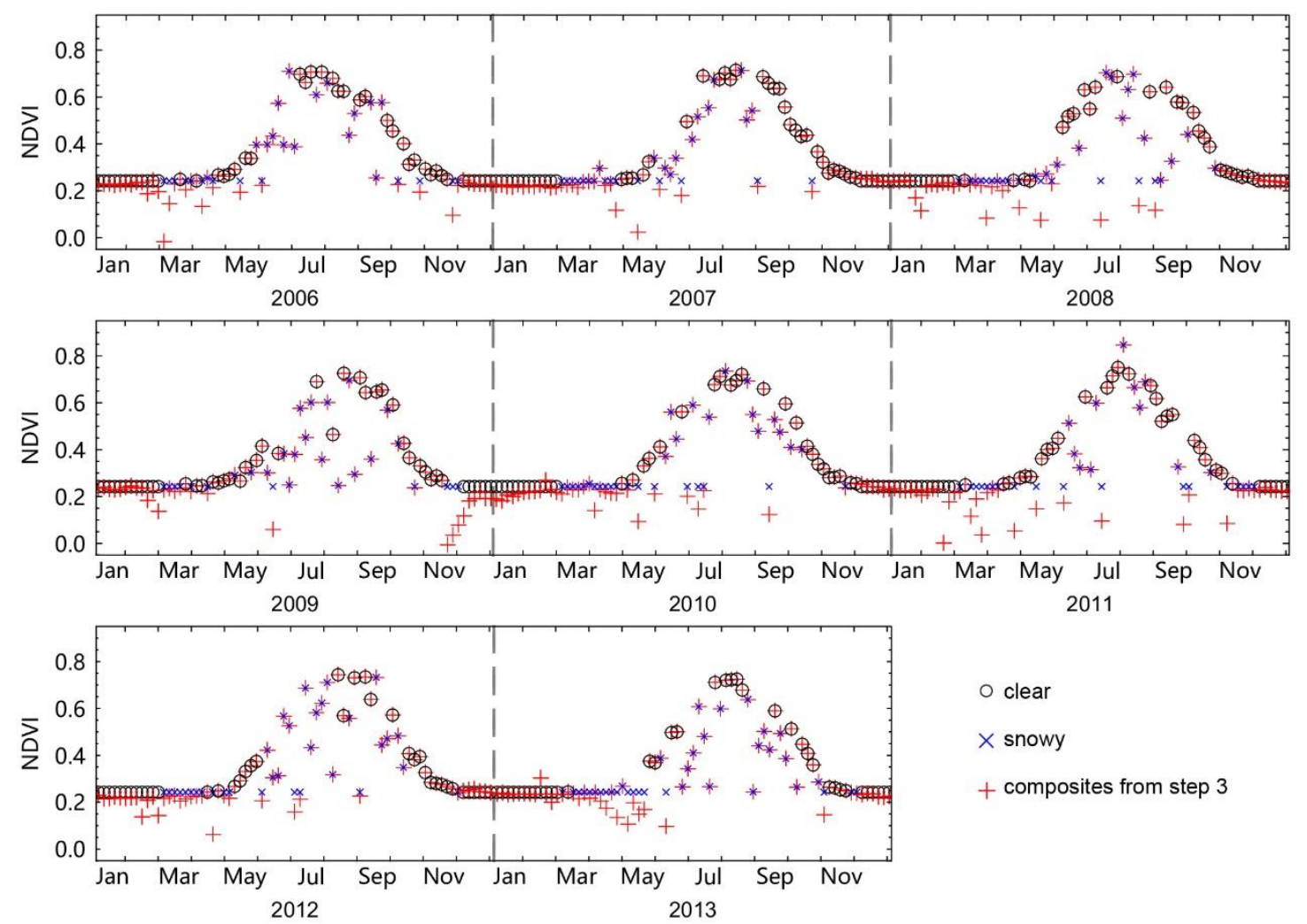

O clear

$\times$ snowy

+ composites from step 3

Figure SM2. An example showing the elimination of snow cover contamination in NDVI data.

5) Identifying irregularly high and low NDVI values. Disturbances in surface reflectance data, which are caused by cloud contamination, bidirectional effects, and data transmission errors, result in irregularly high and low NDVI values. Most of these irregular NDVI values could be marked by using the quality flag in step 1 . However, because of the uncertainty of the quality flag, there was still a sharp increase or sudden large decrease of NDVI values flagged as "clear" in the 5-day NDVI profile from March to November. Because vegetation growth is a continuous process without large increases or decreases in greenness over a few days, NDVI values that showed sharp decreases or increases were defined as irregularly low or high NDVI values, respectively, and they were identified by using the 
shape of the NDVI curve and an outlier detection method.

The irregularly low NDVI values were identified by using the shape of the NDVI curve. Assuming that the 5-day NDVI increased or decreased gradually in a seasonal course, for any 5-day NDVI at time $t$, denoted as $N D V I(t)$, an $N D V I(t)$ was identified as an irregularly low value, if there existed two positive integers $k$ and $m$ satisfying

$$
\begin{aligned}
& N D V I(t)-N D V I(t-k) \leq-k \times(0.15 \times \operatorname{maxNDVI}) \\
& N D V I(t)-N D V I(t+m) \leq-m \times(0.15 \times \operatorname{maxNDVI})
\end{aligned}
$$

where $1 \leq k \leq 6,1 \leq m \leq 6$, and maxNDVI was the 75th percentile of the time series of annual maximum NDVI from 2000 to 2018. In a few cases, there may have been two consecutive irregularly low values, which were identified as follows. Two consecutive NDVI values, $N D V I(t)$ and $N D V I(t+1)$, were identified as consecutive irregularly low values if they satisfied the following inequalities:

$$
\begin{gathered}
N D V I(t)-N D V I(t-1) \leq-1 \times(0.15 \times \operatorname{maxNDVI}) \\
N D V I(t+1)-N D V I(t-1) \leq-0.9 \times(0.15 \times \operatorname{maxNDVI}) \\
N D V I(t+1)-N D V I(t+2) \leq-2 \times(0.15 \times \operatorname{maxNDVI}) .
\end{gathered}
$$

The irregularly high NDVI values were identified by using the shape of the NDVI curve and an outlier detection method. The NDVI curve shape-based method included two procedures. Procedure 1 was to detect non-consecutive irregularly high NDVI values. Assuming that the 5-day NDVI increased or decreased gradually in a seasonal course, an NDVI value at time $t, N D V I(t)$, was identified as an irregularly high value if it satisfied

$$
N D V I(t) \geq 1.15 \times \max \{N D V I(t-6), N D V I(t-5), \ldots, N D V I(k), \ldots, N D V I(t+6)\}
$$

where $t-6 \leq k \leq t+6$ and $k \neq t$.

In some cases, there could be two or more irregularly high NDVI values within 1 month around peak season that could not be detected by using the above algorithm. Such irregularly high NDVI values were identified in Procedure 2, which used the information of a non-consecutive irregularly high NDVI value identified in Procedure 1. We first constructed an array by selecting non-consecutive irregularly high NDVI values in Procedure 1, which were the annual maximum values (denoted as $\mathrm{NDVI}_{\mathrm{IHM}}$ ). Then, the NDVI values were identified as irregularly high NDVI values if they were $15 \%$ higher than the median value of the array of $\mathrm{NDVI}_{\mathrm{IHM}}$. 
Because the NDVI values around the peak season were essential for retrieving $D_{\mathrm{LCO}}$, to be more robust, the irregularly high NDVI values were also identified by using Grubb's test (Grubbs, 1950). We first composed an array by using the three highest NDVI values of each year. The outliers in this array were then detected by using Grubb's test at a significance level of $\alpha=0.05$. Owing to inter-annual 502 variations in the annual maximum greenness, the outliers detected by Grubb's test may not necessarily 503 have been the irregularly high NDVI values. Therefore, in a given year, only outliers that were $15 \%$ 504 higher than the mean of the three highest non-outlier NDVI values for that year were identified as irregularly high NDVI values. Finally, all the irregularly high NDVI values identified above were used as irregularly high NDVI values.

The figure SM3 gives examples of irregularly low and high NDVI values.
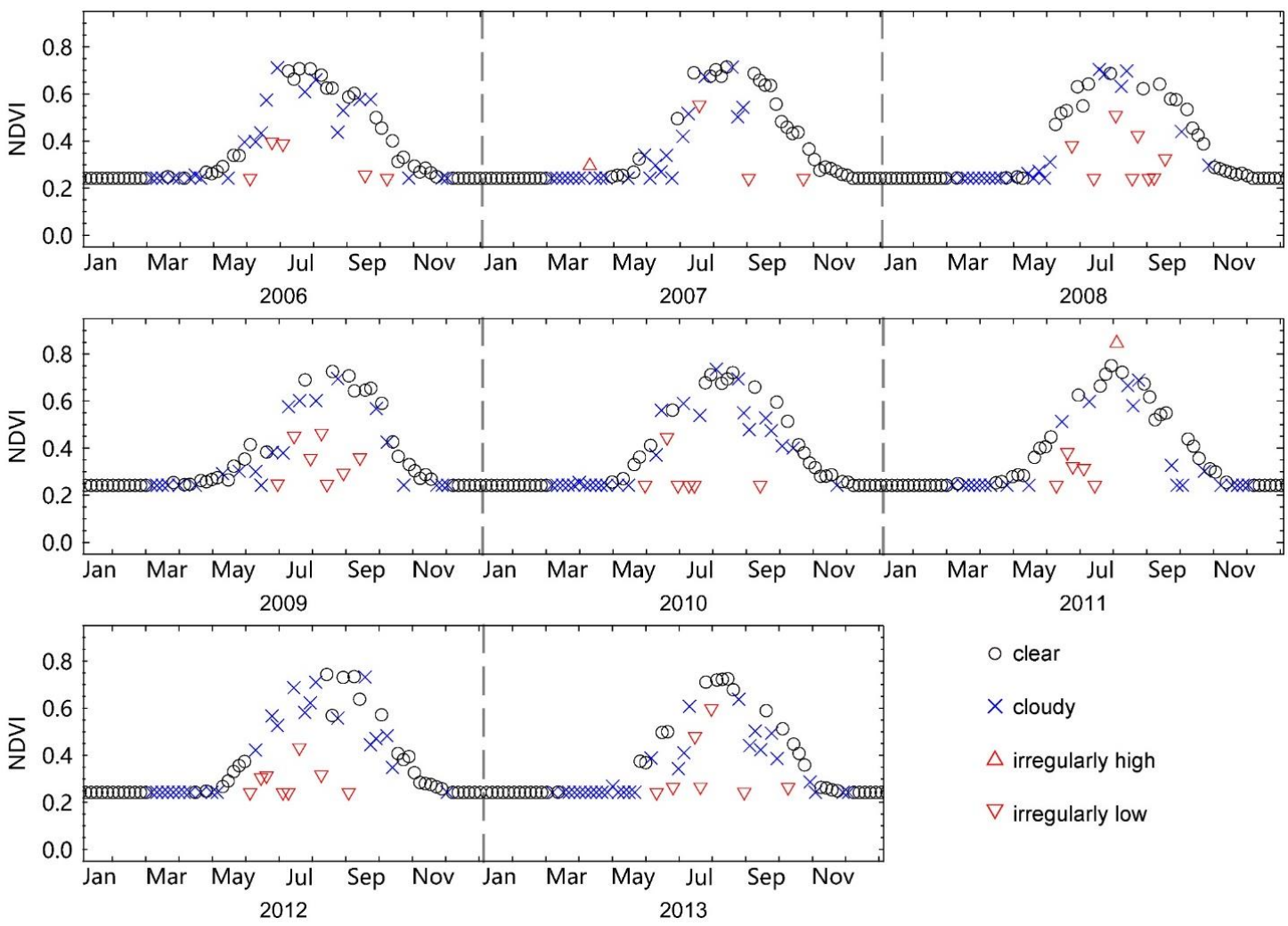

O clear

$\times$ cloudy

$\triangle$ irregularly high

$\nabla$ irregularly low

Figure SM3. An example showing irregularly high and low NDVI values identified in the 5-day composited NDVI time series.

6) Processing the NDVI values flagged as "cloudy". Because clouds are overestimated by the cloud flag (Wilson et al., 2014), there were a considerable number of high NDVI values during March- 
514 November that were flagged as "cloudy" but that appeared to be reasonable in the seasonal NDVI 515 profile. We detected these NDVI values and promoted their flags to be "uncertain" ("uncertain" 516 indicates a quality higher than "cloudy" but lower than "clear", see Cao et al. (2018) for details). First, a 517 pixel-year was excluded from our study if each of the NDVI values from May to September was either 518 "cloudy" or "irregular". Second, for NDVI values lower than $90 \%$ of their annual range plus the 519 background NDVI value, the NDVI at time $t, N D V I(t)$, was flagged as "uncertain" if it satisfied the 520 following,

522 where $N D V I(t)$ had been flagged as "cloudy", and NDVI(t-2), NDVI( $t-1), \operatorname{NDVI}(t+1)$, and $N D V I(t+2)$

523 had all been flagged as "cloudy" or "irregular".

524 Moreover,

$$
N D V I(t) \geq 0.85 \times \max \{N D V I(t-12), N D V I(t-11), \ldots, N D V I(t-1)\}
$$

526 for $N D V I(t)$ in an ascending period (i.e., from early March to the time of annual maximum NDVI), and 527

528 for $N D V I(t)$ in a descending period (i.e., from the time of annual maximum NDVI to late November). 529 The figure SM4 gives an example of NDVI values that were promoted from "cloudy" to "uncertain". 530 

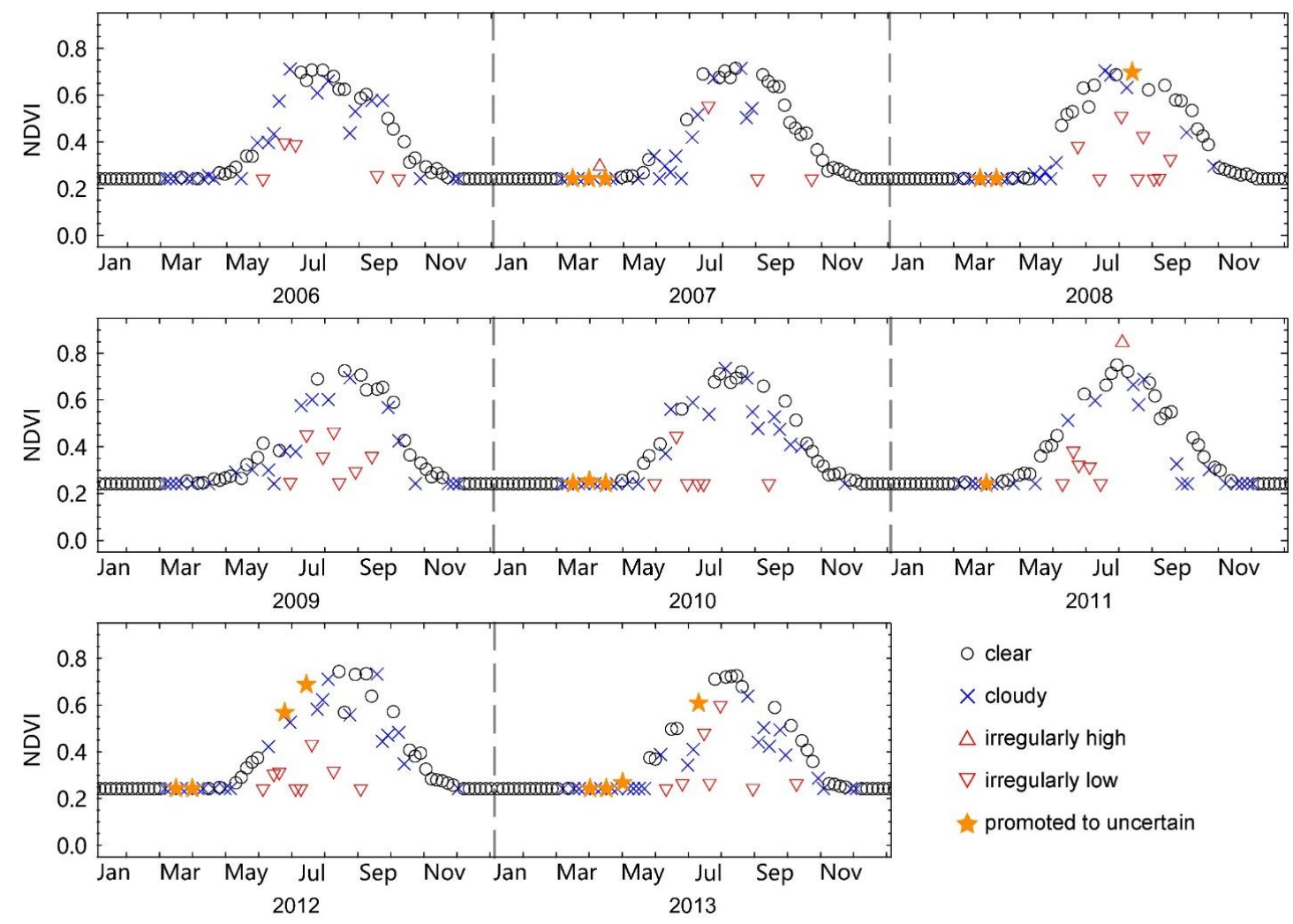

O clear

$\times$ cloudy

$\triangle$ irregularly high

$\nabla$ irregularly low

promoted to uncertain

532 Figure SM4. An example showing NDVI values with flags promoted from "cloudy" to "uncertain".

7) Reconstructing 5-day continuous high-quality NDVI time series. Because clouds and poor atmospheric conditions contaminate NDVI values, we applied a Savitzky-Golay filter to reconstruct a 536 high-quality NDVI time-series as described by Cao et al. (2018) and Shen et al. (2014). The source code 537 of Spatial-Temporal Savitzky-Golay (STSG) is available at https://github.com/cao538 sre/STSG_IDL_program (assessed on 19 December 2018). Before we applied the filter, the "irregular" 539 quality flags were merged to "cloudy". In our study, we used the same parameter setting as Cao et al. 540 (2018), except that the half width of the search window and the half width of the smoothing window 541 were both set to 5. The figure SM5 gives an example of the filtering. 

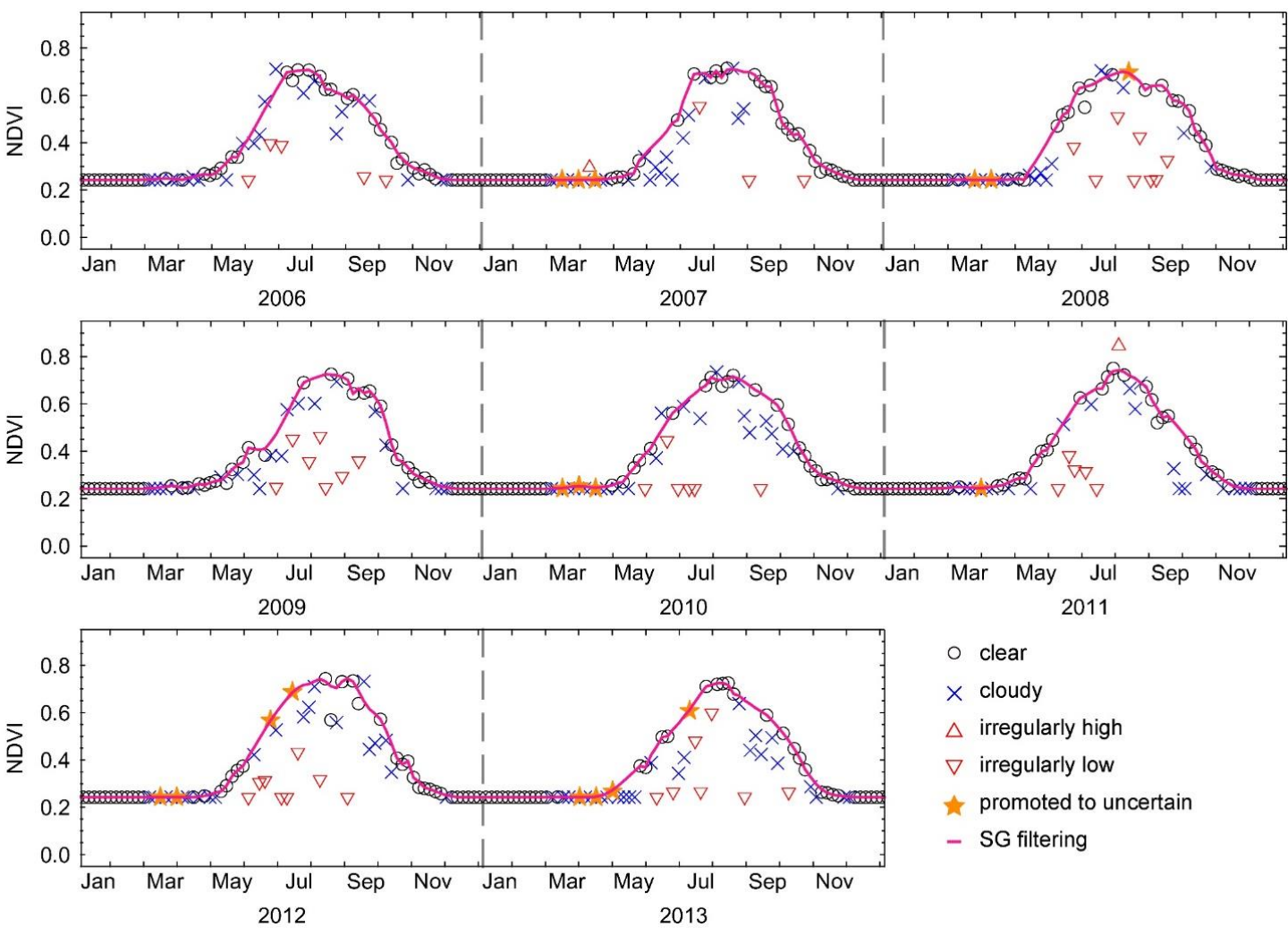

○ clear

$\times$ cloudy

$\triangle$ irregularly high

$\nabla$ irregularly low

$\star$ promoted to uncertain

- SG filtering

543 Figure SM5. An example showing the output of SG filtering.

544

545 


\section{Comparison between satellite $D_{\mathrm{LCO}}$ and $D_{\mathrm{LCO}}$ from PhenoCam dataset}

To better match the PhenoCam images, we used the satellite MOD09A1 dataset (collection 6) which has a spatial resolution of $500 \mathrm{~m}$ and temporal resolution of 8 days. The dataset was downloaded from https://modis.ornl.gov/globalsubset/ on March 10, 2021. The PhenoCam dataset V2.0 was downloaded from https://daac.ornl.gov/cgi-bin/dsviewer.pl?ds_id=1674 on August 29, 2020. From the high-frequency (typically, 30 minute) imagery collected over several years, the GCC (green chromatic coordinate) time series of a region-of-interest (ROI) that delineates an area of specific vegetation type was provided by the PhenoCam dataset. The VCI (vegetation contrast index) time series was calculated as the ratio of the green to the sum of the red and blue bands (Zhang et al., 2018). For the comparison between satellite $D_{\mathrm{LCO}}$ and $D_{\mathrm{LCO}}$ from the PhenoCam dataset, processing steps are as follows:

Step 1, the sites for agricultural lands, urban areas, or heterogeneous landscape within the area of a $500 \mathrm{~m} \times 500 \mathrm{~m}$ pixel were excluded by visually examining the images in Google Earth. Then, daily time series were created by calculating the 90th percentile of GCC or VCI for each day. After that, 5-day medium value filtering was used to smooth the short term fluctuations and noises.

Step 2, a time series was excluded if there was no data in any consecutive 30 days from annual maximum and to the end of year.

Step 3, the annual time series were fitted to a generalized sigmoid function (eq 7 in Klosterman et al (Klosterman et al., 2014)).

Step 4, in many of the sites, there was considerable mismatch between the annual NDVI and GCC (or VCI) trajectories. To remove some of those mismatched annual trajectories, we excluded the siteyears for which the date of annual maximum NDVI differed by more than 30 days from that of GCC (or VCI) or the Pearson's correlation coefficient between NDVI and GCC (or VCI) lower than 0.75. In this step, the date of annual maximum NDVI (or GCC, VCI) was determined using 25-day smoothed times series of the fitted curves to eliminate short time variations. The Pearson's correlation coefficient was calculated between fitted daily NDVI and GCC (or VCI) for the period from the date of annual maximum greenness and the date when greenness dropped by $60 \%$. The period for calculating correlation coefficient was determined using the earlier one of the dates of annual maximum NDVI and GCC (or VCI) and the later one of the dates when NDVI and GCC (or VCI) dropped by $60 \%$. This criterion was not applied to deciduous broadleaf forest, because annual maximum of GCC or VCI usually occurred in late May or early June whereas annual maximum of NDVI was usually in late July or early August. After that, we excluded the annual NDVI time series for which the mean NDVI of the 
57831 days period with annual maximum NDVI in the $16^{\text {th }}$ day was less than 1.15 times the mean NDVI of 579 December.

580 The satellite $D_{\mathrm{LCO}}$ explained about $80 \%$ of the variations in PhenoCam derived $D_{\mathrm{LCO}}$ (Fig. 2 in the 581 main text), although the mismatch between the annual NDVI and GCC trajectories leads to large $D_{\mathrm{LCO}}$ 582 difference between NDVI and GCC (Figure SM6) or VCI (Figure SM7).

583

584

585

586

587
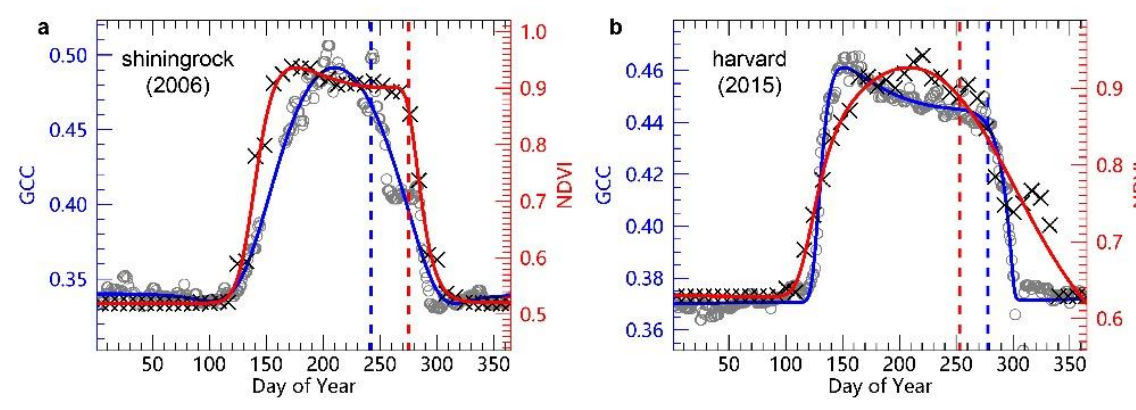

$\circ \circ \circ \mathrm{GCC}$

$\times \times \times \mathrm{NDVI}$

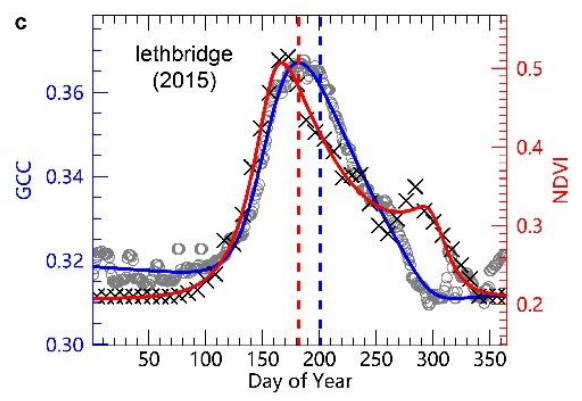

GCC fitting - - - $D_{\llcorner\mathrm{LO}}$ from GCC

NDVI fitting - - - - $D_{-c o}$ from NDVI

Figure SM6. Examples that mismatch between the annual NDVI and GCC trajectories leads to large

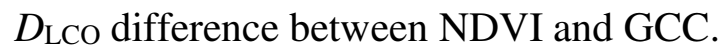
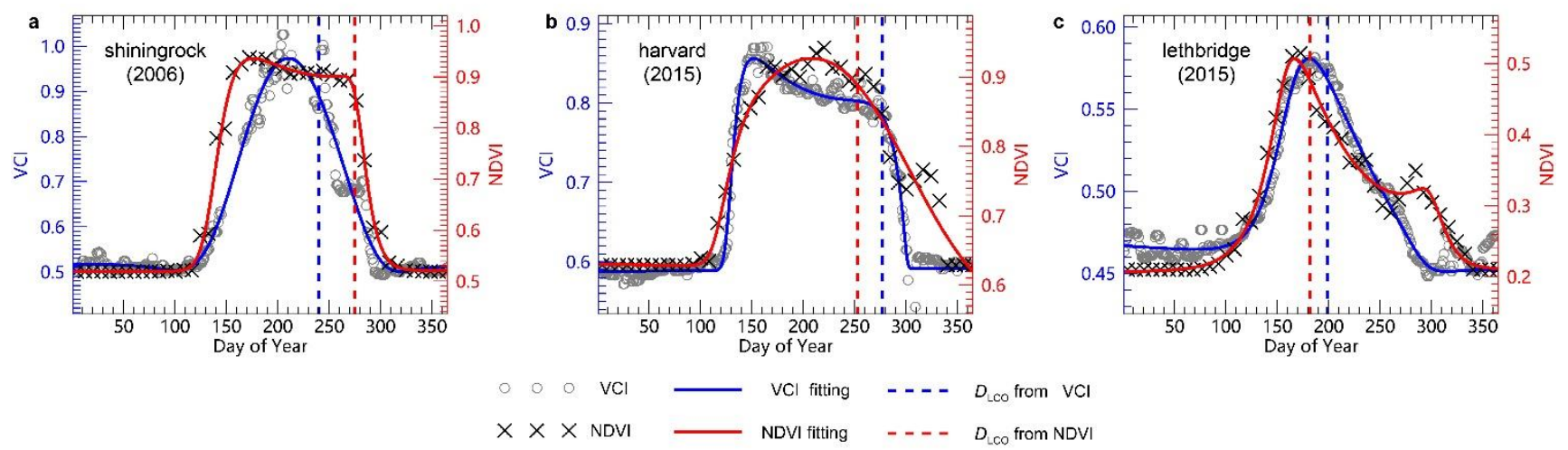

Figure SM7. Examples that mismatch between the annual NDVI and VCI trajectories leads to large

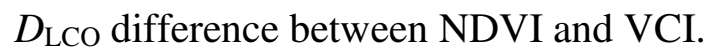


594

595

Aikio, S., Taulavuori, K., Hurskainen, S., Taulavuori, E. \& Tuomi, J. (2019) Contributions of day length, temperature and individual variability on the rate and timing of leaf senescence in the common lilac Syringa vulgaris. Tree Physiology, 39, 961-970.

Amiro, B. (2016) FLUXNET2015 CA-Man Manitoba - Northern Old Black Spruce (former BOREAS Northern Study Area). In. FluxNet; University of Manitoba

Arain, M.A. (2016a) FLUXNET2015 CA-TP4 Ontario - Turkey Point 1939 Plantation White Pine. In. FluxNet; McMaster University

Arain, M.A. (2016b) FLUXNET2015 CA-TP3 Ontario - Turkey Point 1974 Plantation White Pine. In. FluxNet; McMaster University

Aurela, M., Tuovinen, J.-P., Hatakka, J., Lohila, A., Mäkelä, T., Rainne, J. \& Lauria, T. (2016) FLUXNET2015 FI-Sod Sodankyla. In. FluxNet; Finnish Meteorological Institute

Beck, P.S.A., Atzberger, C., Høgda, K.A., Johansen, B. \& Skidmore, A.K. (2006) Improved monitoring of vegetation dynamics at very high latitudes: A new method using MODIS NDVI. Remote Sensing of Environment, 100, 321-334.

Bernhofer, C., Grünwald, T., Moderow, U., Hehn, M., Eichelmann, U. \& Prasse, H. (2016a) FLUXNET2015 DE-Tha Tharandt. In. FluxNet; TU Dresden

Bernhofer, C., Grünwald, T., Moderow, U., Hehn, M., Eichelmann, U. \& Prasse, H. (2016b) FLUXNET2015 DE-Gri Grillenburg. In. FluxNet; TU Dresden

Berveiller, D., Delpierre, N., Dufrêne, E., Pontailler, J.-Y., Vanbostal, L., Janvier, B., Mottet, L. \& Cristinacce, K. (2016) FLUXNET2015 FR-Fon Fontainebleau-Barbeau. In. FluxNet; CNRS

Black, T.A. (2016a) FLUXNET2015 CA-Obs Saskatchewan - Western Boreal, Mature Black Spruce. In. FluxNet; The University of British Columbia

Black, T.A. (2016b) FLUXNET2015 CA-Oas Saskatchewan - Western Boreal, Mature Aspen. In. FluxNet; The University of British Columbia

Blanken, P. (2016) FLUXNET2015 US-NR1 Niwot Ridge Forest (LTER NWT1). In. FluxNet; University of Colorado

Böhlenius, H., Huang, T., Charbonnel-Campaa, L., Brunner, A.M., Jansson, S., Strauss, S.H. \& Nilsson, O. (2006) CO/FT regulatory module controls timing of flowering and seasonal growth cessation in trees. Science, 312, 1040-1043.

Cao, R., Chen, Y., Shen, M., Chen, J., Zhou, J., Wang, C. \& Yang, W. (2018) A simple method to improve the quality of NDVI time-series data by integrating spatiotemporal information with the Savitzky-Golay filter. Remote Sensing of Environment, 217, 244257.

Chen, J. (2016) FLUXNET2015 US-Oho Oak Openings. In. FluxNet; University of Toledo / Michigan State University

Davidson, H. (1957) Photoperiodic responses on selected woody ornamental shrubs. Michigan State University of Agriculture and Applied Science. Department of Horticulture,

De Ligne, A., Manise, T., Heinesch, B., Aubinet, M. \& Vincke, C. (2016) FLUXNET2015 BE-Vie Vielsalm. In. FluxNet; University of Liege - Gembloux Agro-Bio Tech; University catholic of Louvain-la-Neuve

Desai, A. (2016) FLUXNET2015 US-PFa Park Falls/WLEF. In. FluxNet; University of Wisconsin

Dolman, H., Van Der Molen, M., Parmentier, F.-J., Marchesini, L.B., Dean, J., Van Huissteden, K. \& Maximov, T. (2016) FLUXNET2015 RU-Cok Chokurdakh. In. FluxNet; Vrije 
Universiteit Amsterdam

Downs, R.J. \& Borthwick, H.A. (1956) Effects of photoperiod on growth of trees. Botanical Gazette, 117, 310-326.

Elmore, A.J., Guinn, S.M., Minsley, B.J. \& Richardson, A.D. (2012) Landscape controls on the timing of spring, autumn, and growing season length in mid-Atlantic forests. Global Change Biology, 18, 656-674.

Fennell, A. \& Hoover, E. (1991) Photoperiod influences growth, bud dormancy, and cold acclimation in Vitis labruscana and V. riparia. Journal of the American Society for Horticultural Science. American Society for Horticultural Science, 116, 270-273.

Fracheboud, Y., Luquez, V., Björkén, L., Sjödin, A., Tuominen, H. \& Jansson, S. (2009) The control of autumn senescence in European aspen. Plant Physiology, 149, 1982-1991.

Gianelle, D., Cavagna, M., Zampedri, R. \& Marcolla, B. (2016a) FLUXNET2015 IT-MBo Monte Bondone. In. FluxNet; Edmund Mach Foundation

Gianelle, D., Zampedri, R., Cavagna, M. \& Sottocornola, M. (2016b) FLUXNET2015 IT-Lav Lavarone. In. FluxNet; Edmund Mach Foundation

Gough, C., Bohrer, G. \& Curtis, P. (2016) FLUXNET2015 US-UMB Univ. of Mich. Biological Station. In. FluxNet; Ohio State University; Virginia Commonwealth University

Grubbs, F.E. (1950) Sample criteria for testing outlying observations. Annals of Mathematical Statistics, 21, 27-58.

Hamilton, J.A., El, K.W., Hart, A.T., Runcie, D.E., Arango-Velez, A. \& Cooke, J.E. (2016) The joint influence of photoperiod and temperature during growth cessation and development of dormancy in white spruce (Picea glauca). Tree Physiology, 36, tpw061.

Heide, O.M. (1974) Growth and Dormancy in Norway Spruce Ecotypes (Picea abies) I. Interaction of Photoperiod and Temperature. Physiologia Plantarum, 30, 1-12.

Heide, O.M. (2001) Photoperiodic control of dormancy in Sedum telephium and some other herbaceous perennial plants. Physiologia Plantarum, 113, 332-337.

Hörtnagl, L., Eugster, W., Buchmann, N., Paul-Limoges, E., Etzold, S. \& Haeni, M. (2016a) FLUXNET2015 CH-Lae Laegern. In. FluxNet; ETH Zurich

Hörtnagl, L., Eugster, W., Merbold, L., Buchmann, N., Etzold, S., Haesler, R. \& Haeni, M. (2016b) FLUXNET2015 CH-Dav Davos. In. FluxNet; ETH Zurich

Howe, G.T., Gardner GHackett, W.P. \& Furnier, G.R. (1996) Phytochrome control of short-dayinduced bud set in black cottonwood. Physiologia Plantarum, 97, 95-103.

Ibrom, A. \& Pilegaard, K. (2016) FLUXNET2015 DK-Sor Soroe. In. FluxNet; Technical University of Denmark (DTU)

Janssens, I. (2016) FLUXNET2015 BE-Bra Brasschaat. In. FluxNet; University of Antwerp

Junttila, O. (1980) Effect of photoperiod and temperature on apical growth cessation in two ecotypes of Salix and Betula. Physiologia Plantarum, 48, 347-352.

Keskitalo, J., Bergquist, G., Gardeström, P. \& Jansson, S. (2005) A cellular timetable of autumn senescence. Plant Physiol, 139, 1635-1648.

Klosterman, S.T., Hufkens, K., Gray, J.M., Melaas, E., Sonnentag, O., Lavine, I., Mitchell, L., Norman, R., Friedl, M.A. \& Richardson, A.D. (2014) Evaluating remote sensing of deciduous forest phenology at multiple spatial scales using PhenoCam imagery. Biogeosciences, 11, 4305-4320.

Knohl, A., Tiedemann, F., Kolle, O., Schulze, E.-D., Kutsch, W., Herbst, M. \& Siebicke, L. (2016) FLUXNET2015 DE-Hai Hainich. In. FluxNet; University of Goettingen, Bioclimatology 
Kramer, P.J. (1936) Effect of variation in length of day on growth and dormancy of trees. Plant Physiology, 11, 127-137.

Law, B. (2016) FLUXNET2015 US-Me2 Metolius mature ponderosa pine. In. FluxNet; Oregon State University

Lund, M., Jackowicz-Korczynski, M. \& Abermann, J. (2016) FLUXNET2015 DK-ZaH Zackenberg Heath. In. FluxNet; Aarhus University

Mammarella, I., Vesala, T., Keronen, P., Kolari, P., Launiainen, S., Pumpanen, J., Rannik, Ü., Siivola, E., Levula, J. \& Pohja, T. (2016) FLUXNET2015 FI-Hyy Hyytiala. In. FluxNet; University of Helsinki

Massman, B. (2016) FLUXNET2015 US-GLE GLEES. In. FluxNet; USDA Forest Service

Matteucci, G. (2016) FLUXNET2015 IT-Col Collelongo. In. FluxNet; Istituto di Ecologia e Idrologia Forestale CNR

McCaughey, H. (2016) FLUXNET2015 CA-Gro Ontario - Groundhog River, Boreal Mixedwood Forest. In. FluxNet; Queen's University

Minerbi, S. \& Montagnani, L. (2016) FLUXNET2015 IT-Ren Renon. In. FluxNet; Autonomous Province of Bolzano, Forest Services

Misra, G. \& Biswal, U.C. (1973) Factors Concerned in Leaf Senescence. I. Effects of Age, Chemicals, Petiole, and Photoperiod on Senescence in Detached Leaves of Hibiscus rosa-sinensis L. Botanical Gazette, 134, 5-11.

Moors, E. \& Elbers, J. (2016) FLUXNET2015 NL-Loo Loobos. In. FluxNet; ALTERRA / Wageningen Environmental Research

Munger, J.W. (2016) FLUXNET2015 US-Ha1 Harvard Forest EMS Tower (HFR1). In. FluxNet; Harvard University

Novick, K. \& Phillips, R. (2016) FLUXNET2015 US-MMS Morgan Monroe State Forest. In. FluxNet; Indiana University

Oleksyn, J., Tjoelker, M.G. \& Reich, P.B. (1992) Growth and biomass partitioning of populations of European Pinus sylvestris L. under simulated $50^{\circ}$ and $60^{\circ} \mathrm{N}$ daylengths: evidence for photoperiodic ecotypes. New Phytologist, 120, 561-574.

Olmsted, C.E. (1951) Experiments on Photoperiodism, Dormancy, and Leaf Age and Abscission in Sugar Maple. Botanical Gazette, 112, 365-393.

Paus, E., Nilsen, J. \& Junttila, O. (1986) Bud dormancy and vegetative growth in Salix-Polaris as affected by temperature and photoperiod. Polar Biology, 6, 91-95.

Rinne, P., Saarelainen, A. \& Junttila, O. (1994) Growth cessation and bud dormancy in relation to ABA level in seedlings and coppice shoots of Betula pubescens as affected by a short photoperiod, water stress and chilling. Physiologia Plantarum, 90, 451-458.

Scott, R. (2016a) FLUXNET2015 US-SRM Santa Rita Mesquite. In. FluxNet; United States Department of Agriculture

Scott, R. (2016b) FLUXNET2015 US-Wkg Walnut Gulch Kendall Grasslands. In. FluxNet; United States Department of Agriculture

Shen, M., Zhang, G., Cong, N., Wang, S., Kong, W. \& Piao, S. (2014) Increasing altitudinal gradient of spring vegetation phenology during the last decade on the Qinghai-Tibetan Plateau. Agricultural and Forest Meteorology, 189-190, 71-80.

Šigut, L., Havrankova, K., Jocher, G., Pavelka, M. \& Janouš, D. (2016) FLUXNET2015 CZ-BK1 Bily Kriz forest. In. FluxNet; Global Change Research Institute CAS

Varlagin, A., Kurbatova, J. \& Vygodskaya, N. (2016) FLUXNET2015 RU-Fyo Fyodorovskoye. In. FluxNet; A.N. Severtsov Institute of Ecology and Evolution 
731 Vermote, E.F. (2015) MOD09CMG MODIS/Terra Surface Reflectance Daily L3 Global 0.05Deg CMG V006. In: NASA EOSDIS Land Processes DAAC

Vermote, E.F., Roger, J.C. \& Ray, J.P. (2015) MODIS Surface Reflectance User's Guide, Collection 6, Version 1.4. MODIS Land Surface Reflectance Science Computing Facility,

Wang, D.Y., Hu, S., Li, Q., Cui, K.M. \& Zhu, Y.X. (2002) Photoperiod control of apical bud and leaf senescence in pumpkin (Cucurbita pepo) strain 185. Acta Botanica Sinica, 44, 5562.

Wilson, A.M., Parmentier, B. \& Jetz, W. (2014) Systematic land cover bias in Collection 5 MODIS cloud mask and derived products - A global overview. Remote Sensing of Environment, 141, 149-154.

Zhang, X. (2015) Reconstruction of a complete global time series of daily vegetation index trajectory from long-term AVHRR data. Remote Sensing of Environment, 156, 457-472.

Zhang, X., Jayavelu, S., Liu, L., Friedl, M.A., Henebry, G.M., Liu, Y., Schaaf, C.B., Richardson, A.D. \& Gray, J. (2018) Evaluation of land surface phenology from VIIRS data using time series of PhenoCam imagery. Agricultural and Forest Meteorology, 256-257, 137-149. 